
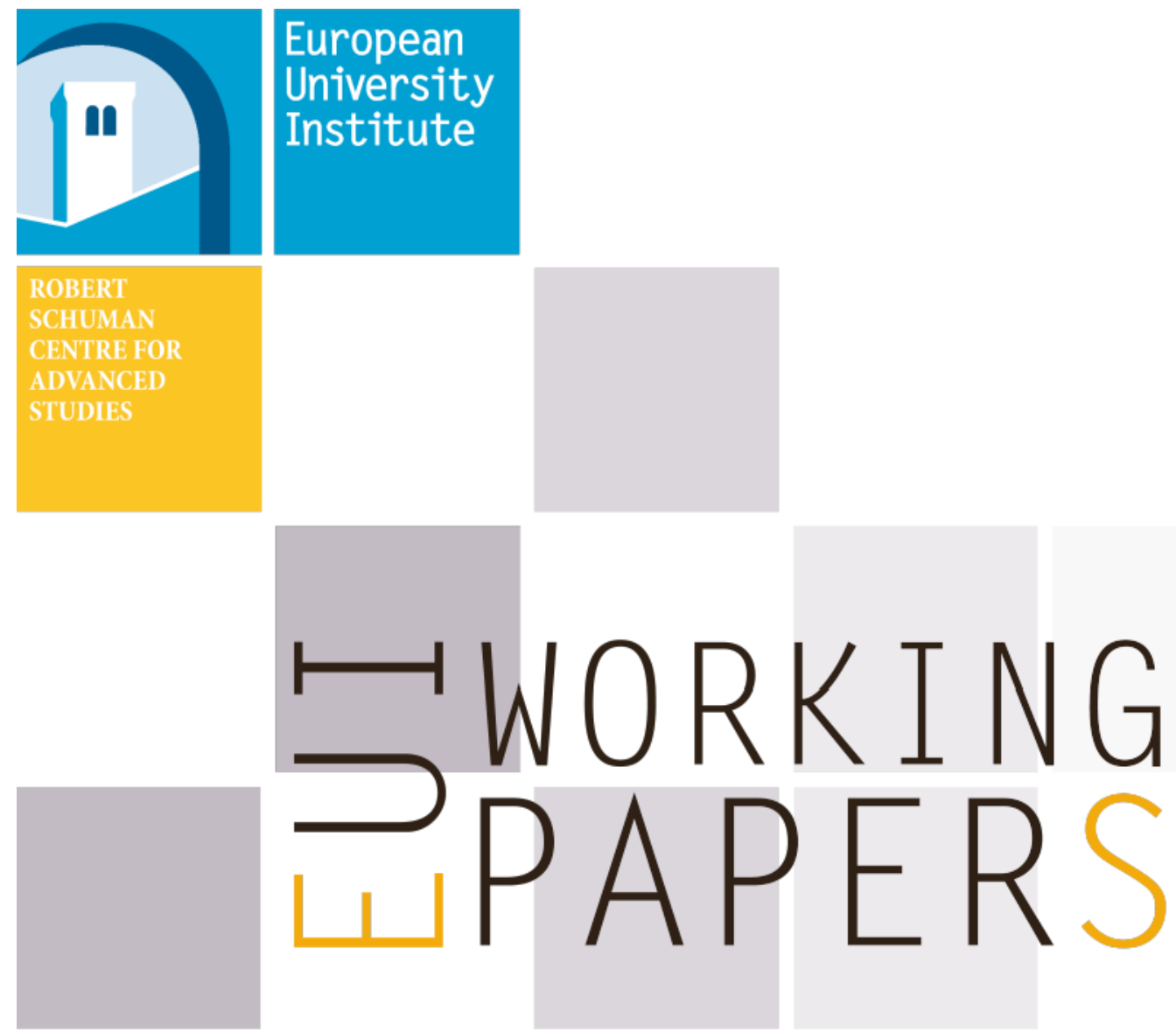

RSCAS 2019/59

Robert Schuman Centre for Advanced Studies Global Governance Programme-355

The RESPECT Survey Instrument

Matteo Fiorini, Bernard Hoekman, Naïs Ralaison, Aydin Yildirim 

European University Institute

Robert Schuman Centre for Advanced Studies

Global Governance Programme

\section{The RESPECT Survey Instrument}

Matteo Fiorini, Bernard Hoekman, Naïs Ralaison, Aydin Yildirim

EUI Working Paper RSCAS 2019/59 
This text may be downloaded only for personal research purposes. Additional reproduction for other purposes, whether in hard copies or electronically, requires the consent of the author(s), editor(s). If cited or quoted, reference should be made to the full name of the author(s), editor(s), the title, the working paper, or other series, the year and the publisher.

ISSN 1028-3625

(C) Matteo Fiorini, Bernard Hoekman, Naïs Ralaison, Aydin Yildirim, 2019

Printed in Italy, July 2019

European University Institute

Badia Fiesolana

I - 50014 San Domenico di Fiesole (FI)

Italy

www.eui.eu/RSCAS/Publications/

www.eui.eu

cadmus.eui.eu 


\section{Robert Schuman Centre for Advanced Studies}

The Robert Schuman Centre for Advanced Studies, created in 1992 and currently directed by Professor Brigid Laffan, aims to develop inter-disciplinary and comparative research on the major issues facing the process of European integration, European societies and Europe's place in $21^{\text {st }}$ century global politics.

The Centre is home to a large post-doctoral programme and hosts major research programmes, projects and data sets, in addition to a range of working groups and ad hoc initiatives. The research agenda is organised around a set of core themes and is continuously evolving, reflecting the changing agenda of European integration, the expanding membership of the European Union, developments in Europe's neighbourhood and the wider world.

For more information: http://eui.eu/rscas

The EUI and the RSCAS are not responsible for the opinion expressed by the author(s).

\section{The Global Governance Programme}

The Global Governance Programme is one of the flagship programmes of the Robert Schuman Centre. It is a community of outstanding professors and scholars, that produces high quality research and engages with the world of practice through policy dialogue. Established and early-career scholars work on issues of global governance within and beyond academia, focusing on four broad and interdisciplinary areas: Global Economics, Europe in the World, Cultural Pluralism and Global Citizenship.

The Programme also aims to contribute to the fostering of present and future generations of policy and decision makers through its executive training programme: the Academy of Global Governance, where theory and 'real world' experience meet and where leading academics, top-level officials, heads of international organisations and senior executives discuss on topical issues relating to global governance.

For more information: http://globalgovernanceprogramme.eui.eu

The European University Institute and the Robert Schuman Centre are not responsible for the opinions expressed by the author(s). 



\begin{abstract}
This paper reports findings from an on-line expert survey implemented as part of the Horizon 2020supported research project RESPECT (Realizing Europe's Soft Power in External Cooperation and Trade). The RESPECT survey provides information on perceptions of trade policy practitioners and expert observers on the common commercial policy of the EU with a specific focus on the perceived utility and effectiveness of linking trade to non-trade policy objectives - such as sustainable development, human rights, labor standards and environmental protection. After discussing the design and implementation of the survey, the paper provides a descriptive analysis of the results.
\end{abstract}

\title{
Keywords
}

European Union; trade policy; non-trade objectives; survey 



\section{Introduction ${ }^{1}$}

The EU perceives itself as a normative actor in international relations. A key feature of the 2015 EU "Trade for All" strategy is the call for trade and investment policy to take responsibility for supporting and promoting EU values and standards. It notes that doing so requires coherence across policy areas as well as commonality of action (European Commission, 2015). Key policy areas include the common commercial policy, which determines the conditions for trade in goods and services as well as investment flows into and out of the European single market, official development assistance and economic diplomacy programs implemented by both EU Member States and EU institutions. All these instruments are used by the EU to pursue its external normative goals.

The Horizon 2020-supported research project RESPECT (Realizing Europe's Soft Power in External Cooperation and Trade $)^{2}$ seeks to analyze the factors that support or inhibit the realization of EU non-trade policy objectives (NTPOs) established in the Treaty of Lisbon? such as sustainable development, human rights, labor standards and environmental protection. One component of the project comprises a web-based survey instrument. The RESPECT survey was designed to collect opinions on EU trade and trade-related external policies from a population of practitioners and expert observers. The survey centers on perceptions by practitioners regarding the drivers and implementation of EU trade policy and the appropriateness and effectiveness of trade as an instrument to pursue and achieve NTPOs. ${ }^{3}$ The RESPECT questionnaire complements existing survey instruments which tend to target public opinion more generally. The specific perspective taken in the survey aimed to add value to the body of existing evidence regarding views on the connection between trade policy and NTPOs.

This paper is organized as follows. Section 2 briefly introduces the RESPECT survey instrument in the context of the existing body of survey evidence on trade policy. Section 3 describes the implementation of the RESPECT survey. Section 4 presents the methodology used in the descriptive analysis. Results are reported in Section 5. Section 6 offers some initial conclusions.

\section{The RESPECT questionnaire and related survey evidence}

The RESPECT survey is designed to collect opinions on EU trade and trade-related external policies from a population of practitioners and observers. The survey centers on perceptions by practitioners regarding the drivers and implementation of EU trade policy and the appropriateness and effectiveness of trade as an instrument to pursue and achieve Non Trade Policy Objectives (NTPOs). NTPOs include the promotion of human rights, labor, environmental protection and anti-corruption as well as economic development in non-EU countries. Given the nature of the targeted population, the RESPECT questionnaire complements existing survey instruments which tend to target public opinion more generally. The specific perspective taken in the RESPECT survey is intended to add value to the body of existing evidence regarding views on the connection between trade policy and NTPOs given that this is an under-investigated question.

The existing body of survey evidence for EU countries reveals several empirical patterns as regards public opinion towards EU trade and trade-related policy instruments. One source of survey data on the EU are the Eurobarometer polls. These are of three types: the standard

\footnotetext{
${ }^{1}$ This project has received funding from the European Union's Horizon 2020 research and innovation programme under grant agreement No 770680 .

${ }^{2}$ See http://respect.eui.eu/ for a description of the project.

${ }^{3}$ NTPOs include the promotion of human rights, labor, environmental protection and anti-corruption as well as economic development in non-EU countries.
} 
survey, special polls and flash editions. ${ }^{4}$ Responses to the standard Eurobarometer survey (Eurobarometer, 2018) reveal that the majority of EU citizens (more precisely $65 \%$ percent of EU population) agrees that the EU has sufficient power and tools to defend the economic interests of Europe in a global economy. This number has been relatively stable in the surveys undertaken in period bwteeen 2009 and 2018. However, opinions on the welfare effects of globalization on EU Member States (EUMS), which has a bearing on a much broader set of policies than trade policy, reveals much greater polarization in views. The free movement of people, goods and services is recognized by the majority of the respondents (almost $60 \%$, with very little variation over the period 2012-2018) as the most positive result of the EU in the standard Eurobarometer survey. ${ }^{5}$

While this suggests that trade and trade-related policies are regarded as positive features that are associated with important achievements of the EU, it leaves open the question of how exactly trade policy fits in the context of EU soft power tools for the achievement of EU NTPOs.

A number of special Eurobarometer editions have more directly focused on trade topics. A survey instrument commissioned by DG Trade in 1995 revealed that for the most part, Europeans trusted the EU to defend the Union's interests in international organizations such as the WTO, IMF or the World Bank. Six years later, the Eurobarometer special edition 152 (Eurobarometer, 2001) revealed that Europeans seemed to have trust in the EU to defend their interests in international negotiations and thought the EU was well placed to compete on international markets and take advantage of the liberalization of markets. At the same time, it revealed that many also thought that freedom of trade would force the EU to lower its norms regarding environment, public health or consumer protection. Furthermore, they tended to perceive that the organizations tasked with economic policy cooperation did not defend the interests of the population at large: more than one third of Europeans declared that international organizations did not represent their interests, $22.1 \%$ that they did, $14.9 \%$ that it depends and $26.7 \%$ did not have an opinion. Finally, in interviews undertaken in the context of the Eurobarometer special edition 357 in 2010, the majority of participating EU citizens expected the EU to use trade policy to create employment opportunities for European citizens (Eurobarometer, 2010). According to the Eurobarometer timeline (European Commission, 2018), no other DG Trade Eurobarometer special edition has been produced after 2010. However, DG Trade has commissioned a number of Eurobarometer flash editions (the last one in 2014) to survey attitudes on cross-border trade and consumer protection. These provide information on consumer confidence and attitudes towards cross-border online shopping, featuring opinions on product safety, unfair commercial practices, and the reliability of claims regarding the environmental footprints of traded products and services.

Taken together, the Eurobarometer special and flash editions, while touching upon trade-relevant themes, are biased toward the assessment of trade policy effects for internal EU economic variables and do not allow for a systematic and up-to-date assessment of EU trade policy as a tool to contribute to the attainment of EU non-trade objectives in external policy.

Alongside the Eurobarometer survey instruments the European Commission has conducted several public consultations on specific topics including trade. Between 2014 and the end of 2018, 19 trade-related consultations were undertaken, with results reported on the associated dedicated web portal. ${ }^{6}$ Some other targeted consultations can be found on the DG Trade webpage. ${ }^{7}$ The

\footnotetext{
${ }^{4}$ A description of the three types of Eurobarometer editions as well as the reports for all three types of polls can be accessed from the web portal of DG Communication http://ec.europa.eu/COMMFrontOffice/publicopinion/ index.cfm.

5 At the same time, from 2015 onwards, immigration, together with terrorism, appears at the top of the ranking of the most important issues facing the $\mathrm{EU}$ at the moment.

${ }^{6}$ The list and reports of the EC Public Consultations can be found at https://ec.europa.eu/info/ consultations_en.

${ }^{7}$ At http://trade.ec.europa.eu/consultations/.
} 
majority of these trade consultations have a rather narrow focus, usually the effects or design of a specific EU Free Trade Agreement or trade-related regulation. Some have a broader scope, collecting opinions for instance on a potential reform of investor-State dispute resolution and the EU's strategy on adaptation to climate change. While a complete review of these consultations is beyond the scope of this report, what matters is that a systematic investigation of the linkages between trade policy instruments and NTPOs has not been the focus of either EU opinion surveys or the consultations that have been held.

Complementing these EU survey and consultation instruments, survey-based data collection efforts with a specific focus on trade and trade policy have been undertaken by other organizations. Particularly relevant for trade and trade policy are the surveys conducted by the Pew Research Center in 2014 and 2018 (Pew Research Center, 2018). This repeated survey targets public opinion in France, Germany, Greece, Italy, Poland, Spain and the UK. It reveals that more than eight-in-ten Europeans perceive trade to be good for their country. Such sentiments have increased slightly since 2014. Four-in-ten Europeans say international trade creates jobs, while about a third believe trade leads to job losses. Roughly a third also hold the view that trade undermines wages, more than the share who think it leads to wage increases. And, notably, nearly four-in-ten think trade leads to price increases, significantly more than the portion of Europeans who believe that that trade contributes to reductions in product prices.

Another recent contribution to the body of survey-based data on perceptions of trade and trade policy is a survey commissioned by the Bertlesmann Foundation on globalization (Bluth, 2018). This was carried out by YouGov and involved a statistically representative online survey in twelve countries, including two EU Member States (France and Germany) and the UK. Globalization, defined as the increasing movement of products, ideas, money, jobs, culture and people around the world is seen as a force for good for the world by $40 \%$ of respondents in Germany, $41 \%$ in France and $47 \%$ in the UK. This much less than respondents in China $(77 \%)$ or the average for surveyed emerging economies (64\%). France and Germany stand out as outliers when it comes to the opinions on the role of globalization for product quality. More than $60 \%$ of French respondents and almost 50\% of the German ones see a negative causal effect of globalization on product quality. Considering the total population covered in the survey, a majority approves of free trade agreements. This includes Germany and the US. The only exception is France where $42 \%$ of respondents considers trade agreements a bad thing, versus $33 \%$ holding the opposite opinion.

To summarize, the available survey evidence suggests globalization, and more specifically, free trade and related liberal trade policy regimes, are perceived to be a positive achievement by a majority, but that it also gives rise to economic and social risks. The RESPECT survey aims at enhancing information on views on whether trade and trade-related policy can function as a tool to attain social and economic objectives beyond its effect in increasing trade and investment flows. In doing so it includes questions on topics that implicitly come out of the above described body of survey evidence, according to which trade and trade policy might work against social and economic objectives such as labor conditions or the quality of traded goods and services. A distinct feature of the RESPECT survey is its focus on the EU's external social and economic objectives. By doing so it goes beyond existing surveys that tend to center on opinions regarding the effects of trade and trade policy within the EU.

\section{Implementation and empirical population}

Responses to the survey are anonymous. Data presented in this summary report are based on responses to the survey received by QUALTRIX (the online survey application) from July 52018 to June 24 2019. A total of 511 respondents took the survey during this period and 356 completed 
the questionnnaire. Respondents always had the option to avoid answering a question, creating a missing value for the associated variable. For each variable analyzed below the number of respondents providing an answer (non-missing values) is reported. The survey was disseminated by email using a contact list of practitioners and stakeholders (an initial email was followed by 6 reminders, staggered over time). Further dissemination of the survey within the relevant population of EU trade policy stakeholders was promoted by all RESPECT consortium members and, potentially, by respondents from the RESPECT contact list, to colleagues or counterparts (i.e., a snowballing approach).

The survey design allowed respondent to specify his or her professional affiliation and - when applicable - the nationality of their institution or organization, as well as the country where most of their professional activity occur. Figure 0 shows the number of respondents selecting each category of professional affiliation. Respondents from academia or think-tanks constitute the most frequently reported professional category in the data, accounting for $34 \%$ of all respondents. To control for potential idiosyncratic biases that may be associated with this professional category the analysis below reports, alongside results derived from the whole sample, the response patterns obtained when excluding the 'academia/think tank' category from the data.

Figure 0: Respondents' professional affiliation

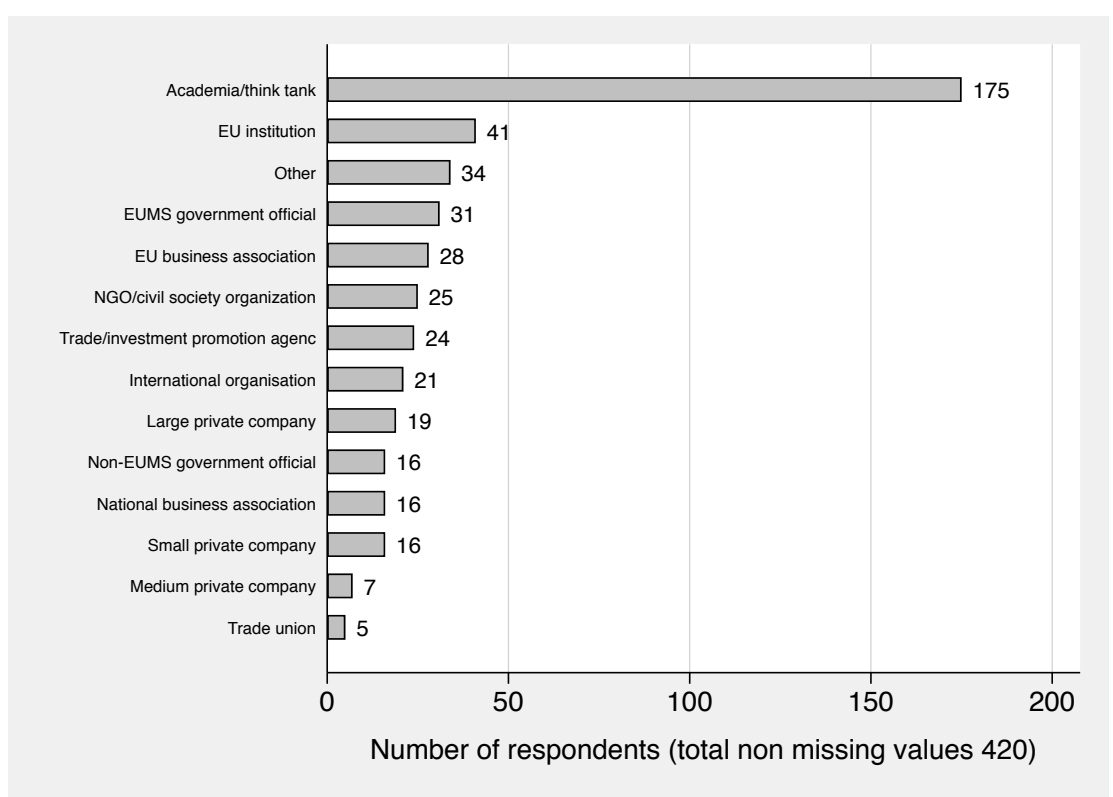

Notes: More than one choice was allowed. No respondent selected the category "Working for a political party". When selecting the category "Other" respondents had the possibility to further specify their professional affiliation. In some of these cases, based on these further specifications, we have associated the respondent also to an existing category different from "Other" (when that additional category had not been already selected by the respondent). For instance, for a respondent specifying "Retired international civil servant" we have selected the category "International organizations" in addition to the category "Other".

Table 1 instead reports the percentage of respondents for each country depending on the nationality of their oganization/institution and on the location of their operations. For each of the 84 countries listed in Table 1 we have at least one respondent whose organization/institution is based in that country or whose professional activities are mostly conducted in that country. The five countries with the highest percentage of respondents in terms of nationality of the organization/institutions as well as of operations' location are Belgium, UK, China, US and Germany. 
Table 1: Nationality of organization/institution and country of operation

\begin{tabular}{|c|c|c|c|c|c|}
\hline Country & Nationality (\%) & Operations (\%) & Country & Nationality (\%) & Operations (\%) \\
\hline Belgium & 10,51 & 13,31 & Croatia & 0,34 & \\
\hline United Kingdom & 9,15 & 9,51 & South Korea & 0,34 & 0,38 \\
\hline United States & 8,47 & 6,08 & Myanmar & 0,34 & 0,38 \\
\hline China & 8,47 & 8,75 & Ecuador & 0,34 & \\
\hline Germany & 8,14 & 7,22 & Hong Kong & 0,34 & \\
\hline Denmark & 4,75 & 2,28 & Azerbaijan & 0,34 & 0,38 \\
\hline Austria & 4,75 & 2,28 & French Southern Territories & 0,34 & 0,38 \\
\hline Italy & 4,07 & 3,42 & Poland & 0,34 & 0,38 \\
\hline The Netherlands & 4,07 & 2,66 & Portugal & 0,34 & \\
\hline Cyprus & 2,03 & 1,14 & Fiji & 0,34 & 0,38 \\
\hline Sweden & 2,03 & 1,90 & Malawi & 0,34 & 0,38 \\
\hline Brazil & 1,36 & 1,90 & Albania & 0,34 & \\
\hline Ghana & 1,36 & 1,52 & Jamaica & 0,34 & 0,38 \\
\hline Spain & 1,36 & 0,76 & Singapore & 0,34 & 1,14 \\
\hline Czech Republic & 1,36 & 1,14 & Cameroon & 0,34 & 0,38 \\
\hline Switzerland & 1,36 & 3,04 & Burkina Faso & 0,34 & 0,38 \\
\hline France & 1,36 & 2,66 & Lesotho & 0,34 & 0,38 \\
\hline Hungary & 1,36 & 1,14 & Belarus & 0,34 & 0,38 \\
\hline India & 1,02 & 1,52 & Saint Helena & 0,34 & 0,76 \\
\hline Canada & 1,02 & 0,76 & Peru & 0,34 & 0,38 \\
\hline Russian Federation & 1,02 & 0,38 & Bosnia and Herzegovina & 0,34 & 0,38 \\
\hline Australia & 1,02 & 1,14 & Montserrat & 0,34 & 0,38 \\
\hline Finland & 1,02 & 0,76 & Armenia & 0,34 & \\
\hline Ireland & 1,02 & 1,14 & Algeria & 0,34 & \\
\hline Mauritius & 0,68 & 0,38 & Trinidad and Tobago & 0,34 & 0,38 \\
\hline Ukraine & 0,68 & 1,14 & Kyrgyzstan & 0,34 & 0,38 \\
\hline Norway & 0,68 & 0,76 & Réunion & & 0,38 \\
\hline New Zealand & 0,68 & 0,38 & Mexico & & 0,38 \\
\hline Uganda & 0,68 & 0,76 & Thailand & & 1,14 \\
\hline Cayman Islands & 0,68 & 0,76 & Morocco & & 0,38 \\
\hline American Samoa & 0,68 & 0,38 & Angola & & 0,38 \\
\hline Japan & 0,68 & 0,38 & Kazakhstan & & 0,38 \\
\hline Bulgaria & 0,68 & 0,38 & Antigua and Barbuda & & 0,38 \\
\hline Taiwan & 0,34 & 0,38 & Vietnam & & 0,38 \\
\hline Indonesia & 0,34 & 0,38 & Afghanistan & & 0,38 \\
\hline South Africa & 0,34 & 0,38 & Paraguay & & 0,38 \\
\hline Bangladesh & 0,34 & 1,14 & Cambodia & & 0,38 \\
\hline Mozambique & 0,34 & 0,38 & Bhutan & & 0,38 \\
\hline Turkey & 0,34 & & Jordan & & 0,38 \\
\hline Estonia & 0,34 & & Ethiopia & & 0,38 \\
\hline Philippines & 0,34 & & United Arab Emirates & & 0,38 \\
\hline Kuwait & 0,34 & 0,38 & Åland Islands & & 0,38 \\
\hline
\end{tabular}

Notes: Nationality (\%) denotes the percentage of respondents selecting the respective country as country of nationality of their organization/company/institution. Operations (\%) instead denotes the percentage of respondents selecting the respective country as the country where most of their professional activity is based. These questions do not apply to respondents working for an EU institution, for an EU-level industry/business association or for an international organization. The total number of non missing values for nationality is 295 . The total number of non missing values for country of operations is 263 .

\section{Analytical methodology}

The analysis of the RESPECT survey results presented below is descriptive. The bulk of the questions are designed to offer a Likert scale answer structure (strongly disagree, disagree, neutral, agree, strongly agree + don't knonw). First, for each question in the survey we report the distribution of responses over all non-missing values in the sample. Second, we replicate the analysis of responses after removing the respondents from academia and think-tanks. Third we show responses for two geo-political categories of respondents: "EU" and "Non-EU". The former category comprises respondents for which three conditions are verified. First, they are working either for an EU institution, or for the government of an EUMS or for an EU-level business association, or for an institution with nationality in a EUMS. Second, their professional activity is based in the EU. Third, they do not have a special focus on a non EU region. The latter category instead is obtained removing "EU" respondents from the sample. Finally, for all Likert-scale-type questions, we report responses for each professional category. Those categories are sorted first according to the scope of agreement within a category (the sum of respondents 
selecting either agree or strongly agree), then according to the scope of disagreement (sum of respondents selecting either disagree or strongly disagree).

\section{Results}

This Section presents the results of the RESPECT survey instrument. It follows the same threepart structure as the online survey instrument. Subsection 5.1 presents the responses to the survey questions pertaining to the design and formation of EU trade and trade-related policy. Subsection 5.2 reports the results for perceptions regarding the results of EU trade and traderelated policy. Finally Subsection 5.3 describes the responses to those survey questions on the implementation and evaluation of EU external policies.

\subsection{Design}

One central topic in the RESPECT survey is the role of EU trade and trade-related policy as a tool to promote and attain NTPOs in non-EU countries. The first question in the survey addresses this theme in the context of EU policy formation. Figure 1 reveals that the majority $(55 \%)$ of respondents tend to think that the EU should make access to its markets by other countries conditional on non-trade outcomes (such as human rights, labor, environmental protection and anti-corruption). This pattern is robust when respondents from academia and think-tanks are removed from the sample and becomes even stronger for "EU" respondents. Instead, in the "Non-EU" group opinions are more polarized.

The other questions in the first part of survey investigate opinions on the political economy of EU trade and trade-related policy formation, in particular whether the design of trade agreements is efficiently informed by consultation of stakeholders (Figure 2), whether the formation of EU trade policy primarily reflects the interests of large EU member states (Figure 3), and whether it primarily serves the interest of the largest firms (Figure 4). Responses presented in Figure 2 suggest that one half of respondents believe EU trade agreements are indeed efficiently informed by consultation of stakeholder. This figure is relatively stable across all subgroups in the data. When it comes to the role of large EUMS and firms, responses reveal that practitioners tend to believe that these two categories of stakeholder are particularly successful in shaping the formation of EU trade policy. Indeed the percentage of respondents that either agree or strongly agree with the statements reported in Question 3 and 4 of the first part of the survey is always strictly bigger than the percentage of those that either disagree or strongly disagree. This pattern is weakened or even reversed for the category of EU respondents. 


\section{Question 1}

The EU should make access to its markets by other countries conditional on non-trade outcomes (such as human rights, labor, environmental protection and anti-corruption)

Figure 1: Results RESPECT survey, Question 1

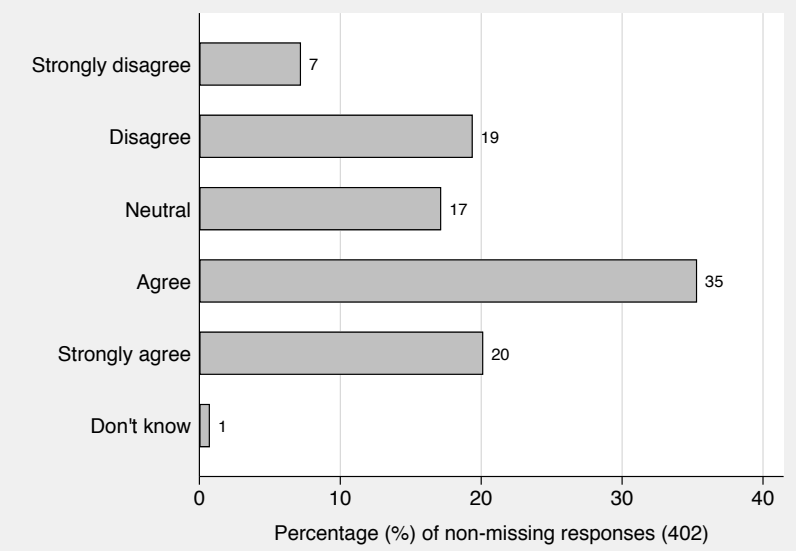

(a) Whole sample

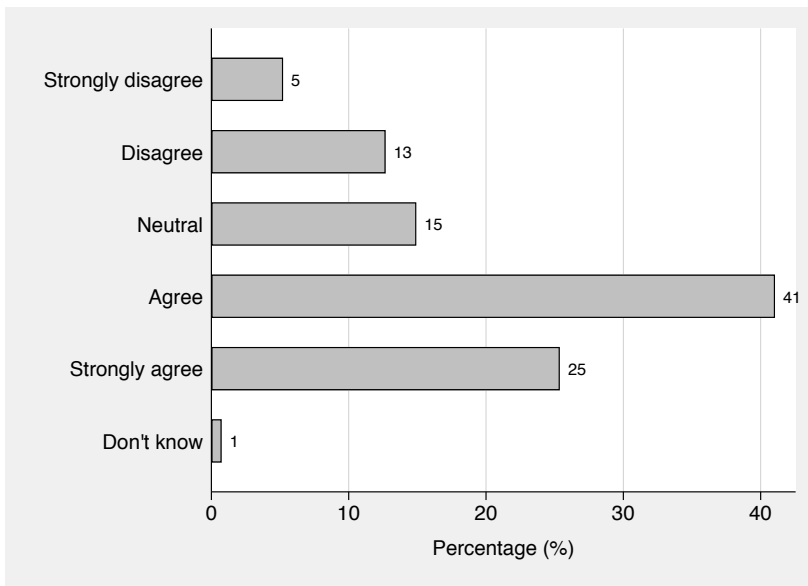

(c) EU

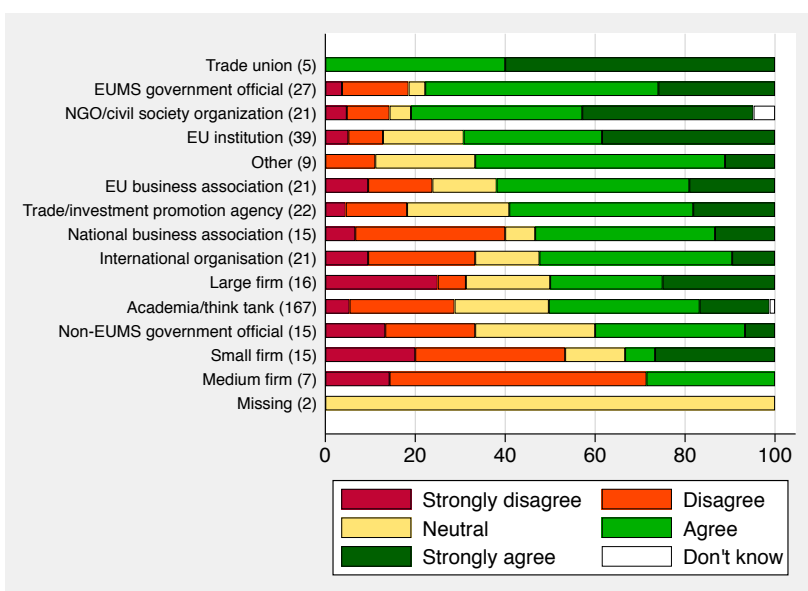

(e) From highest to lowest agreement

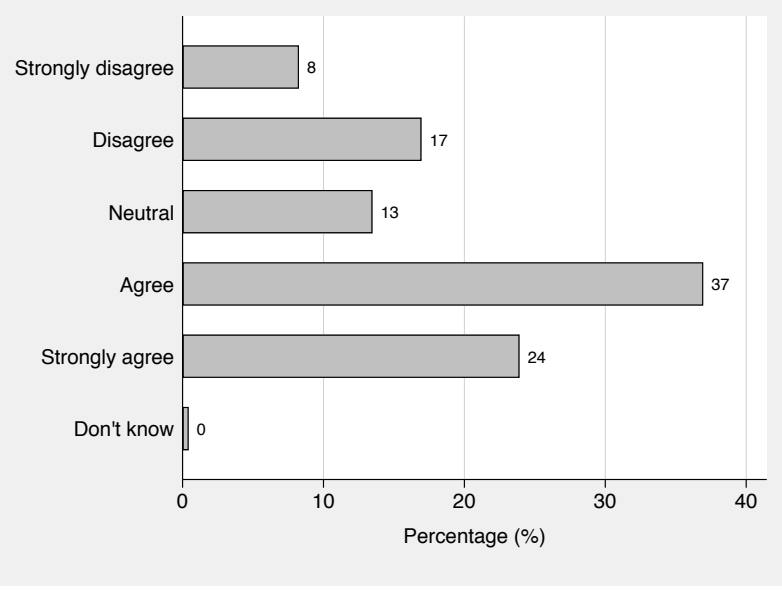

(b) Without academia and think-tanks

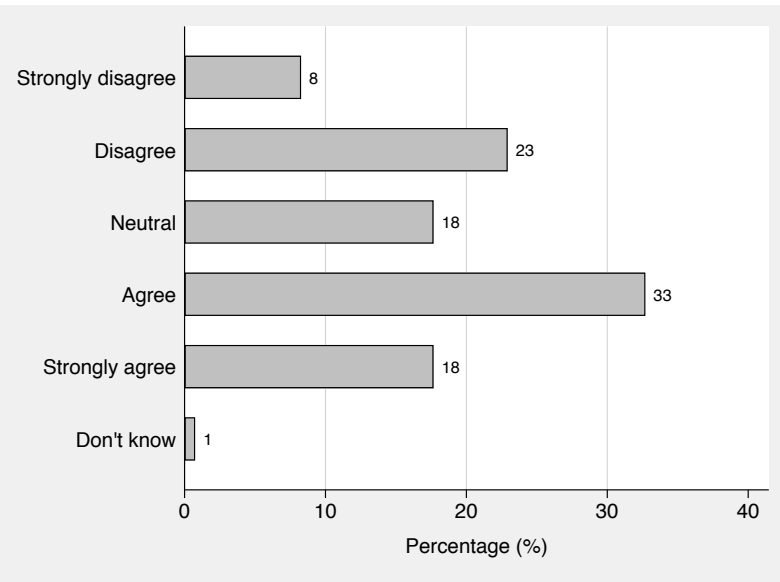

(d) Non-EU

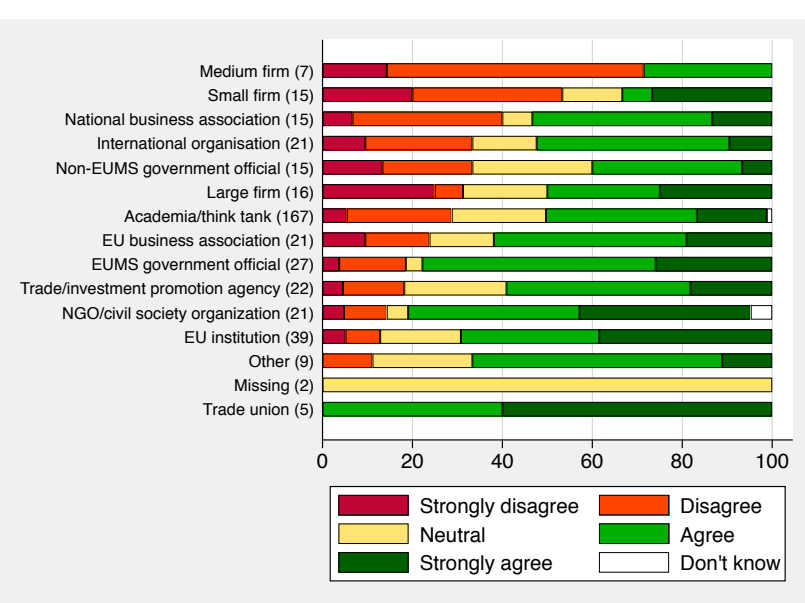

(f) From highest to lowest disagreement 


\section{Question 2}

The design of trade agreements is efficiently informed by consultation of stakeholders.

Figure 2: Results RESPECT survey, Question 2

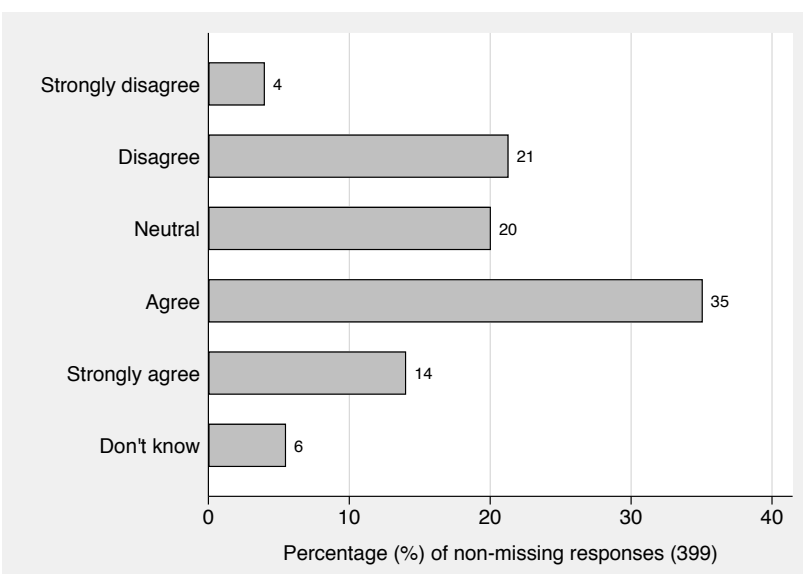

(a) Whole sample

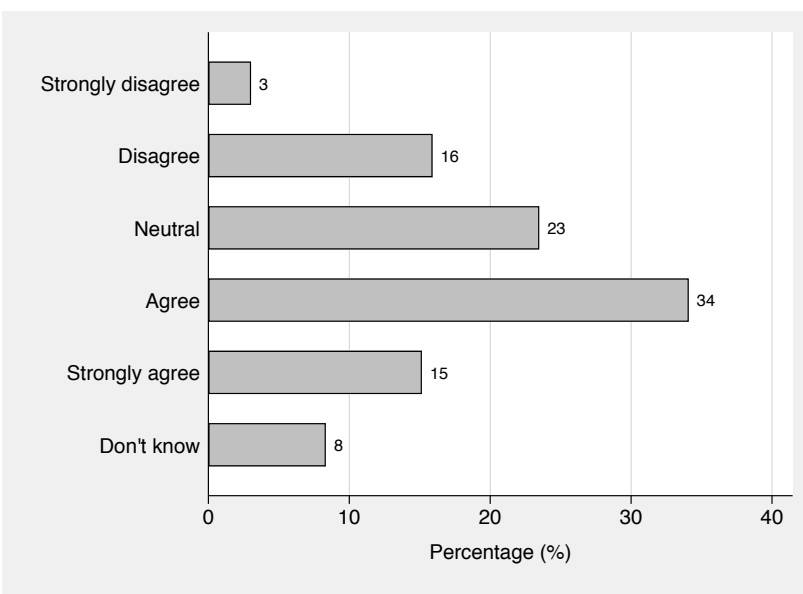

(c) $\mathrm{EU}$

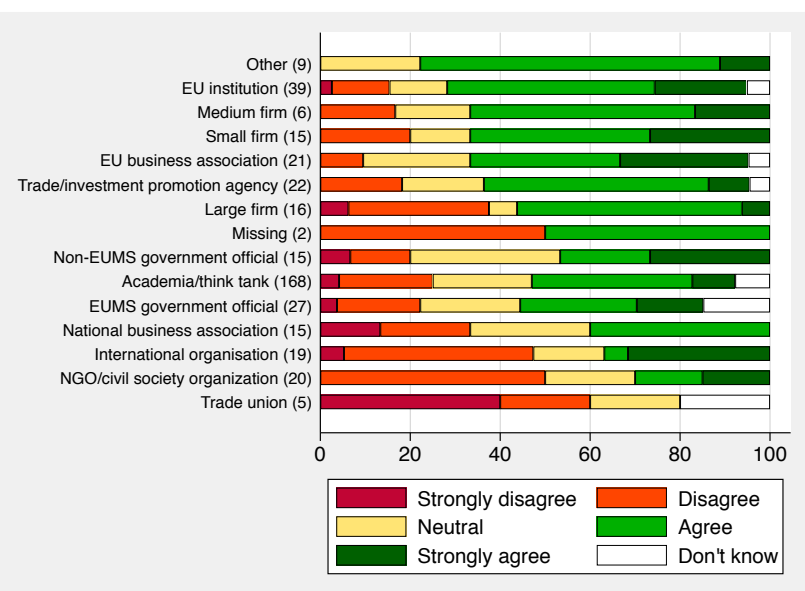

(e) From highest to lowest agreement

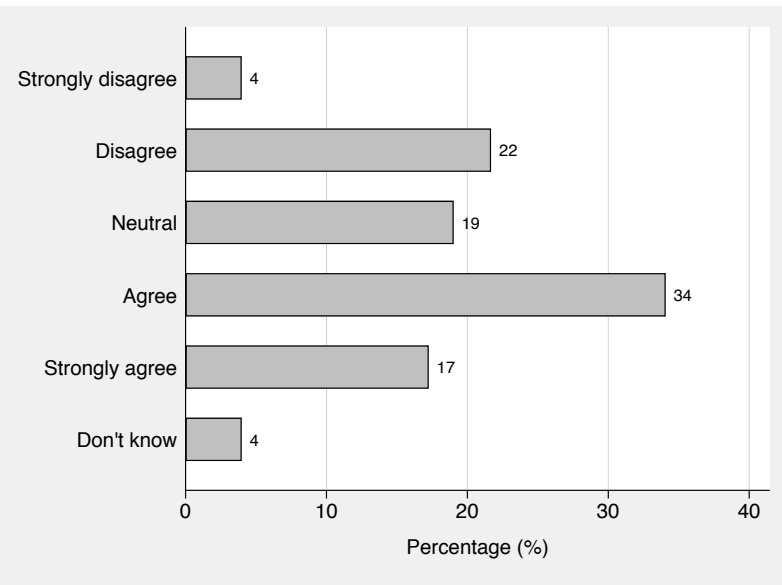

(b) Without academia and think-tanks

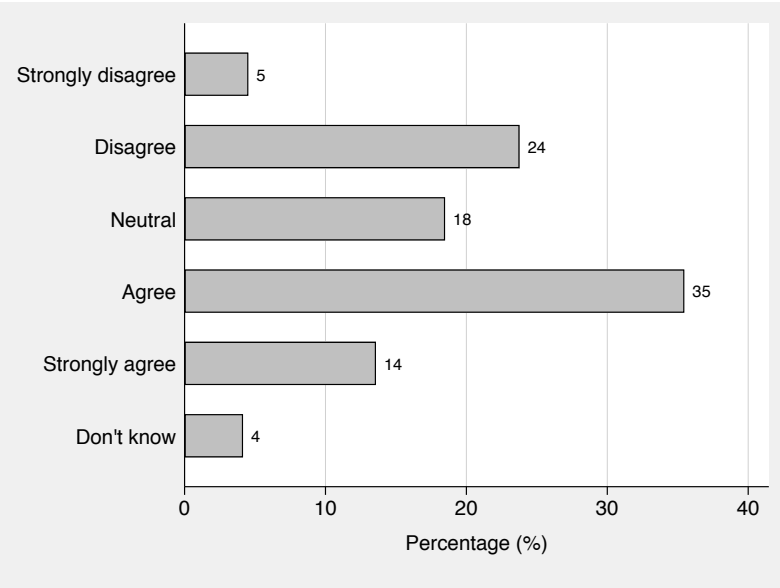

(d) Non-EU

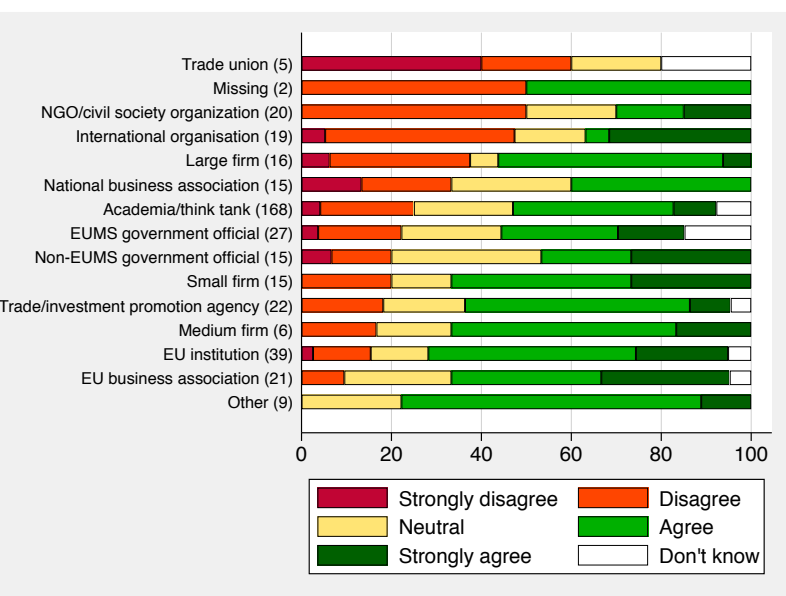

(f) From highest to lowest disagreement 


\section{Question 3}

EU trade policy primarily reflects the interests of large EU member states.

Figure 3: Results RESPECT survey, Question 3

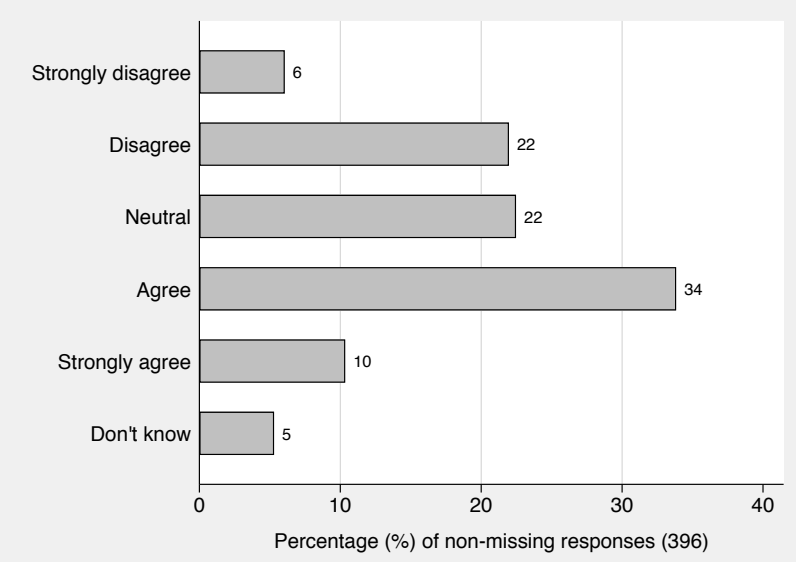

(a) Whole sample

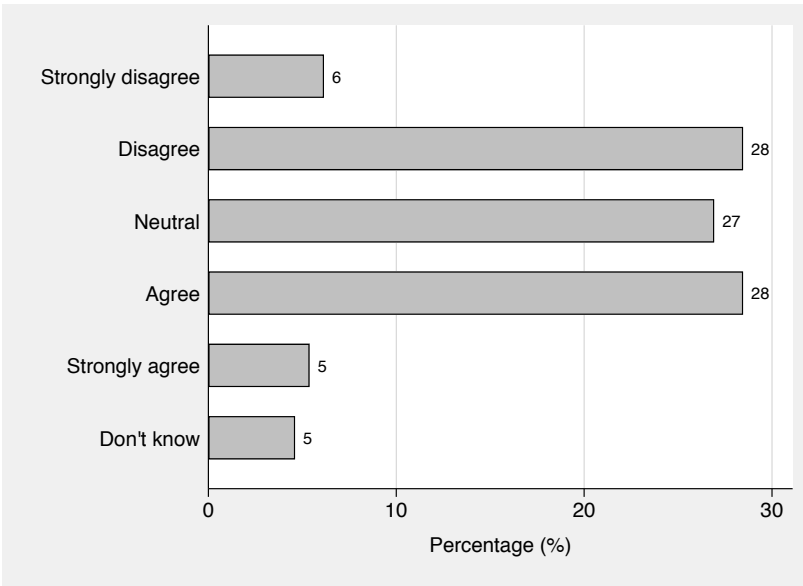

(c) $\mathrm{EU}$

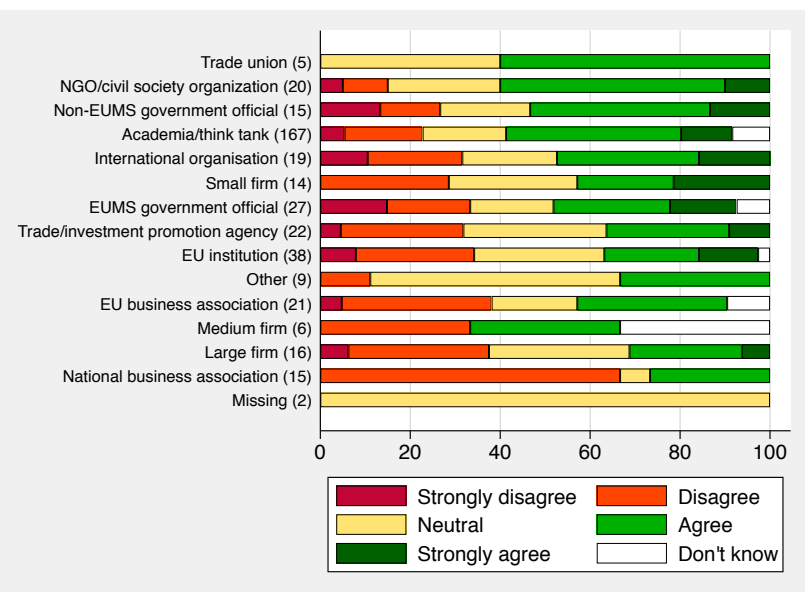

(e) From highest to lowest agreement

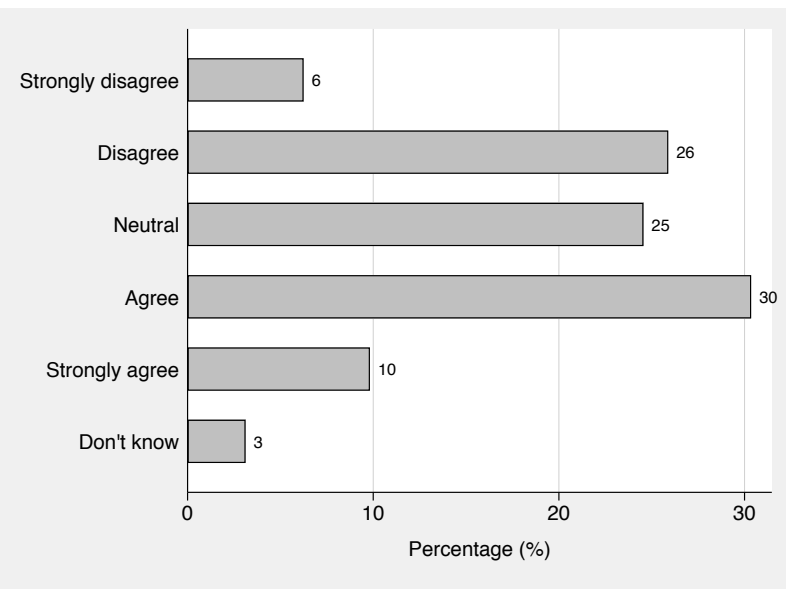

(b) Without academia and think-tanks

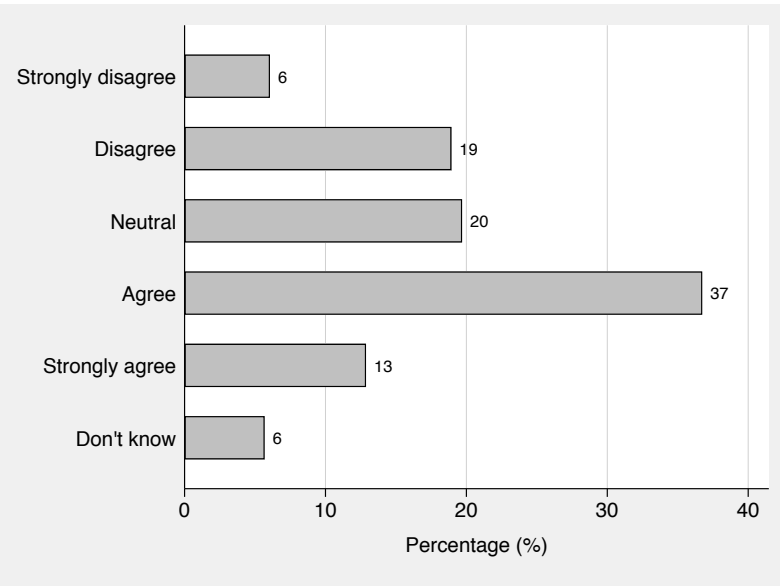

(d) Non-EU

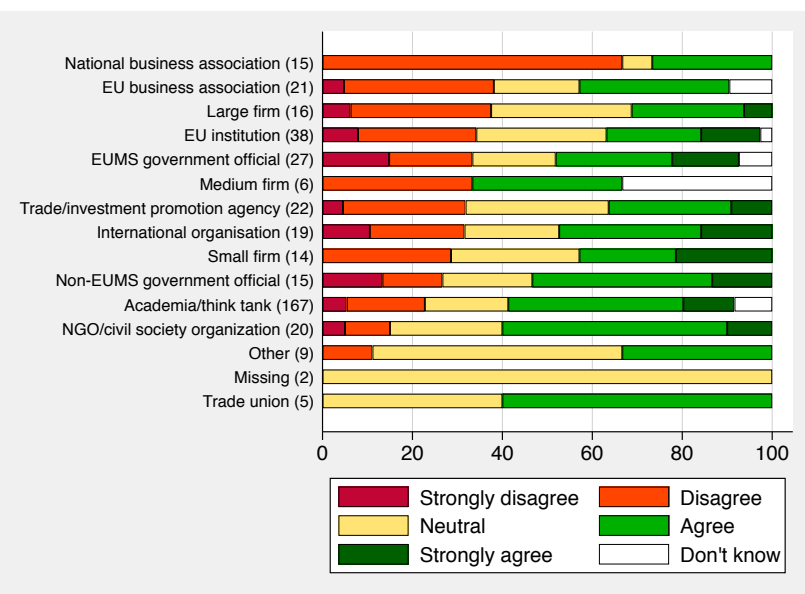

(f) From highest to lowest disagreement 


\section{Question 4}

The formation of EU trade policy primarily serves the interest of the largest firms.

Figure 4: Results RESPECT survey, Question 4

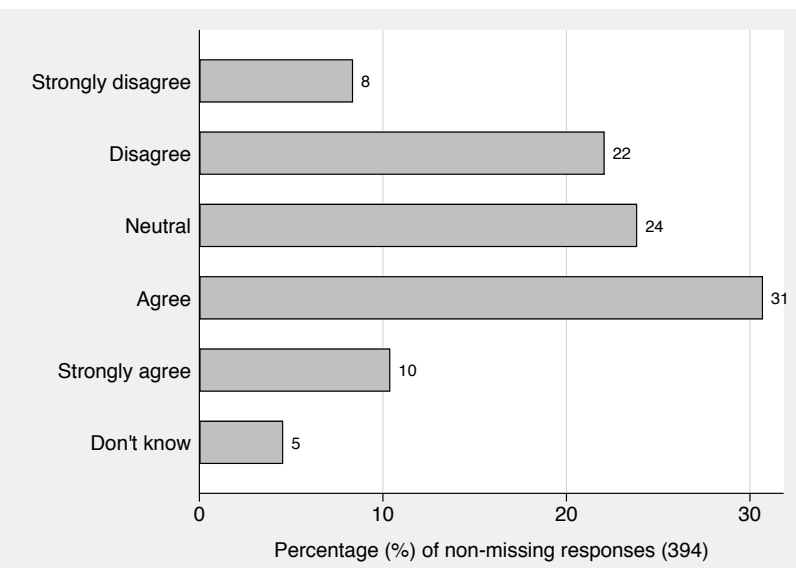

(a) Whole sample

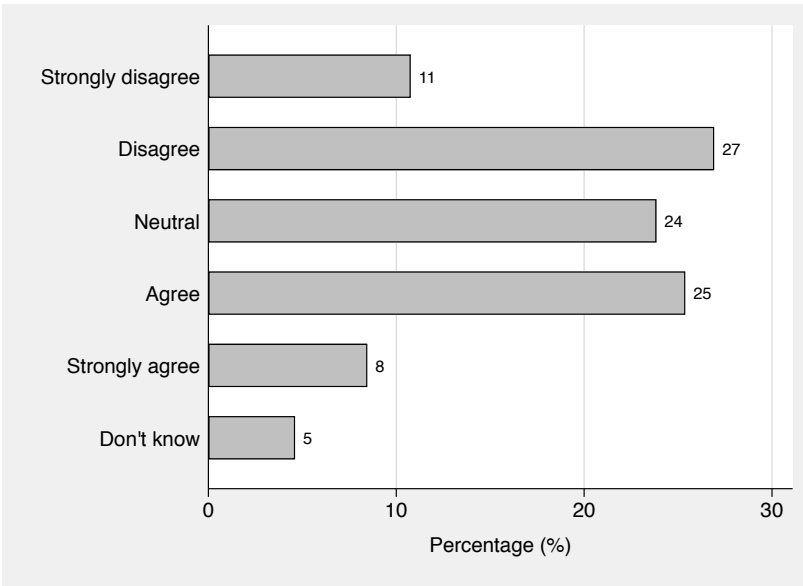

(c) $\mathrm{EU}$

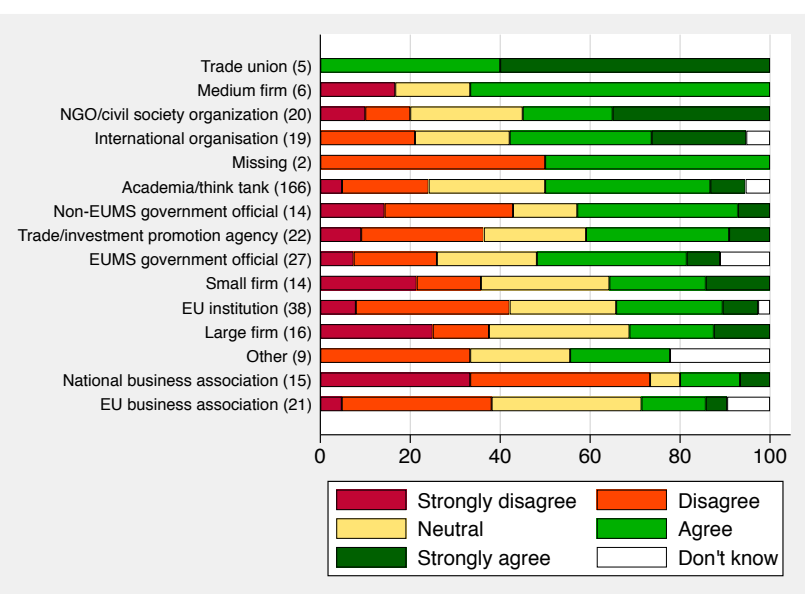

(e) From highest to lowest agreement

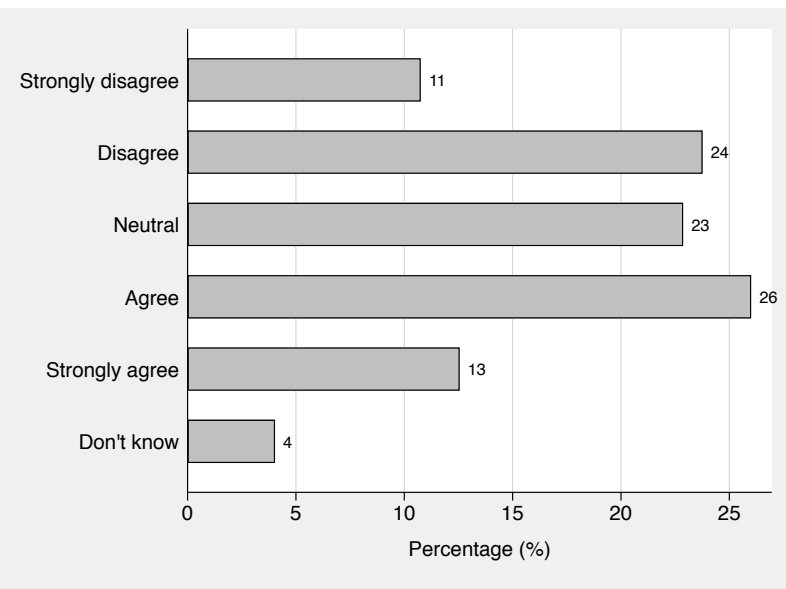

(b) Without academia and think-tanks

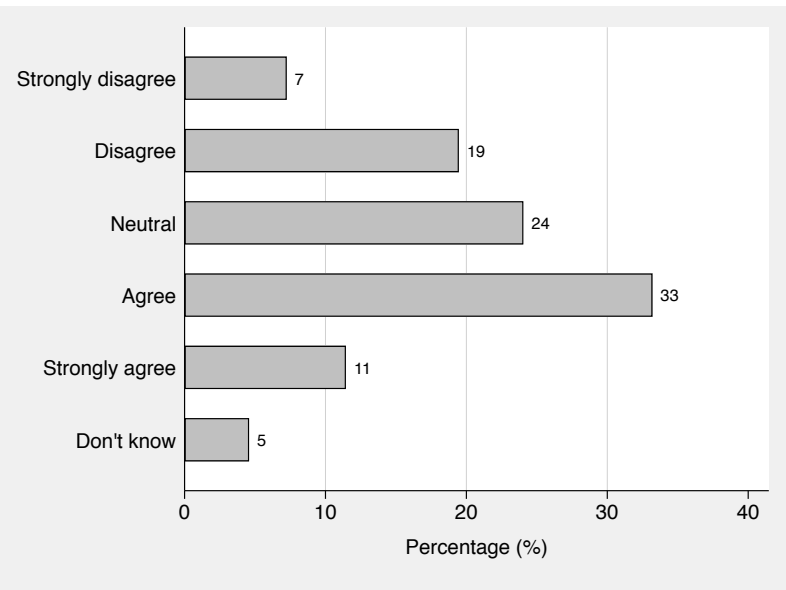

(d) Non-EU

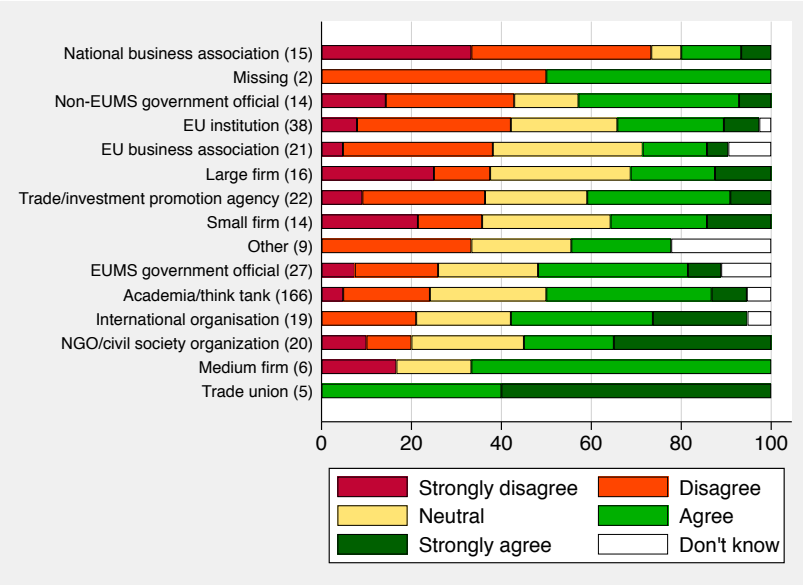

(f) From highest to lowest disagreement 


\subsection{Instruments and results}

The second part of the survey starts by proposing an assessment of the opinions on the effect of trade policy on trade flows, distinguishing between export (Figure 5) and imports (Figure 6). The results here and reveal a strong conviction as regards the positive role of trade agreements for EU exports and imports. This contrasts with the more varied range of views found in general public surveys. Interestingly while the respondents that do not believe trade agreements are good for EU exports account for between 3 and $5 \%$ of the total, when it comes to EU imports the figure increases to between $6 \%$ and $9 \%$. A similar strong and positive attitude emerges regarding EU development assistance, which tends to be considered a good instrument to support trade with non-EU countries (Figure 8).

A substantial polarization emerges when respondents are asked whether the inclusion of non-trade objectives reduces the effectiveness of EU trade policy. As shown in Figure 7 the sample is usually split in two, and in the case of the "Non-EU" subset of respondents, more respondents either agree or strongly agree with the statement reported in Question 7. There is a relatively strong and stable positive belief regarding the capacity of EU trade policy to help realize NTPOs (Figure 9) and economic development in low income countries (Figure 10). Regarding the question whether EU institutions are more effective than other international organisations in improving labor standards in partner countries, the most frequent response is a neutral one (accounting for about $30 \%$ of respondents across the 6 panels in Figure 11). Around the neutral positions opinions are fairly polarized.

This part of the survey also addresses the specific theme of economic diplomacy (Questions 12 and 13). When confronted with the statement "Activities of national trade promotion agencies of European countries work against each other" respondents appear quite uniformly distributed across agreement, disagreement, neutrality, and also the "Don't know" response category (Figure 12). However, the percentage of respondents that either agree or strongly agree with the statement tends to be the largest. Consistent with this, there is a tendency (stronger in this case) to agree there should be more EU-level coordination of national trade promotion activities (Figure 13).

Finally, respondents were asked to indicate which policy instruments they regard as most effective in promoting trade between the EU and developing countries (Question 14) and which are most effective in promoting EU non-trade objectives (Question 15). The top three instruments to promote trade between EU and developing countries are held to be trade agreements, technical assistance and direct investment by European multinationals in partner countries (Figure 14). As regards promoting NTPOs, the most frequently chosen instruments are targeted assistance for NGOs, unions and regulatory bodies, expert dialogues between the EU and partner country stakeholders, and technical assistance (Figure 15). The two rankings are remarkably stable across all six categories of respondents. They suggest limited support for the notion that trade is among the most effective instruments available to the EU to promote NTPOs. 


\section{Question 5}

EU trade agreements help increase exports of EU Member States.

Figure 5: Results RESPECT survey, Question 5

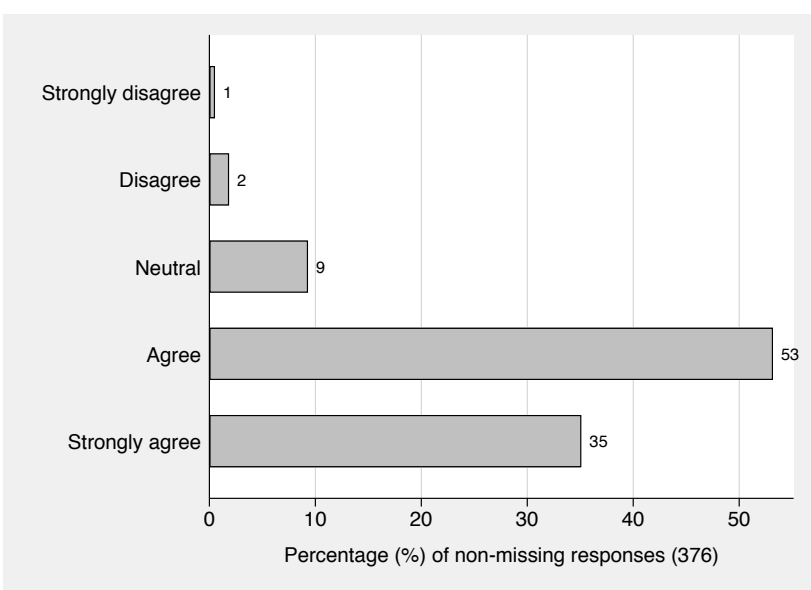

(a) Whole sample

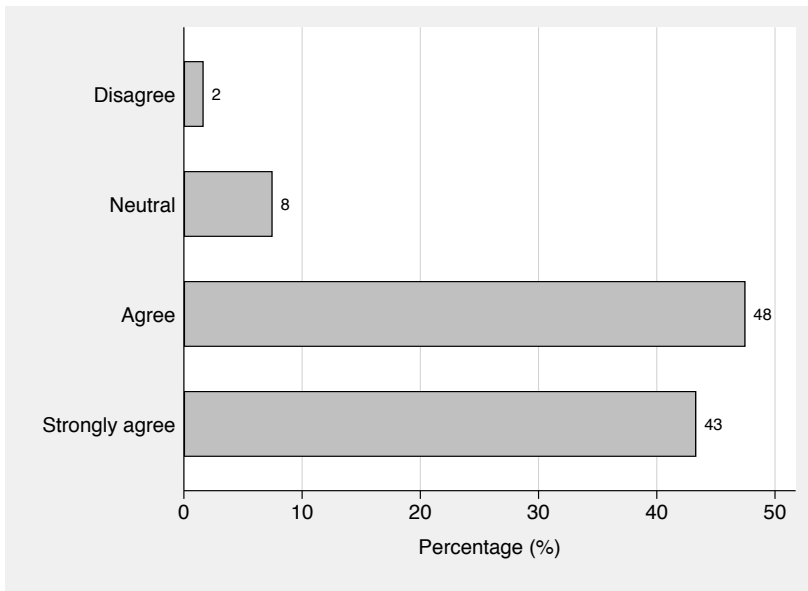

(c) $\mathrm{EU}$

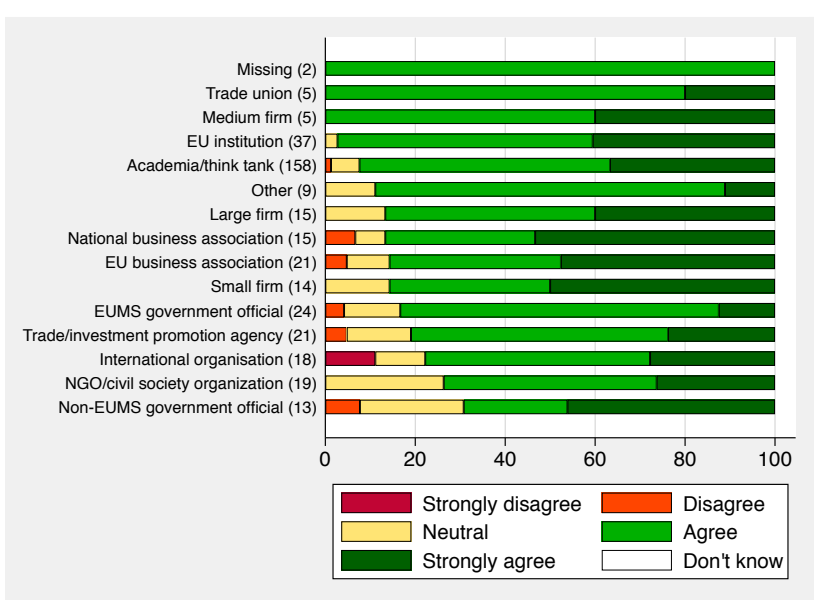

(e) From highest to lowest agreement

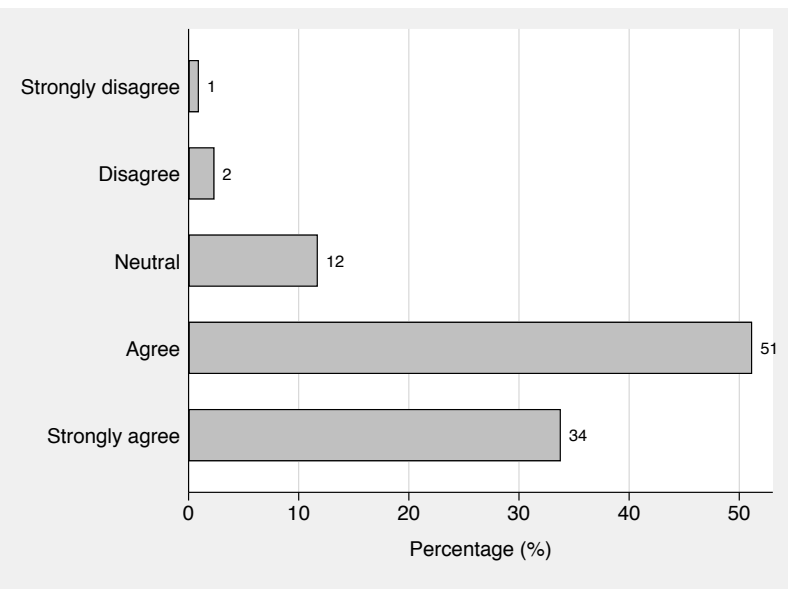

(b) Without academia and think-tanks

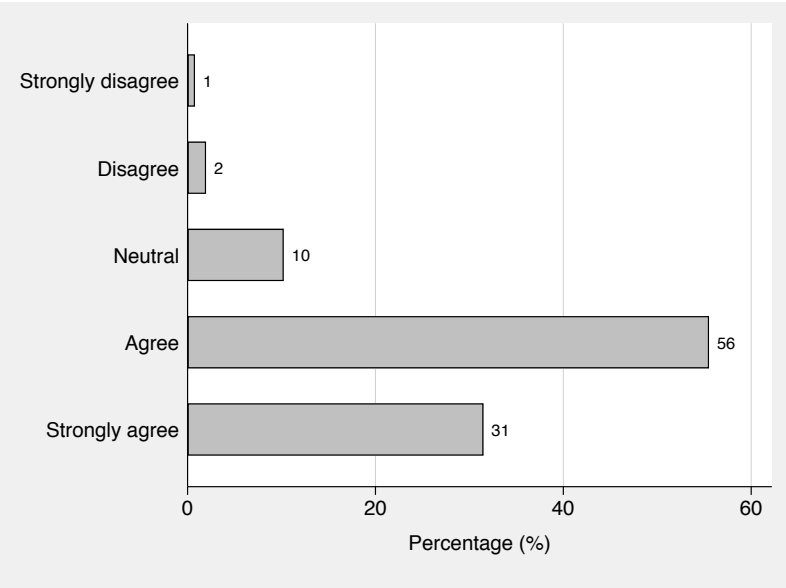

(d) Non-EU

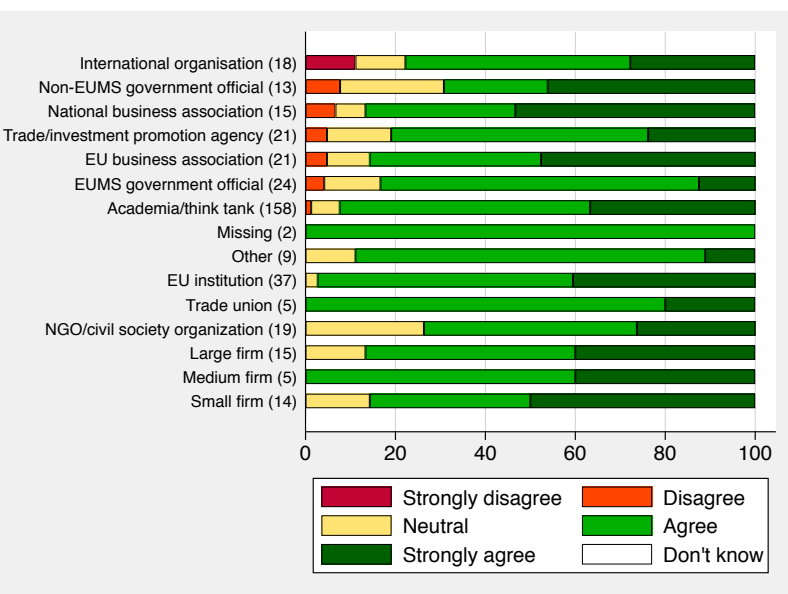

(f) From highest to lowest disagreement 


\section{Question 6}

EU trade agreements help increase imports of EU Member States.

Figure 6: Results RESPECT survey, Question 6

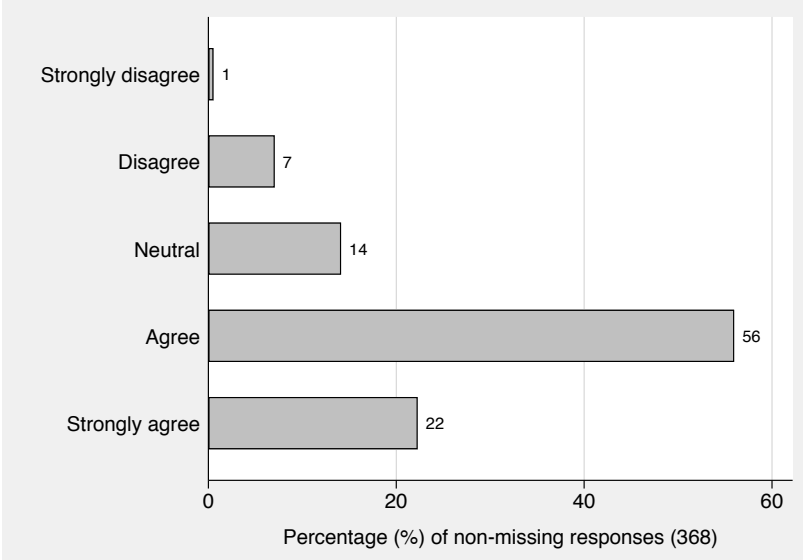

(a) Whole sample

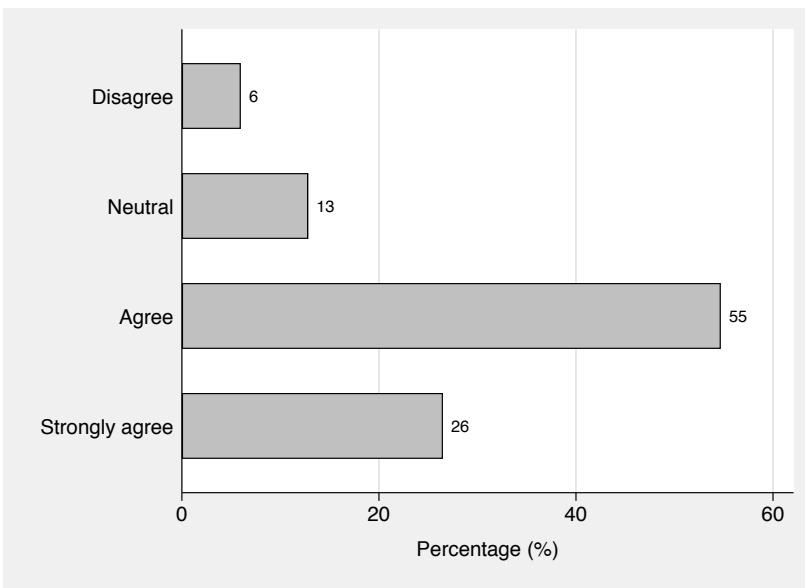

(c) $\mathrm{EU}$

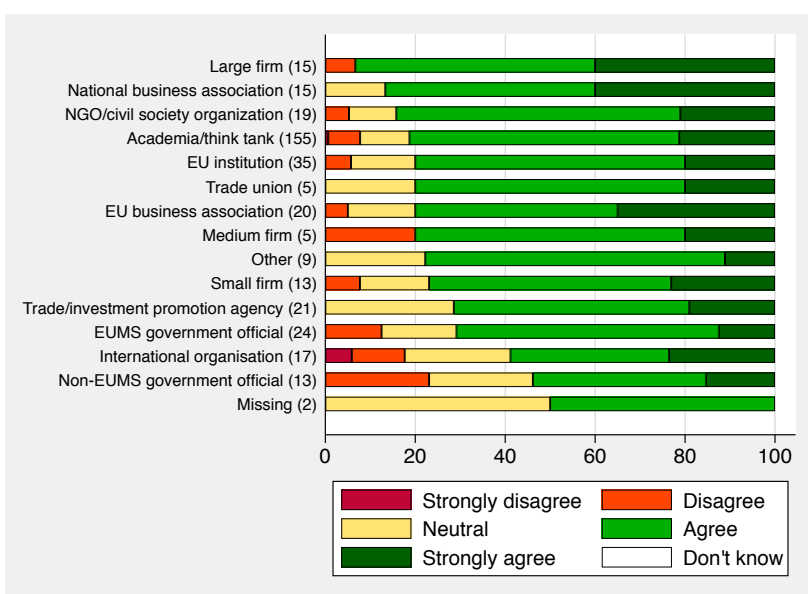

(e) From highest to lowest agreement

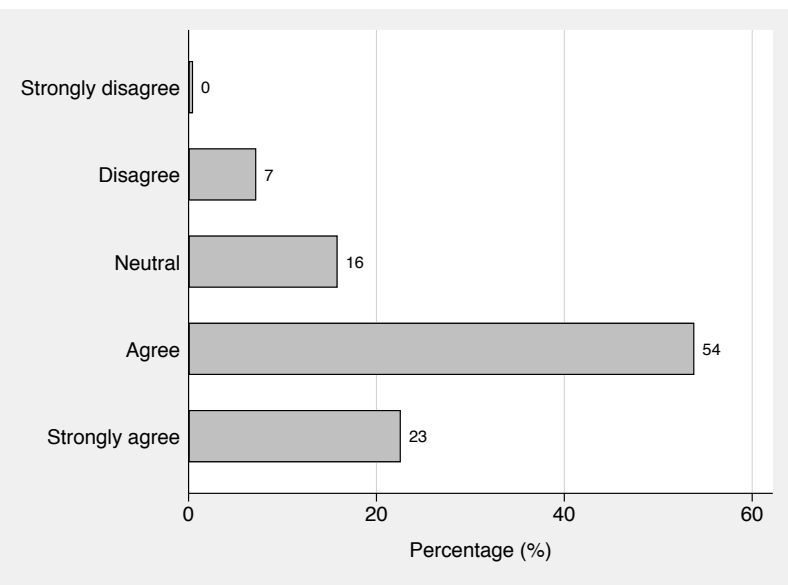

(b) Without academia and think-tanks

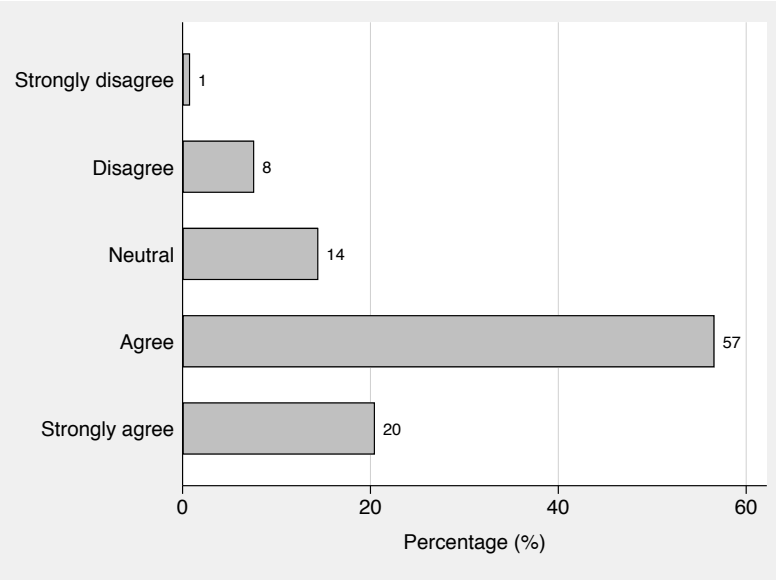

(d) Non-EU

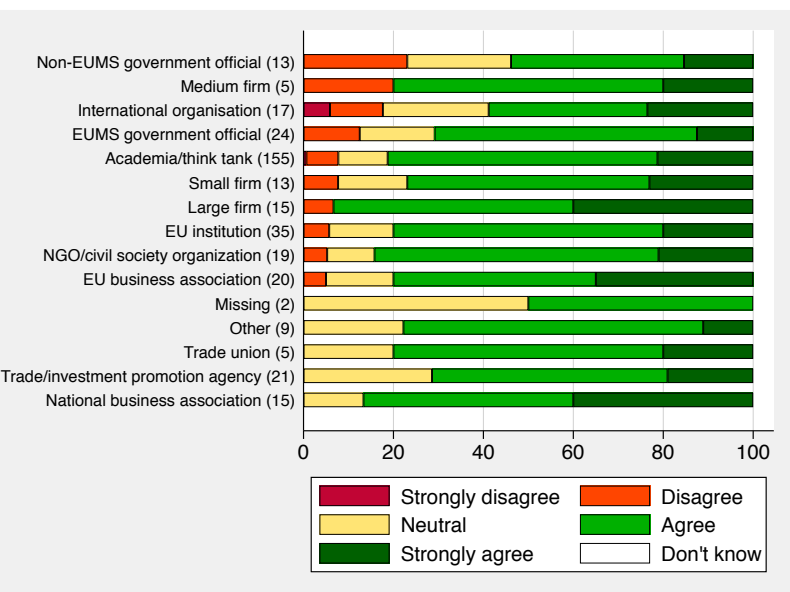

(f) From highest to lowest disagreement 


\section{Question 7}

The inclusion of non-trade objectives reduces the effectiveness of EU trade policy.

Figure 7: Results RESPECT survey, Question 7

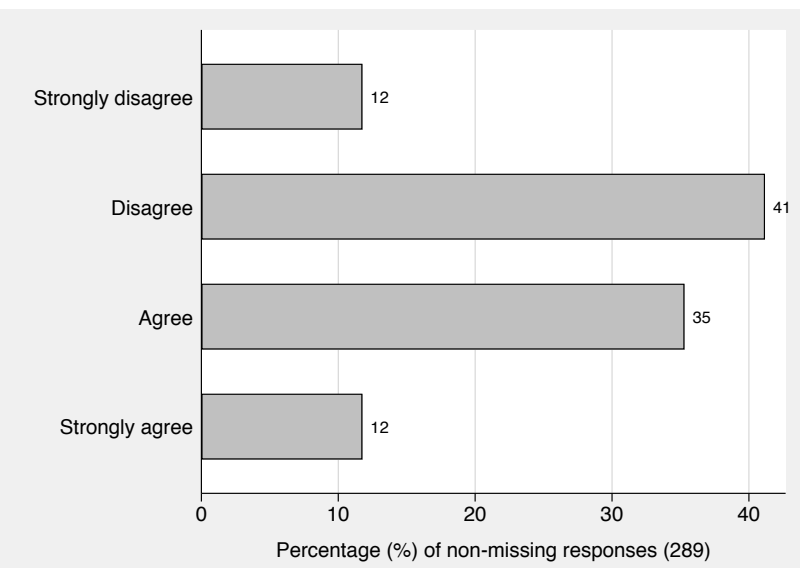

(a) Whole sample

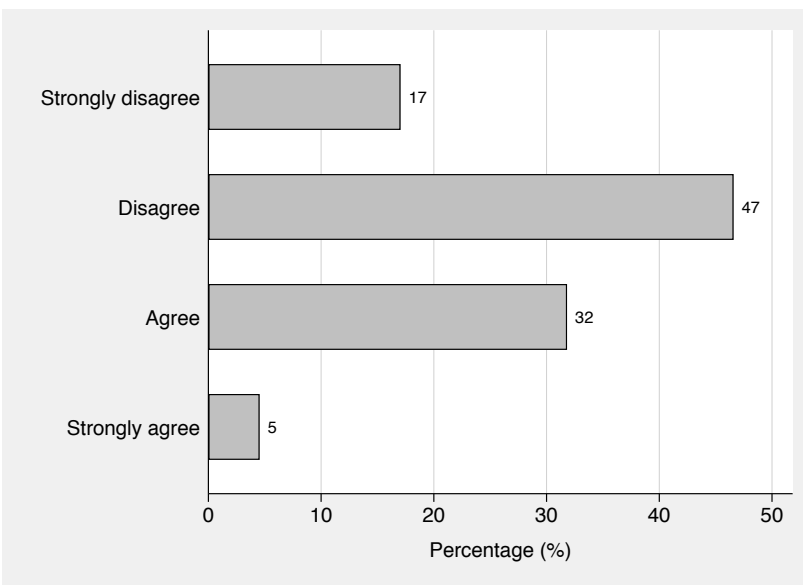

(c) $\mathrm{EU}$

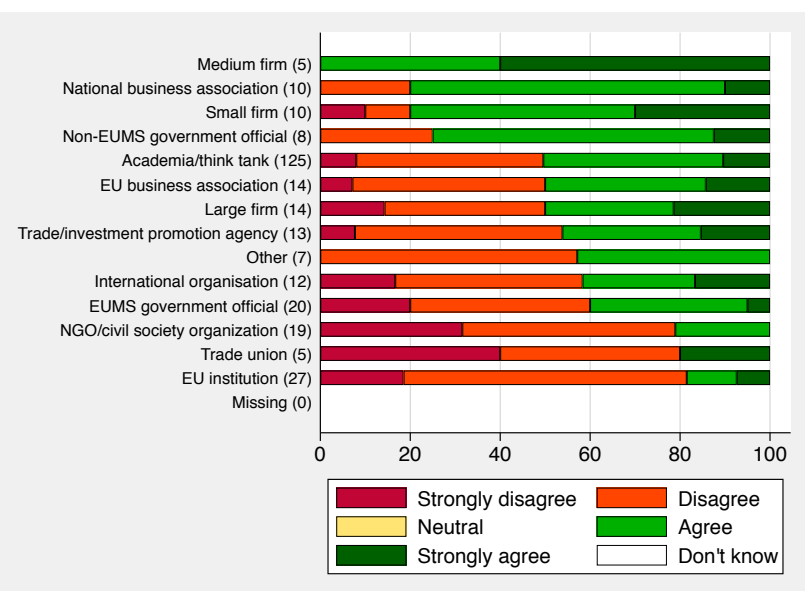

(e) From highest to lowest agreement

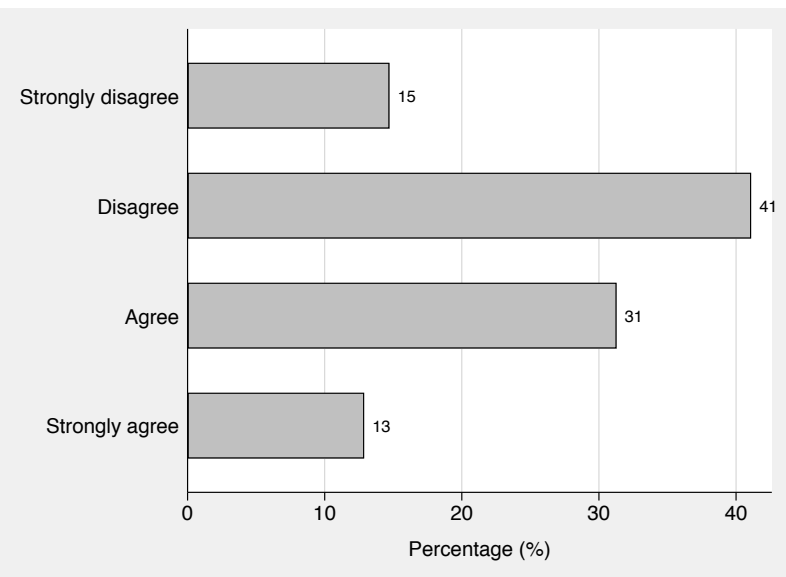

(b) Without academia and think-tanks

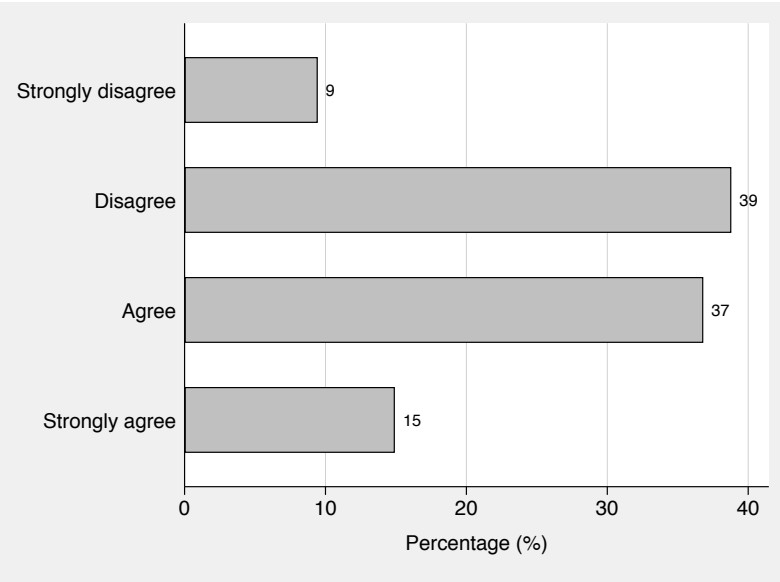

(d) Non-EU

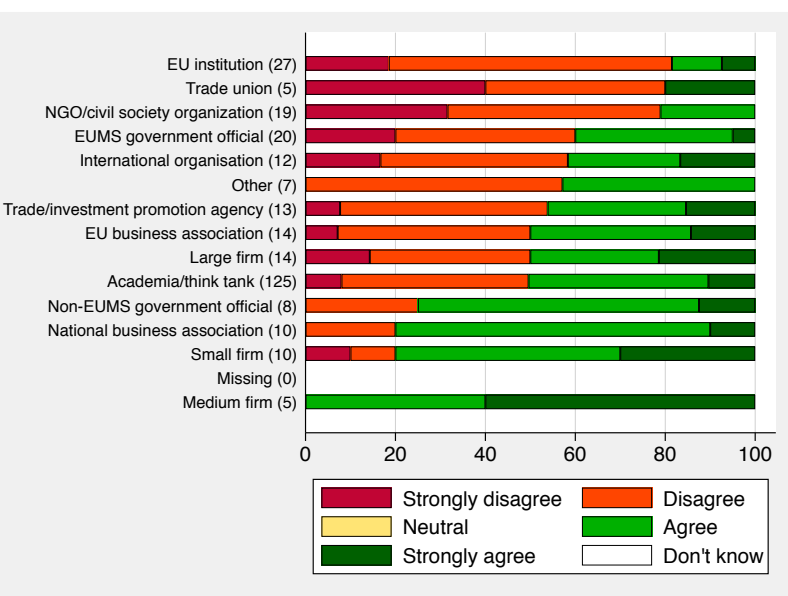

(f) From highest to lowest disagreement 


\section{Question 8}

EU development assistance supports trade with non-EU countries.

Figure 8: Results RESPECT survey, Question 8

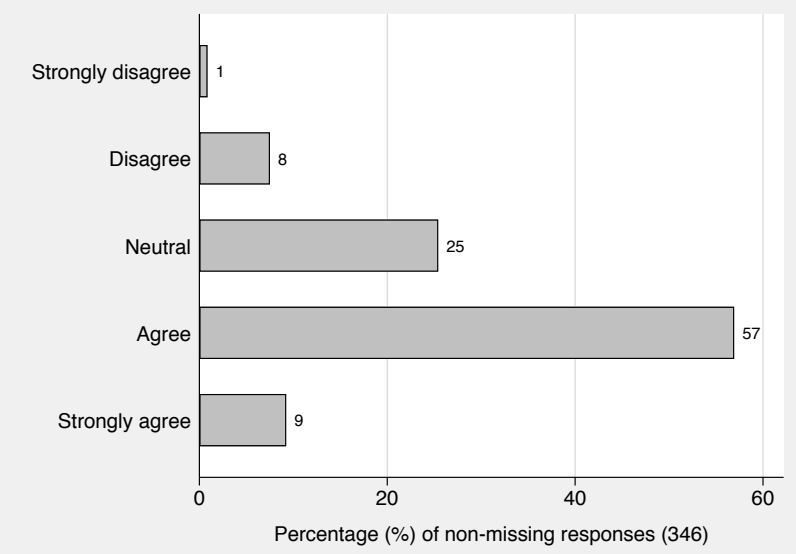

(a) Whole sample

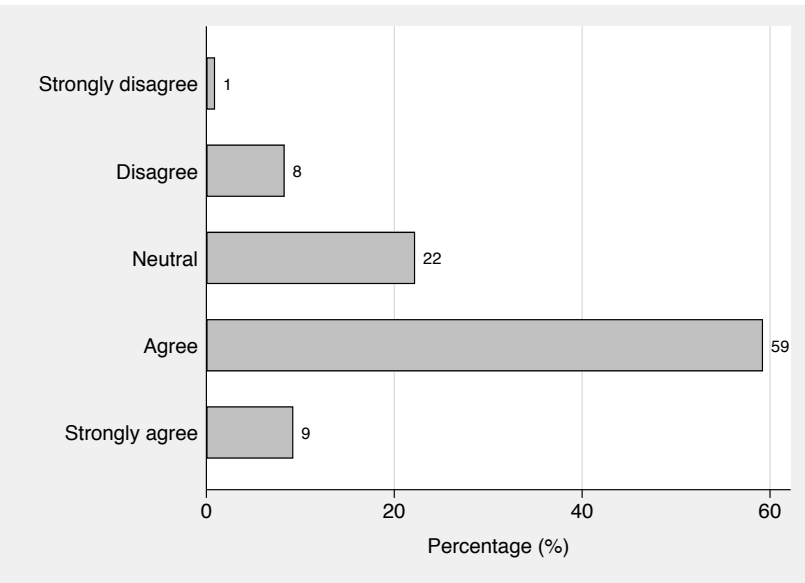

(c) $\mathrm{EU}$

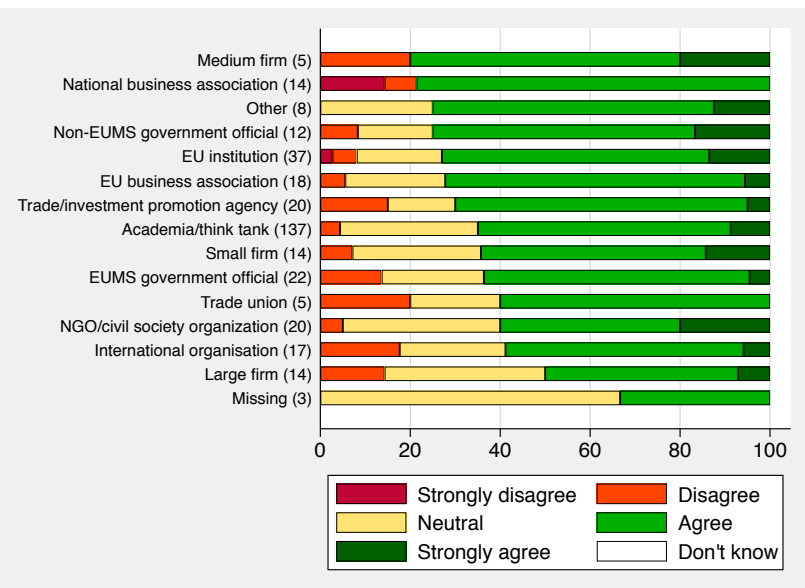

(e) From highest to lowest agreement

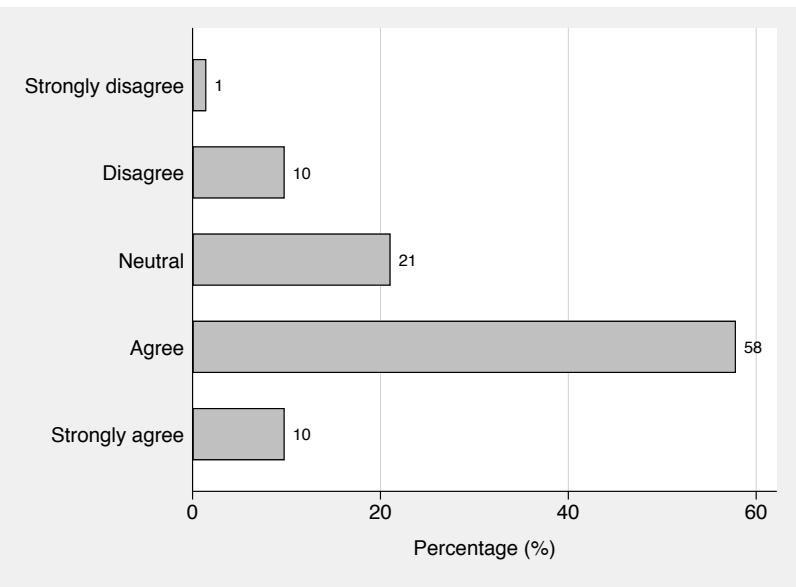

(b) Without academia and think-tanks

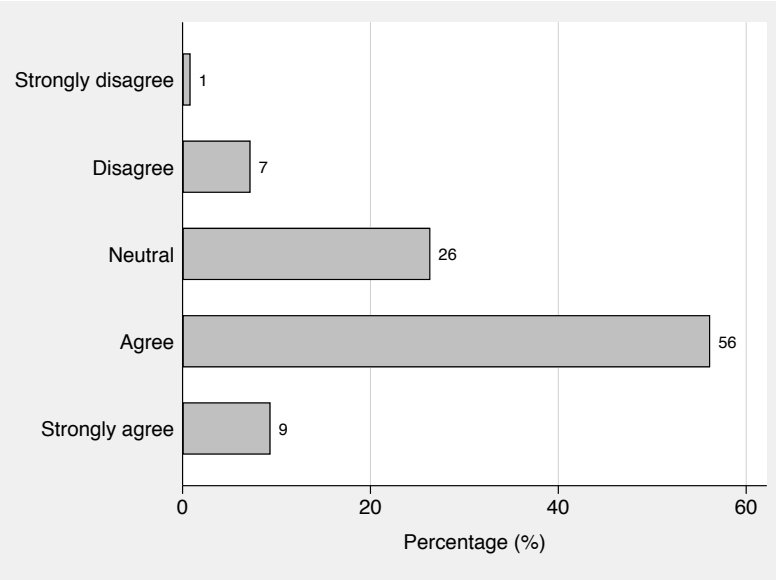

(d) Non-EU

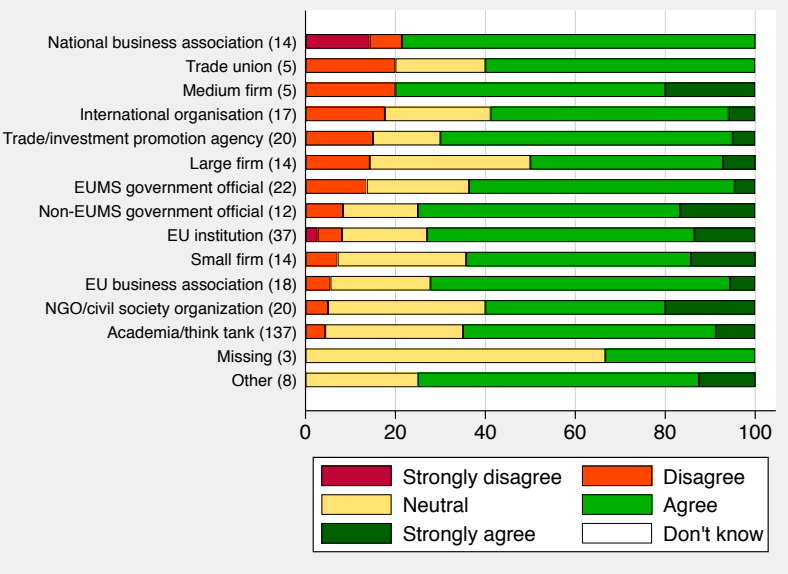

(f) From highest to lowest disagreement 


\section{Question 9}

EU trade policy supports the realisation of EU non-trade objectives (such as human rights, labor, environmental protection and anti-corruption).

Figure 9: Results RESPECT survey, Question 9
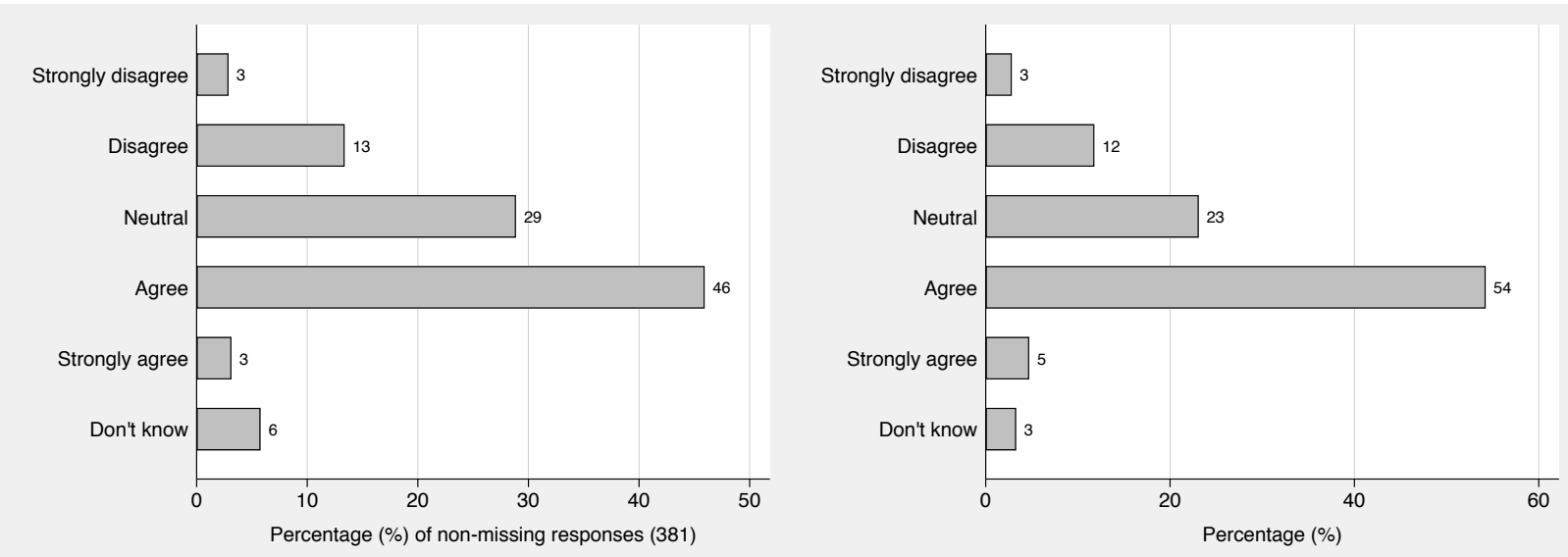

(a) Whole sample

(b) Without academia and think-tanks
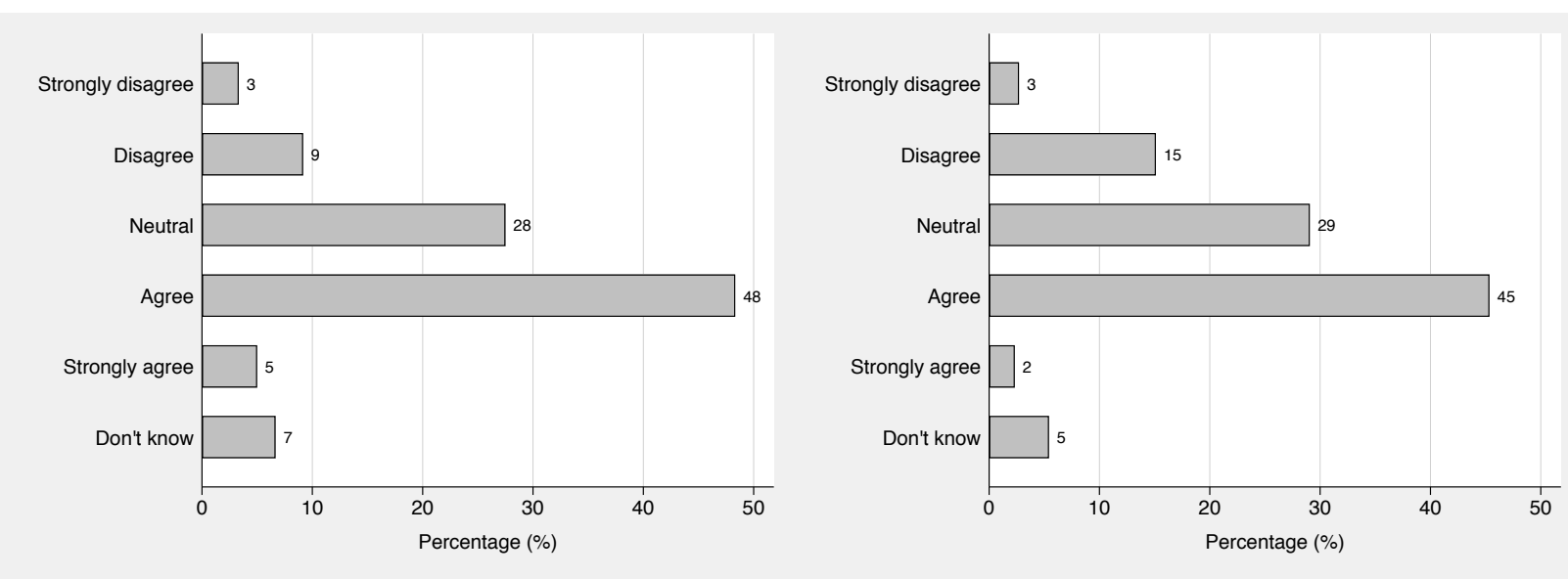

(c) EU

(d) Non-EU

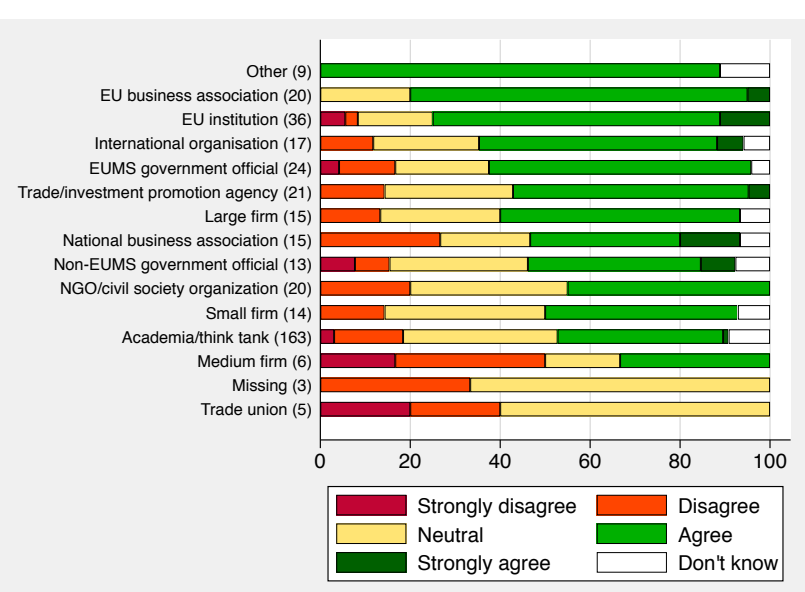

(e) From highest to lowest agreement

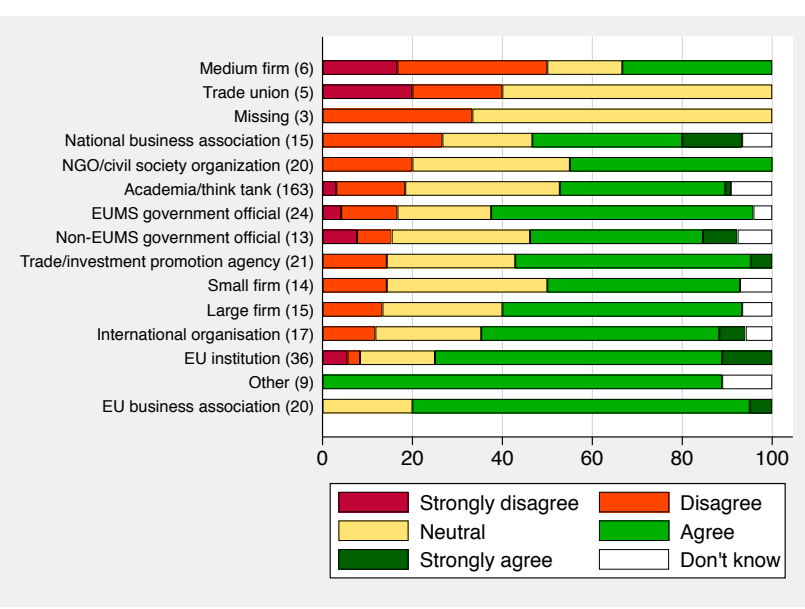

(f) From highest to lowest disagreement 


\section{Question 10}

EU trade policies promote economic development in low income countries.

Figure 10: Results RESPECT survey, Question 10

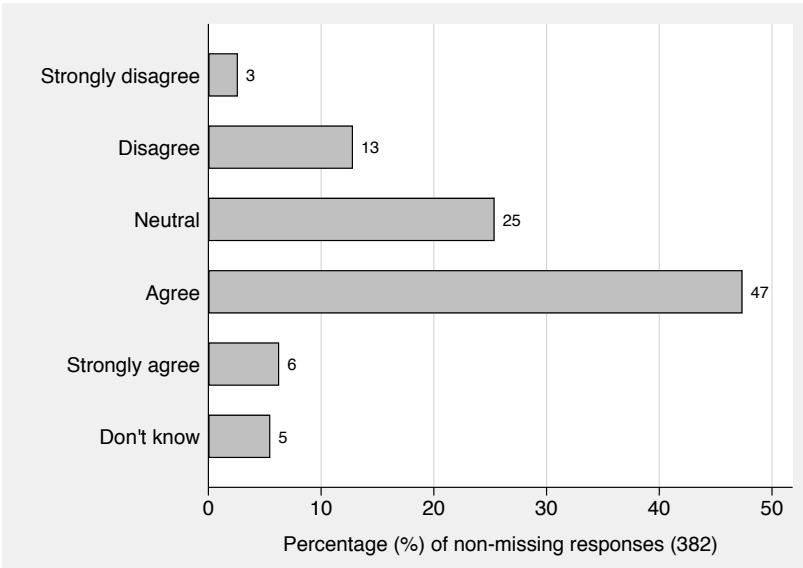

(a) Whole sample

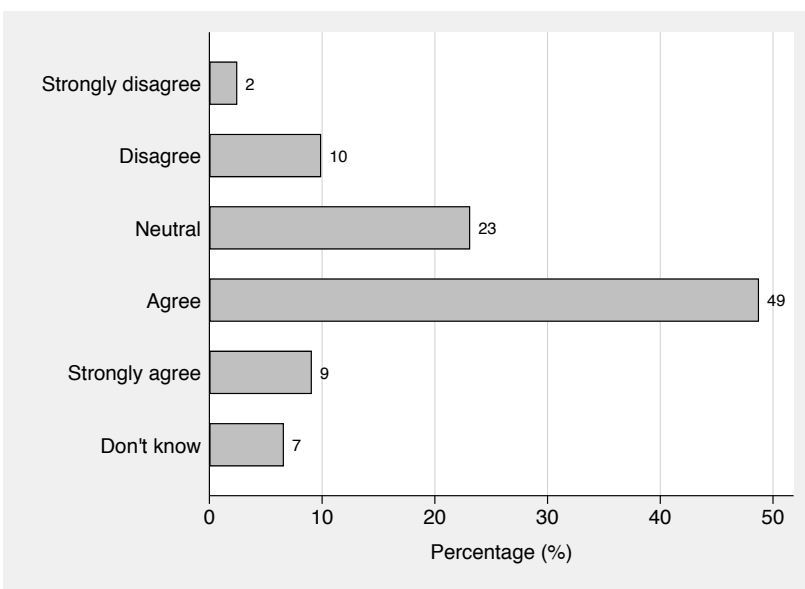

(c) $\mathrm{EU}$

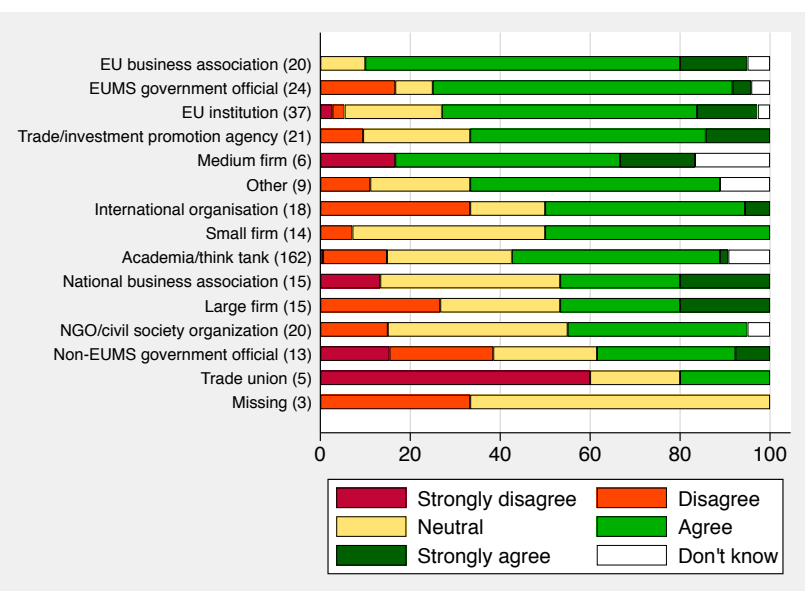

(e) From highest to lowest agreement

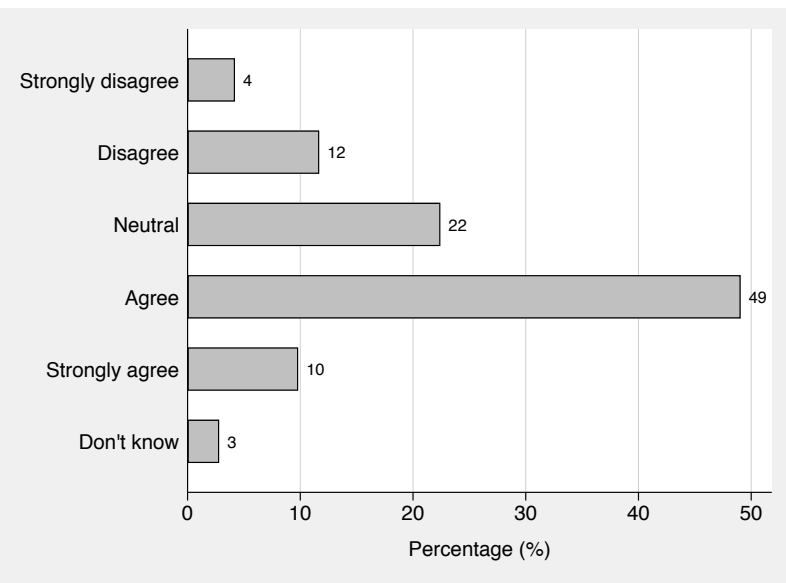

(b) Without academia and think-tanks

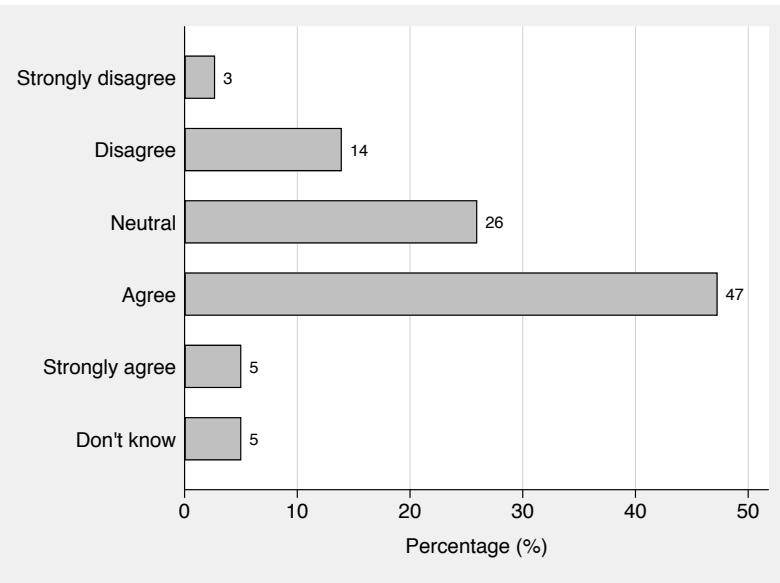

(d) Non-EU

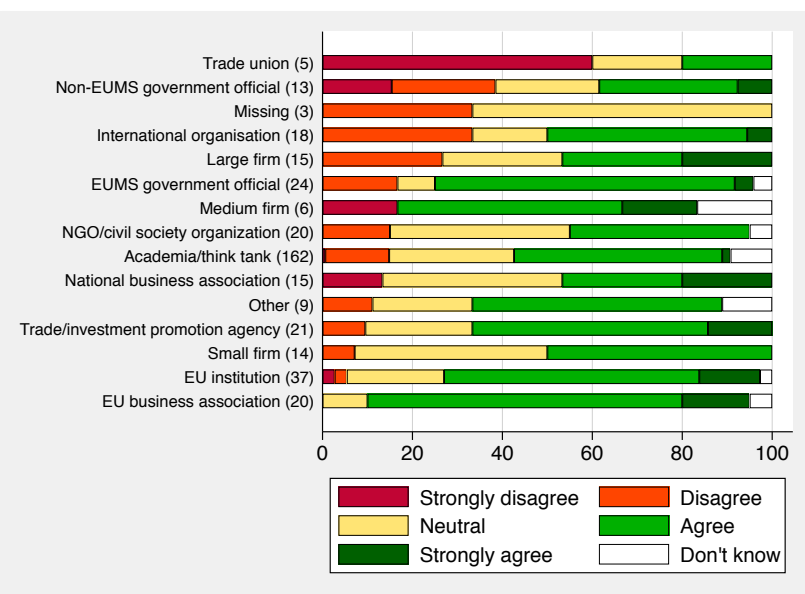

(f) From highest to lowest disagreement 


\section{Question 11}

EU institutions are more effective than other international organisations in improving labor standards in partner countries.

Figure 11: Results RESPECT survey, Question 11

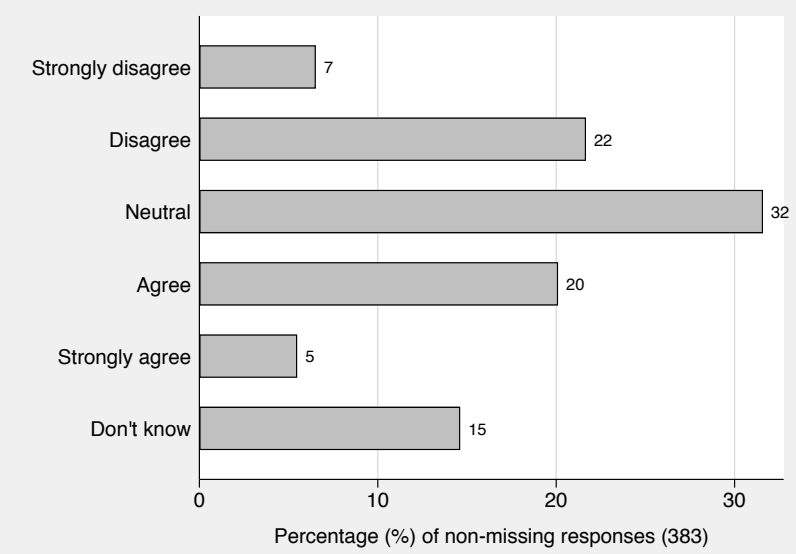

(a) Whole sample

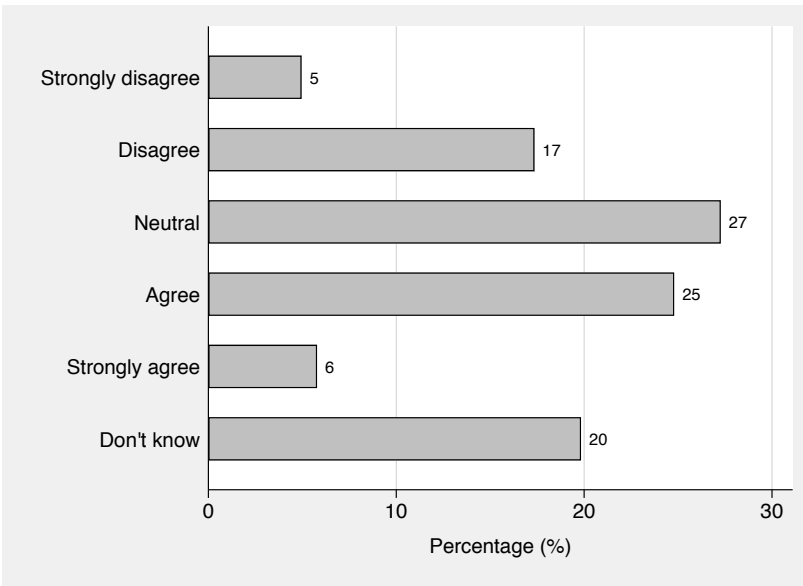

(c) $\mathrm{EU}$

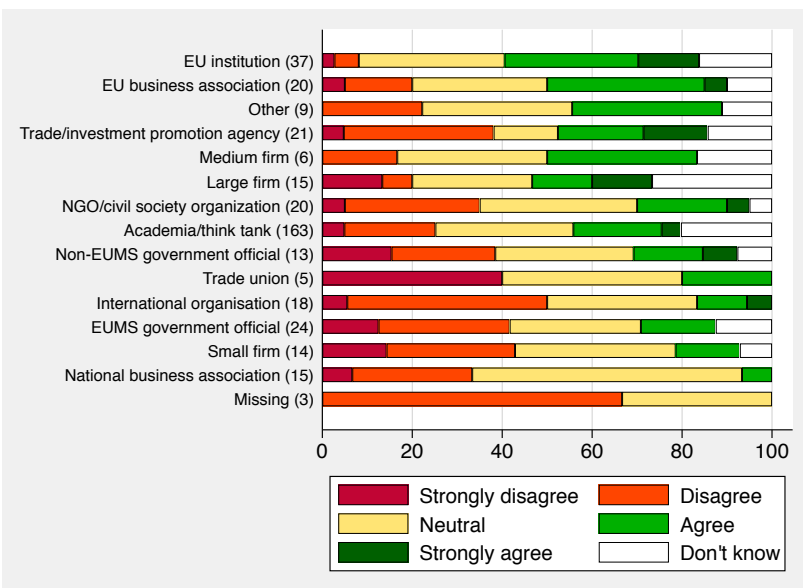

(e) From highest to lowest agreement

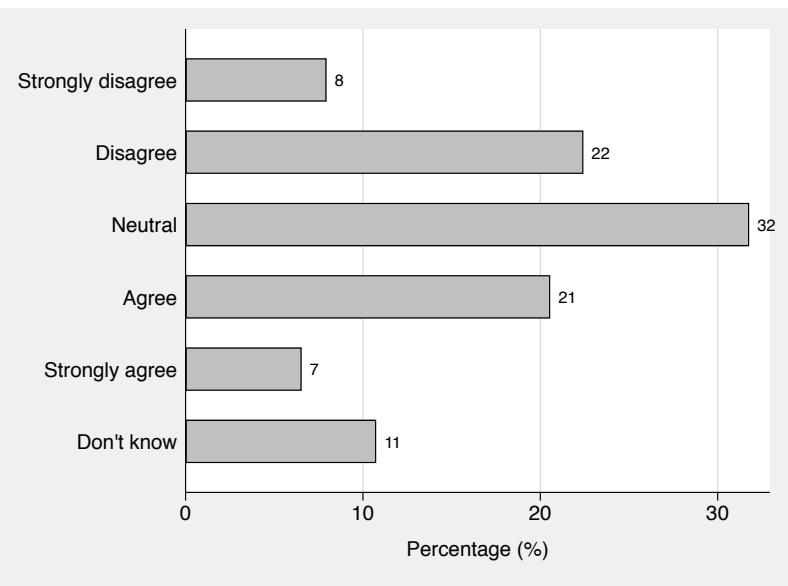

(b) Without academia and think-tanks

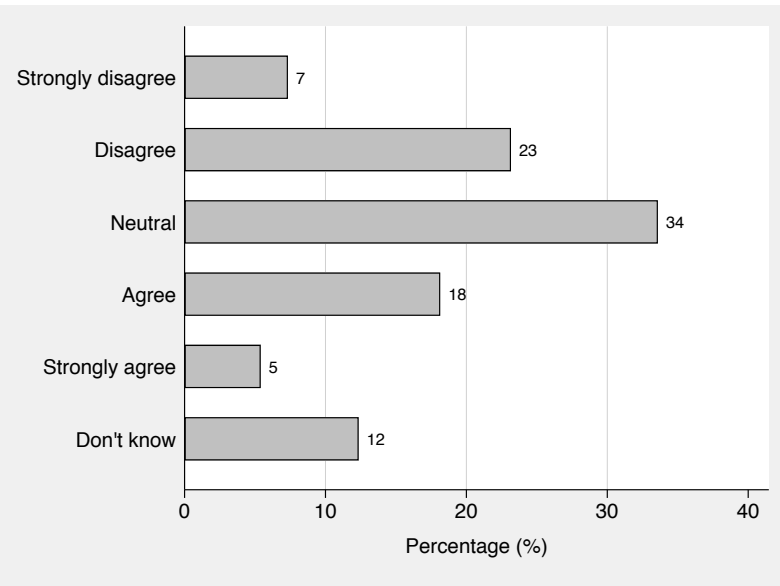

(d) Non-EU

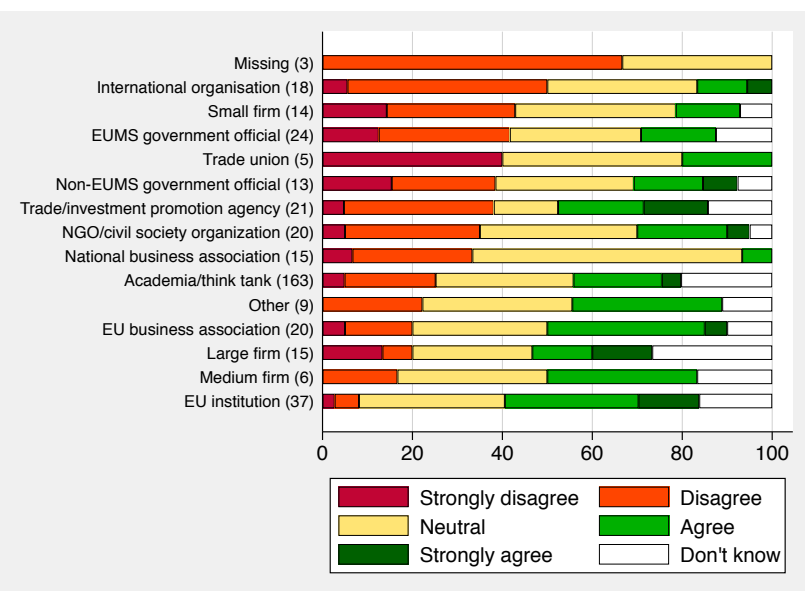

(f) From highest to lowest disagreement 


\section{Question 12}

Activities of national trade promotion agencies of European countries work against each other.

Figure 12: Results RESPECT survey, Question 12

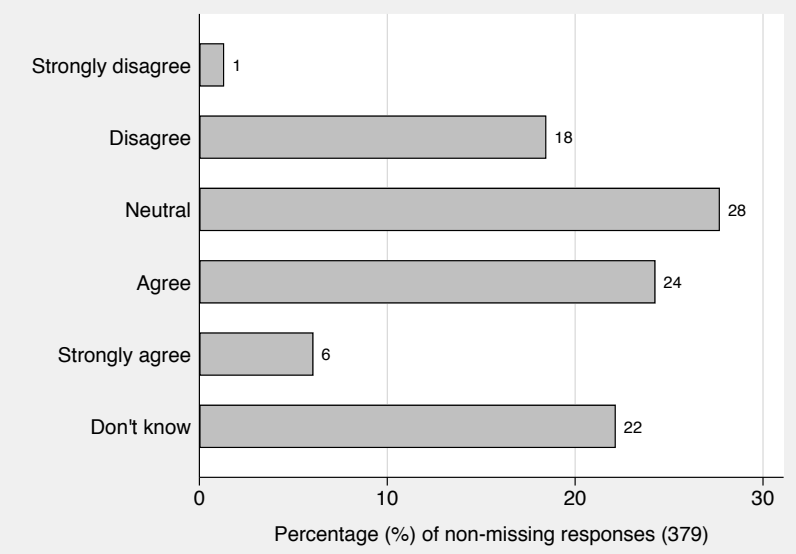

(a) Whole sample

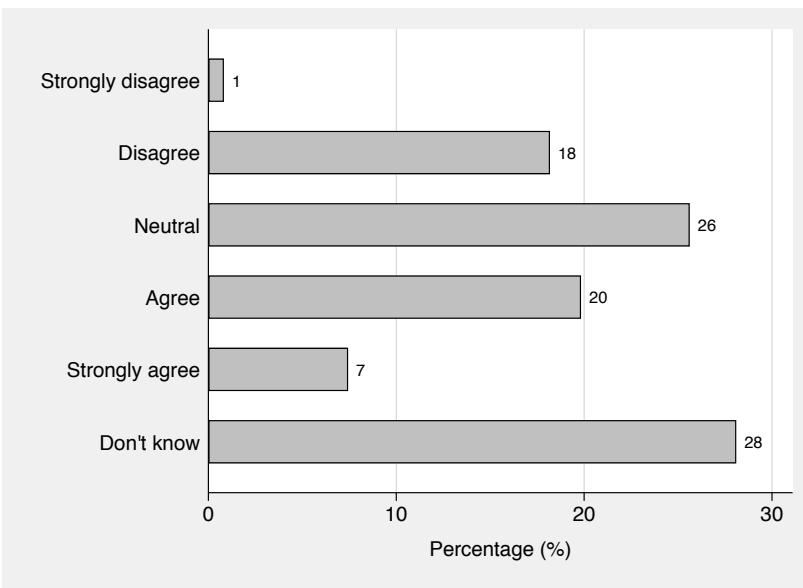

(c) $\mathrm{EU}$

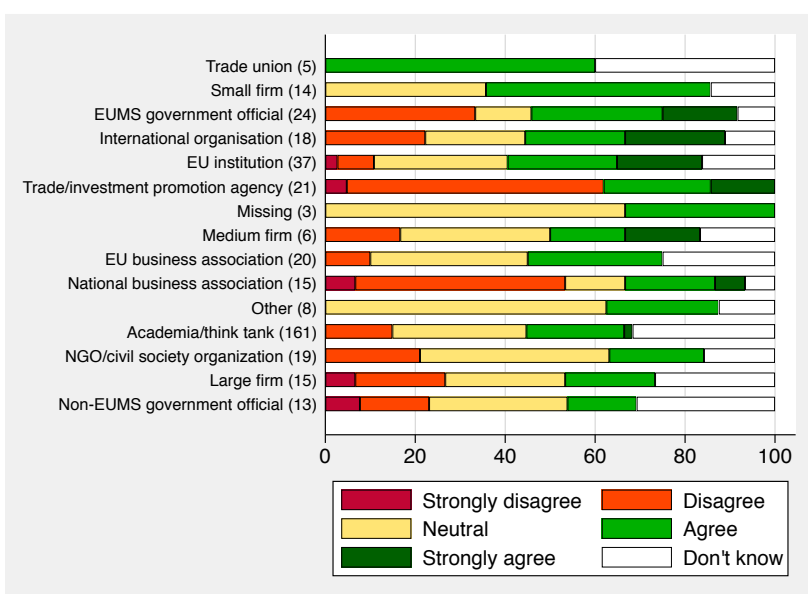

(e) From highest to lowest agreement

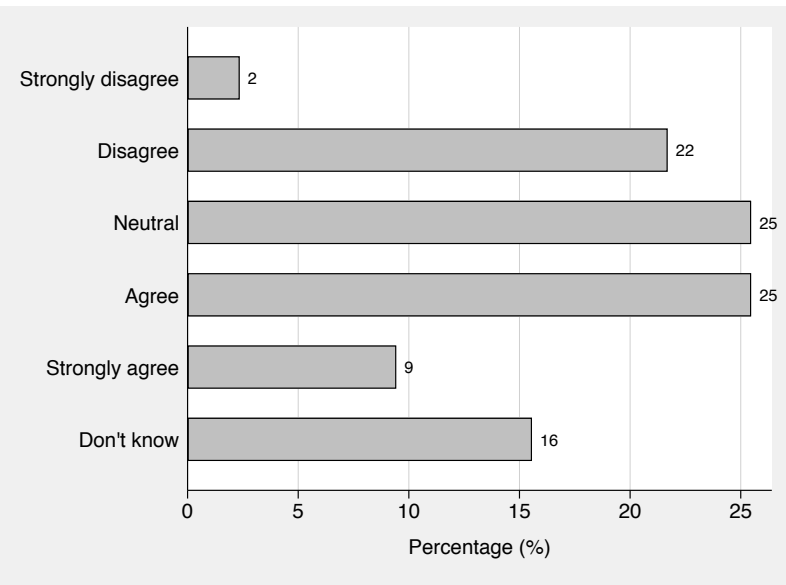

(b) Without academia and think-tanks

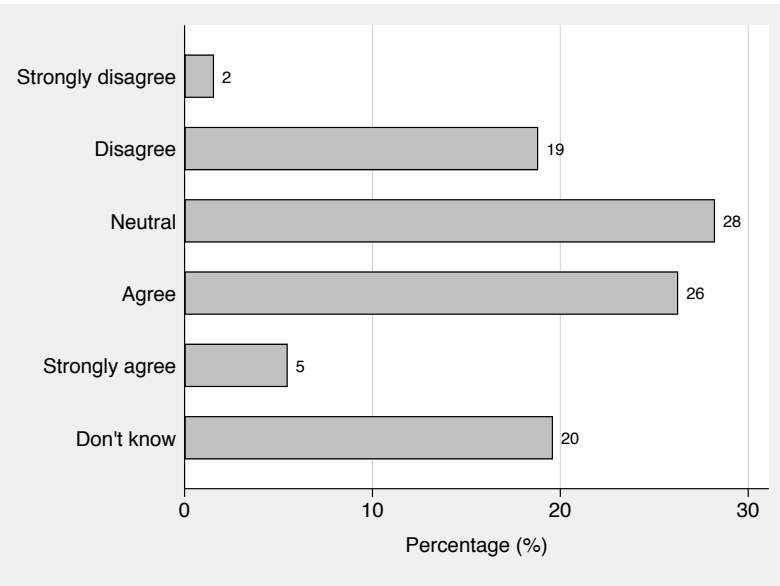

(d) Non-EU

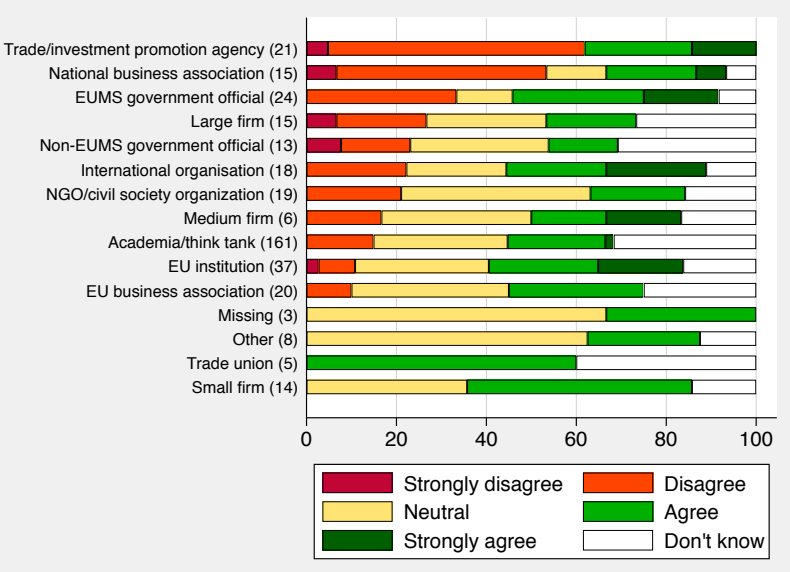

(f) From highest to lowest disagreement 


\section{Question 13}

There should be more EU-level coordination of national trade promotion activities.

Figure 13: Results RESPECT survey, Question 13

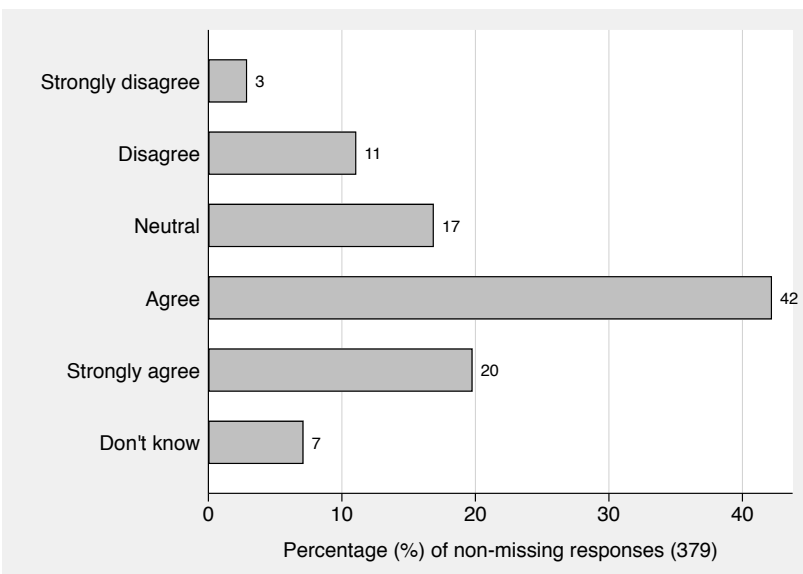

(a) Whole sample

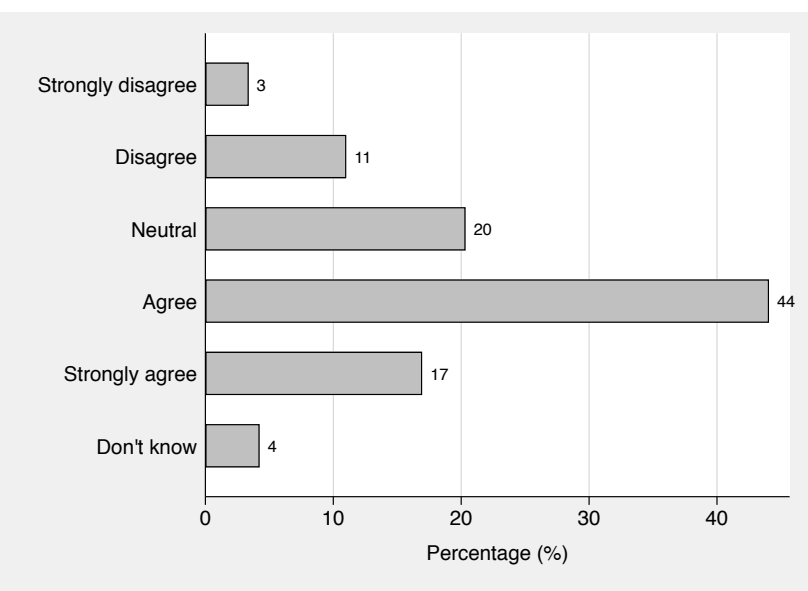

(c) EU

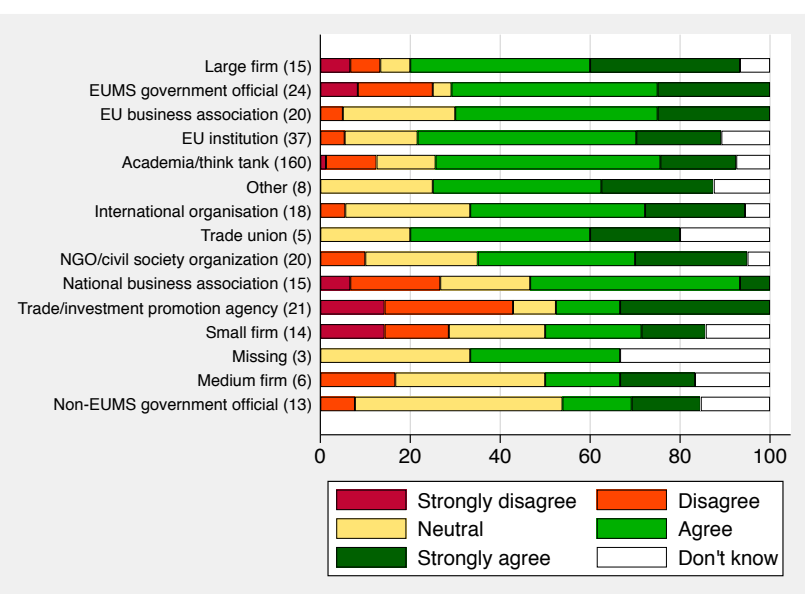

(e) From highest to lowest agreement

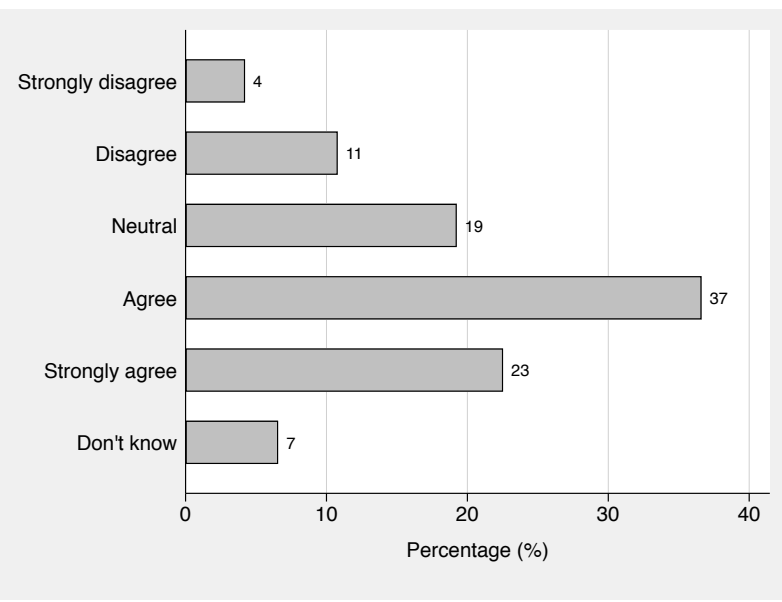

(b) Without academia and think-tanks

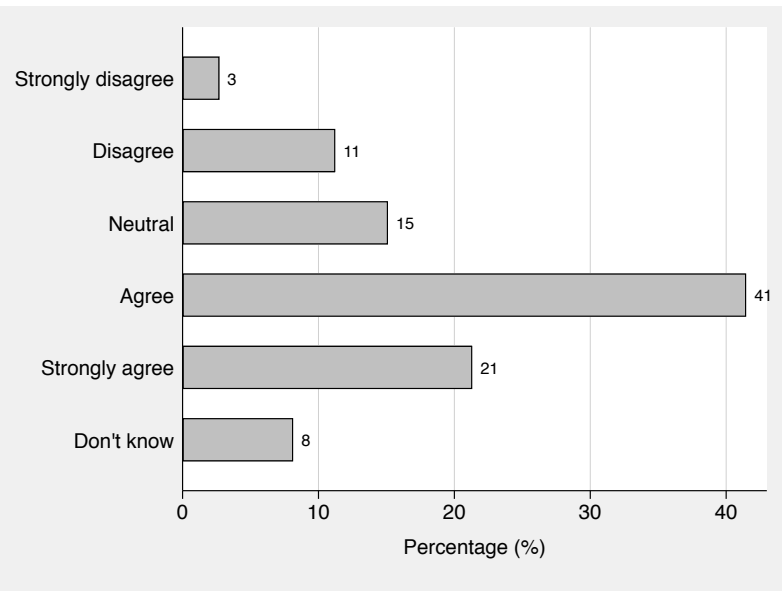

(d) Non-EU

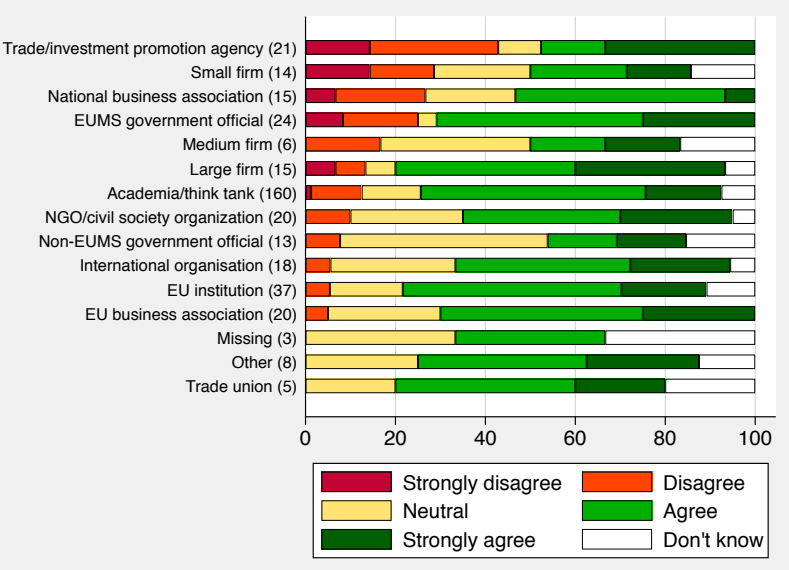

(f) From highest to lowest disagreement 


\section{Question 14}

Which of the following instruments do you believe are most effectively promoting trade between the EU and developing countries?

Figure 14: Results RESPECT survey, Question 14

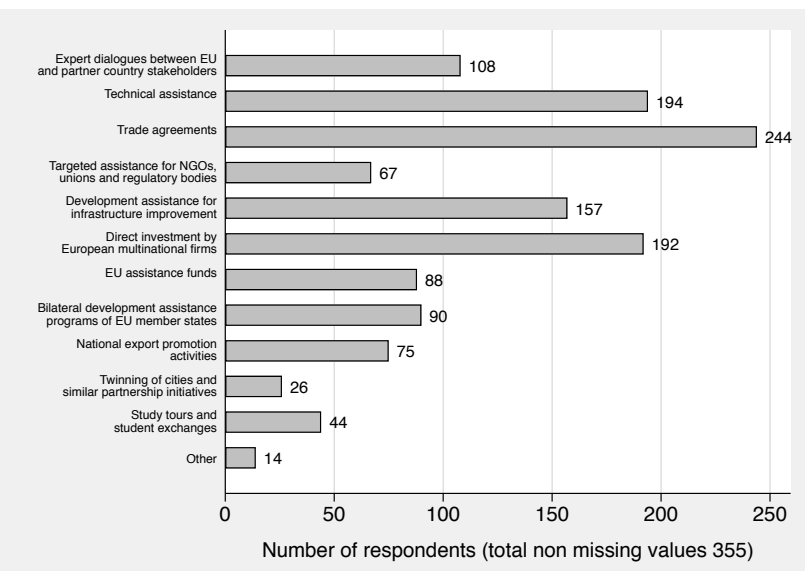

(a) Whole sample

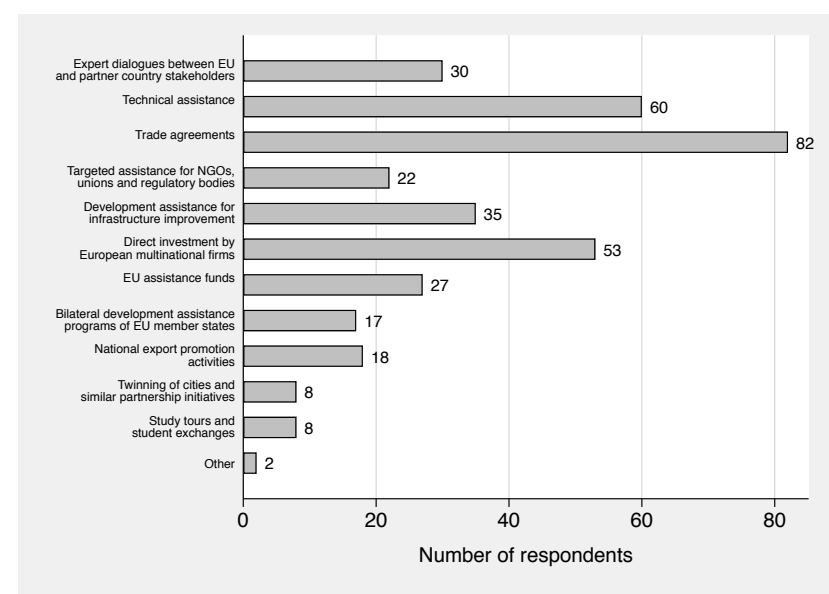

(c) $\mathrm{EU}$

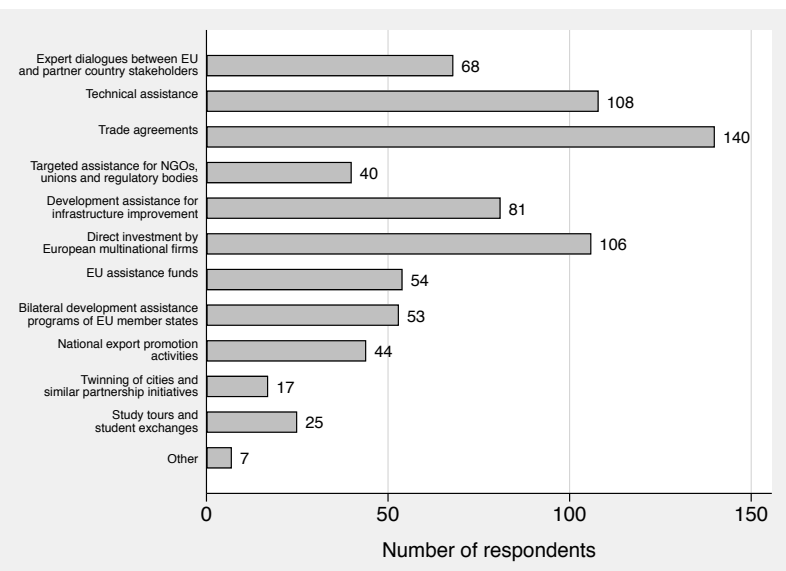

(b) Without academia and think-tanks

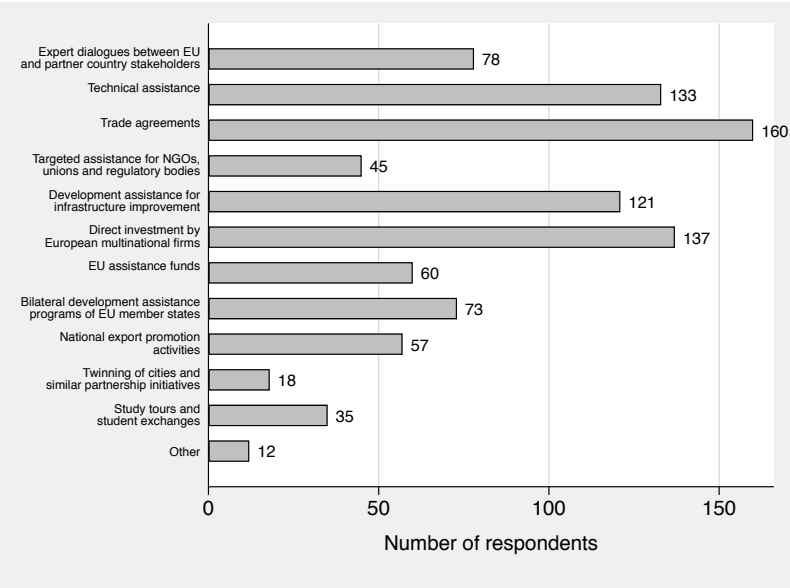

(d) Non-EU 
Table 2: Instruments for trade, percentage share (\%) by professional category

\begin{tabular}{|c|c|c|c|c|c|c|c|c|c|c|c|c|c|c|}
\hline & 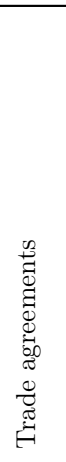 & 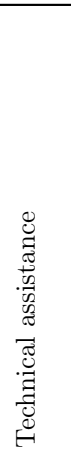 & 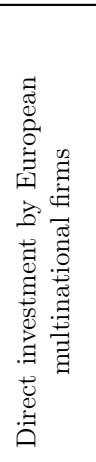 & 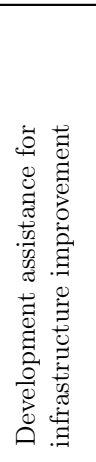 & 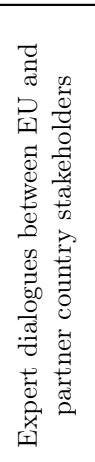 & 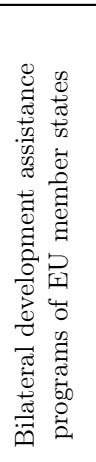 & 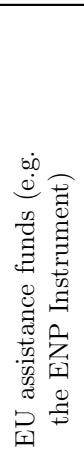 & 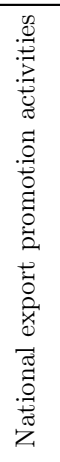 & 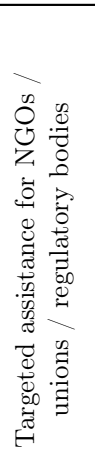 & 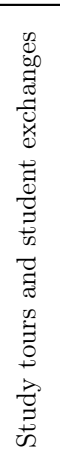 & 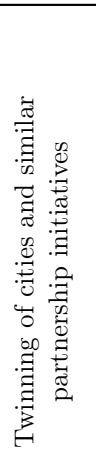 & 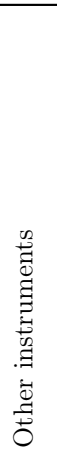 & 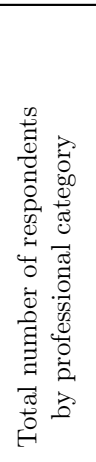 & 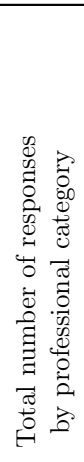 \\
\hline Small firm & 23 & 15 & 19 & 10 & 13 & 4 & 4 & 4 & 4 & 2 & 2 & 0 & 14 & 48 \\
\hline Medium firm & 38 & 15 & 15 & 8 & 0 & 8 & 8 & 8 & 0 & 0 & 0 & 0 & 6 & 13 \\
\hline Large firm & 19 & 14 & 17 & 12 & 12 & 7 & 3 & 0 & 3 & 8 & 3 & 2 & 15 & 59 \\
\hline EU business association & 19 & 14 & 16 & 10 & 13 & 6 & 9 & 5 & 1 & 1 & 3 & 1 & 20 & 77 \\
\hline National business association & 20 & 10 & 16 & 14 & 8 & 10 & 6 & 10 & 0 & 4 & 0 & 0 & 15 & 49 \\
\hline Trade/investment promotion agency & 21 & 12 & 14 & 9 & 6 & 8 & 5 & 13 & 5 & 5 & 2 & 0 & 21 & 85 \\
\hline NGO/civil society organization & 18 & 10 & 8 & 13 & 9 & 9 & 8 & 3 & 10 & 2 & 6 & 2 & 20 & 87 \\
\hline Trade union & 20 & 20 & 13 & 7 & 7 & 0 & 13 & 0 & 13 & 0 & 0 & 7 & 5 & 15 \\
\hline Academia/think tank & 19 & 16 & 15 & 14 & 7 & 7 & 6 & 6 & 5 & 3 & 2 & 1 & 155 & 548 \\
\hline EU institution & 23 & 17 & 14 & 8 & 8 & 4 & 9 & 4 & 8 & 3 & 2 & 0 & 34 & 120 \\
\hline EUMS government official & 16 & 16 & 13 & 10 & 8 & 8 & 8 & 12 & 3 & 2 & 3 & 0 & 23 & 91 \\
\hline Non-EUMS government official & 8 & 16 & 18 & 16 & 12 & 10 & 6 & 4 & 6 & 6 & 0 & 0 & 13 & 51 \\
\hline International organisation & 16 & 16 & 16 & 17 & 8 & 8 & 9 & 1 & 3 & 4 & 1 & 3 & 18 & 77 \\
\hline Other & 16 & 19 & 10 & 6 & 16 & 6 & 10 & 3 & 13 & 0 & 0 & 0 & 8 & 31 \\
\hline Missing & 25 & 13 & 25 & 13 & 0 & 0 & 13 & 0 & 0 & 13 & 0 & 0 & 3 & 8 \\
\hline Total respondents by instrument & 256 & 202 & 201 & 166 & 115 & 94 & 93 & 77 & 69 & 45 & 27 & 14 & & \\
\hline
\end{tabular}




\section{Question 15}

Please select the instruments that you believe are most effective in promoting non-trade objectives (such as human rights, labor, environmental protection and anti-corruption).

Figure 15: Results RESPECT survey, Question 15

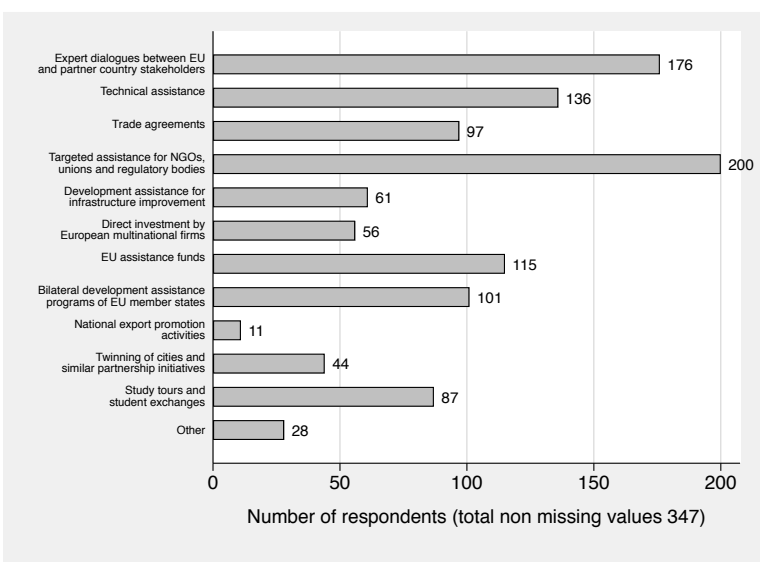

(a) Whole sample

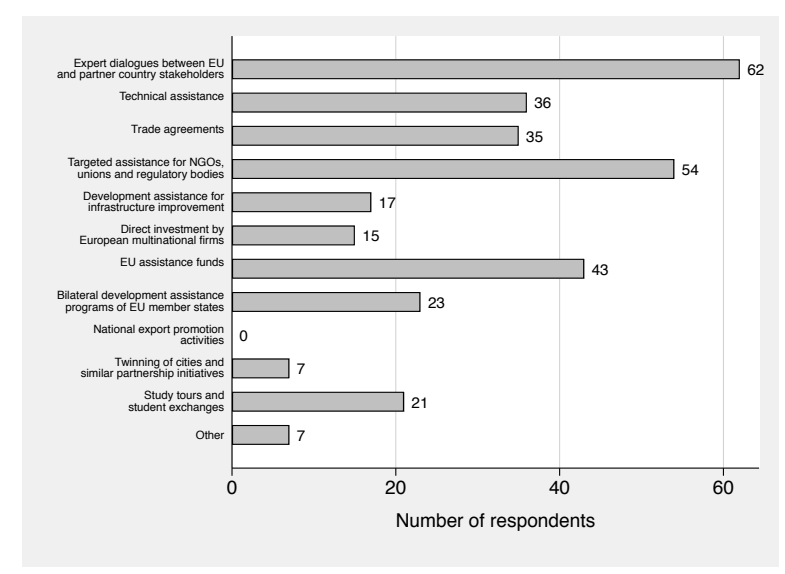

(c) $\mathrm{EU}$

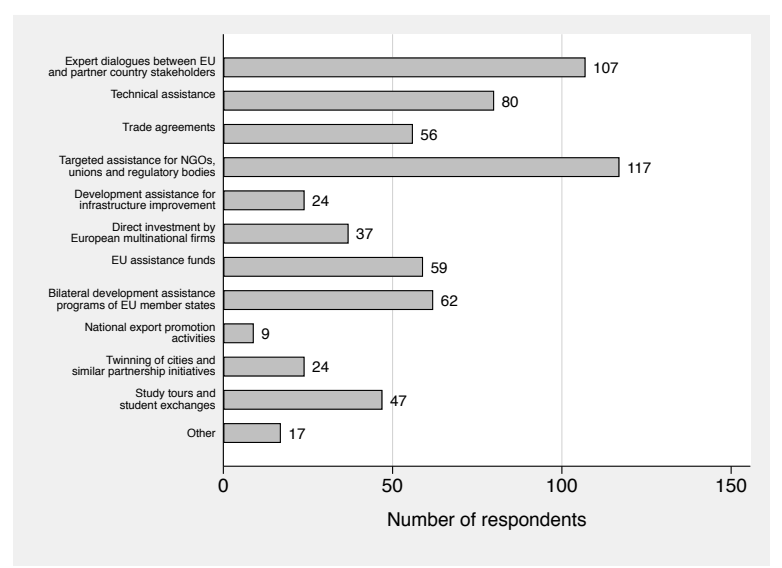

(b) Without academia and think-tanks

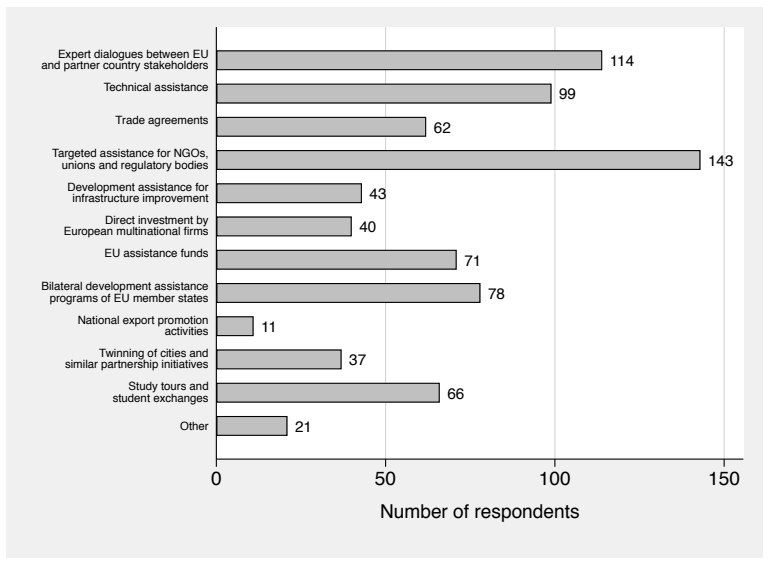

(d) Non-EU 
Table 3: Instruments for the realization of NTPOs, percentage share (\%) by professional category

\begin{tabular}{|c|c|c|c|c|c|c|c|c|c|c|c|c|c|c|}
\hline & 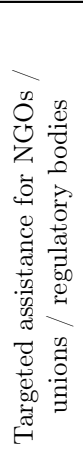 & 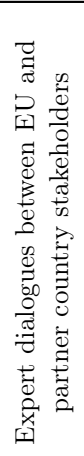 & 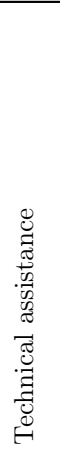 & 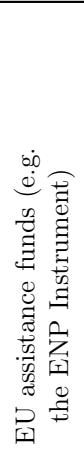 & 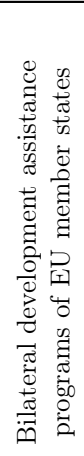 & 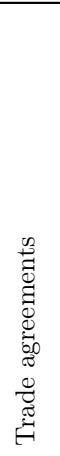 & 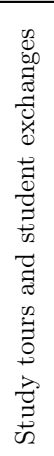 & 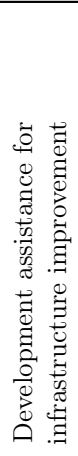 & 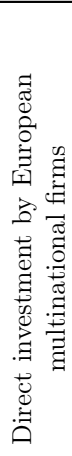 & 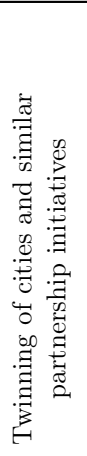 & 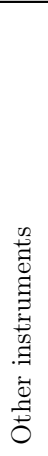 & 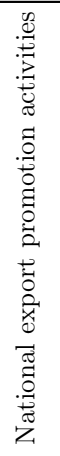 & 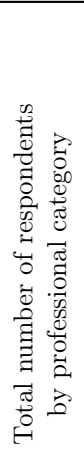 & 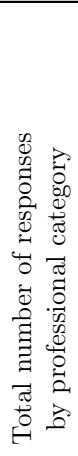 \\
\hline Small firm & 19 & 19 & 14 & 14 & 3 & 8 & 5 & 3 & 8 & 3 & 3 & 3 & 13 & 37 \\
\hline Medium firm & 27 & 27 & 9 & 0 & 0 & 9 & 9 & 0 & 18 & 0 & 0 & 0 & 5 & 11 \\
\hline Large firm & 13 & 17 & 11 & 4 & 9 & 9 & 17 & 4 & 4 & 9 & 4 & 0 & 15 & 47 \\
\hline EU business association & 17 & 23 & 12 & 9 & 5 & 9 & 9 & 3 & 5 & 5 & 3 & 0 & 20 & 65 \\
\hline National business association & 16 & 11 & 18 & 7 & 14 & 7 & 5 & 5 & 7 & 7 & 5 & 0 & 14 & 44 \\
\hline Trade/investment promotion agency & 19 & 14 & 14 & 9 & 14 & 6 & 10 & 2 & 1 & 9 & 0 & 4 & 21 & 81 \\
\hline $\mathrm{NGO} /$ civil society organization & 22 & 13 & 9 & 12 & 8 & 8 & 10 & 4 & 6 & 3 & 3 & 4 & 20 & 78 \\
\hline Trade union & 29 & 21 & 14 & 0 & 7 & 14 & 0 & 0 & 0 & 0 & 14 & 0 & 5 & 14 \\
\hline Academia/think tank & 17 & 15 & 12 & 12 & 8 & 9 & 9 & 8 & 4 & 4 & 2 & 0 & 150 & 466 \\
\hline EU institution & 20 & 20 & 11 & 15 & 5 & 16 & 2 & 4 & 5 & 0 & 2 & 0 & 33 & 96 \\
\hline EUMS government official & 20 & 16 & 11 & 9 & 16 & 9 & 6 & 4 & 5 & 3 & 1 & 0 & 23 & 80 \\
\hline Non-EUMS government official & 18 & 15 & 15 & 10 & 10 & 0 & 8 & 8 & 10 & 5 & 0 & 0 & 13 & 39 \\
\hline International organisation & 13 & 15 & 13 & 8 & 13 & 8 & 7 & 5 & 8 & 3 & 3 & 2 & 18 & 60 \\
\hline Other & 18 & 21 & 11 & 7 & 11 & 7 & 7 & 4 & 4 & 4 & 4 & 4 & 8 & 28 \\
\hline Missing & 43 & 0 & 14 & 14 & 0 & 0 & 0 & 14 & 14 & 0 & 0 & 0 & 3 & 7 \\
\hline Total respondents by instrument & 208 & 184 & 140 & 120 & 104 & 100 & 91 & 63 & 57 & 47 & 28 & 11 & & \\
\hline
\end{tabular}

Notes: the central part of the table reports percentage shares of each instrument as chosen by a respondent category over the total choices made by that category (e.g. $19 \%$ of all choices made by respondents from small firms indicated targeted assistance for NGOs/unions/regulatory bodies as one instrument most effectively promoting non-trade objectives). Instruments (columns) are sorted according to the total number of respondents selecting each instrument across professional categories. These numbers are reported in the bottom panel of the table. The right panel of the table reports the total number of respondents and responses per professional category. There are more responses than respondents as each respondent could select more than one instrument. 


\subsection{Implementation and evaluation}

The third and last part of the survey comprises questions on the implementation and evaluation of EU trade policy. First, the majority of respondents believes the EU is serious about realising non-trade objectives - such as human rights, labor, environmental protection and anti-corruption - in trade partners (Figure 16) as well as about promoting economic development in low income trade partners (Figure 17). However, opinions becomes more polarized when major trade interests are at stake. In that case, almost $40 \%$ of respondents believe the EU ignores violations of human/labor rights or environmental regulation (Figure 23). Moreover, 36\% of respondents agree or strongly agree that the EU only takes trade actions against partner countries regarding non-trade issues (such as labor standards) when pushed to do so by NGOs and public opinion (Figure 24).

Responses reveal slightly more nuanced opinions regarding monitoring and evaluation activities. In particular, a significant percentage of respondents (23\% of the total) perceive there to be no meaningful monitoring of implementation of trade agreements. This figure increases to $28 \%$ for the "EU" group (Figure 18). A relatively uniform distribution of responses across agreement, disagreement, neutral and the "Don't know" category appears for the question whether the EU assesses if its development assistance is used effectively to support the implementation of trade agreements (Figure 19). There is instead a clear predominance of the disagreement categories toward the claim that there is effective monitoring of how the implementation of trade agreements impacts on non-trade outcomes (Figure 20). Similarly, Figure 21 shows that respondents across all categories tend to believe that the EU does not monitor carefully and consistently non-trade outcomes in partner countries. Even though these dimensions of monitoring and evaluation are considered as incomplete, the majority of the empirical population believes that evaluation of the impacts of trade agreements does inform how the EU pursues trade negotiations (Figure 22).

Finally, almost half of respondents either agree or strongly agree that EU trade agreements have effective mechanisms to resolve trade disputes (Figure 25) and that the EU uses conflict resolution mechanisms of trade agreements to address market access barriers in partner countries (Figure 26). 


\section{Question 16}

In implementing its trade strategy, the EU is serious about realising non-trade objectives (such as human rights, labor, environmental protection and anti-corruption in trade partners).

Figure 16: Results RESPECT survey, Question 16
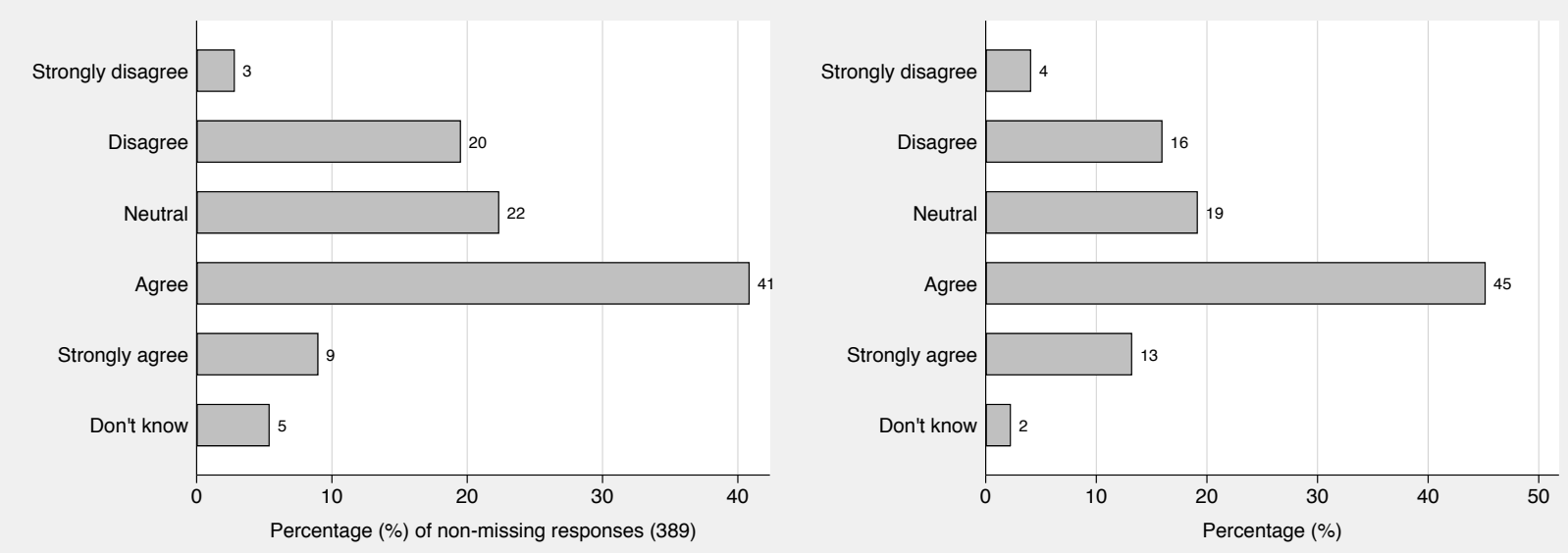

(a) Whole sample

(b) Without academia and think-tanks
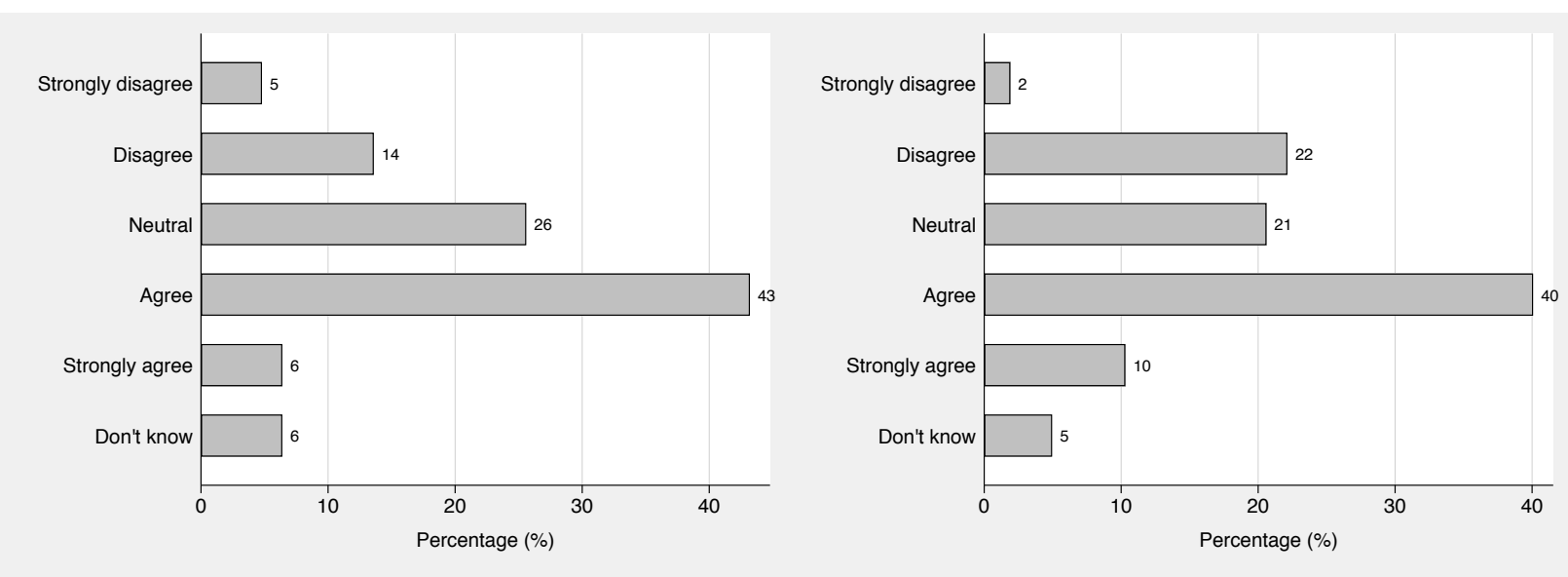

(c) EU

(d) Non-EU

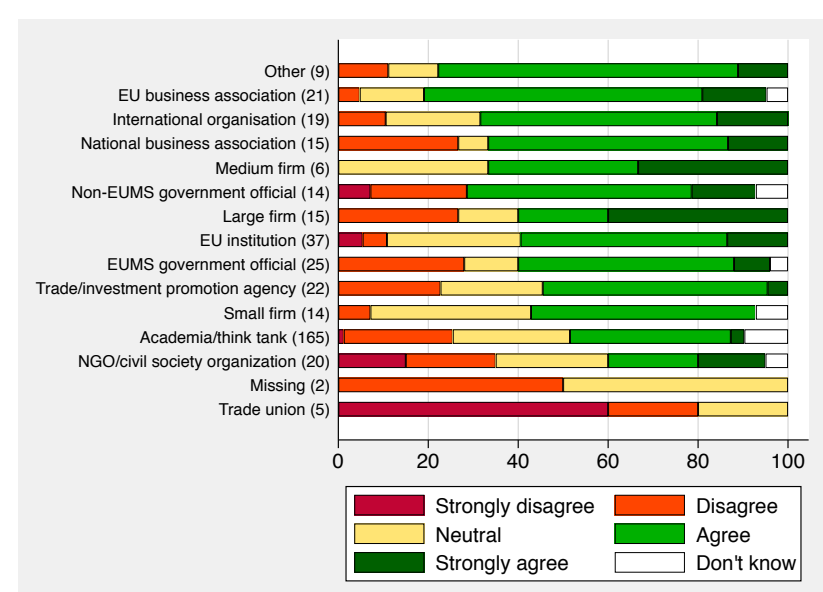

(e) From highest to lowest agreement

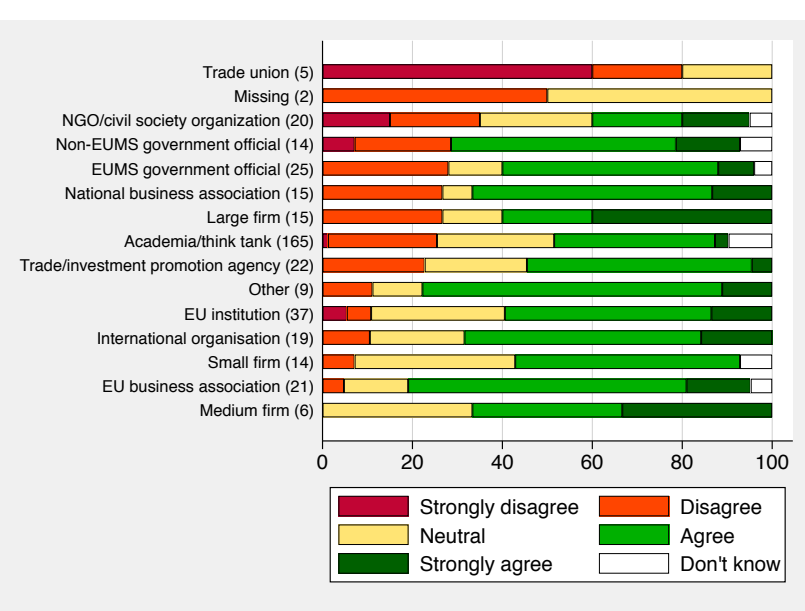

(f) From highest to lowest disagreement 


\section{Question 17}

In implementing its trade strategy, the EU is serious about promoting economic development in low income trade partners.

Figure 17: Results RESPECT survey, Question 17

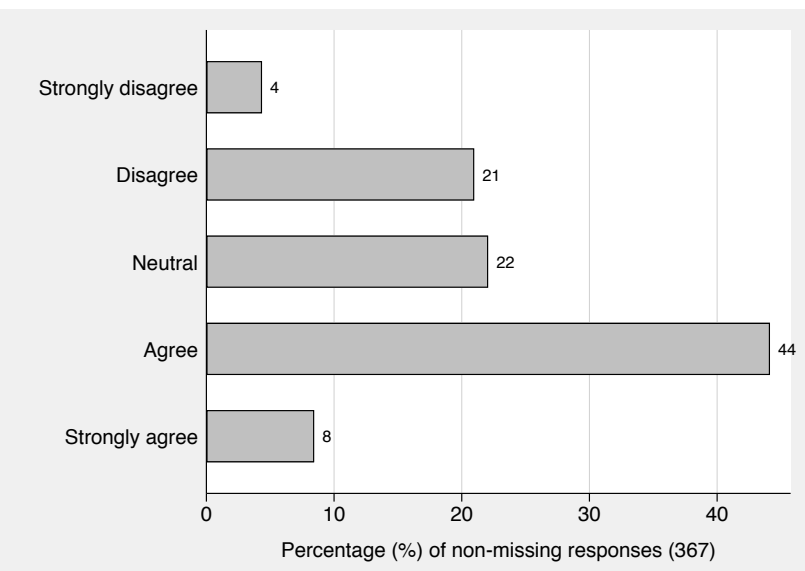

(a) Whole sample

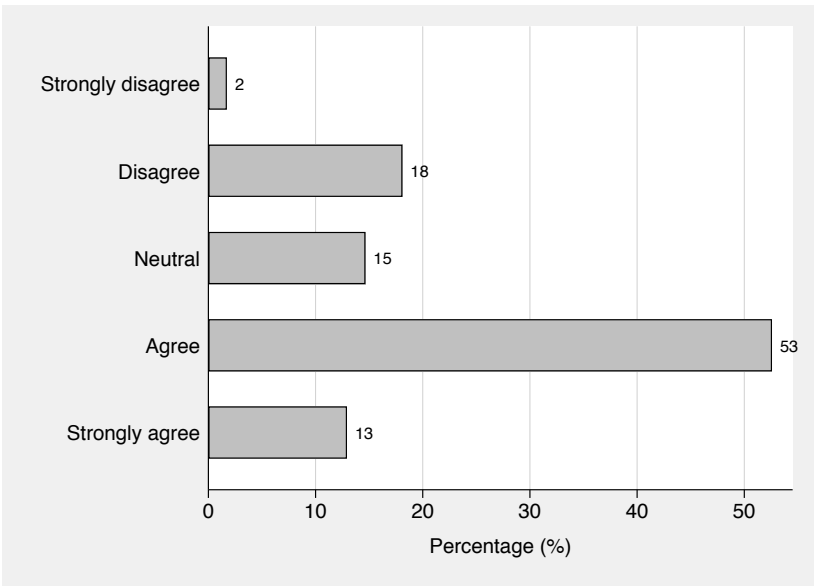

(c) $\mathrm{EU}$

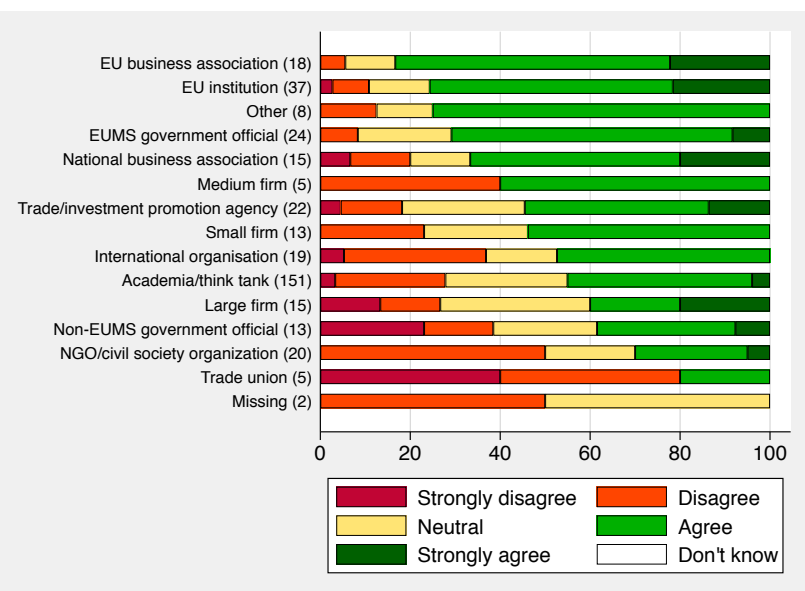

(e) From highest to lowest agreement

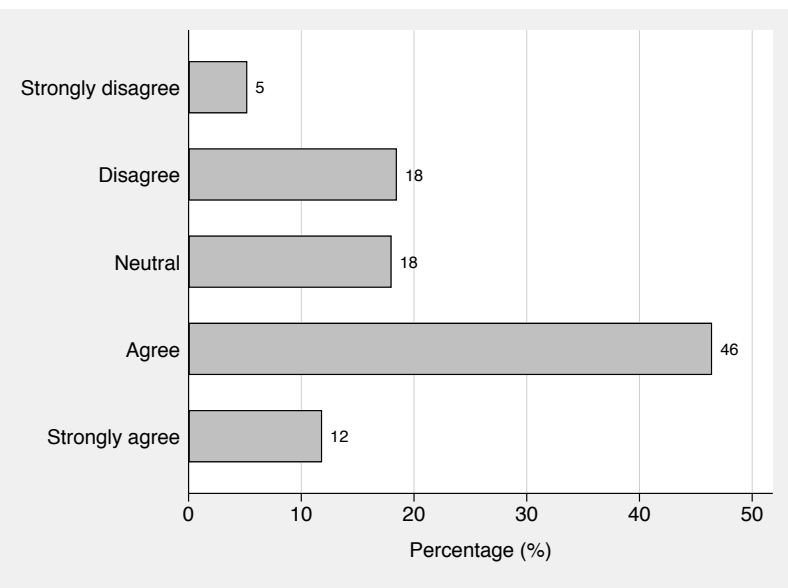

(b) Without academia and think-tanks

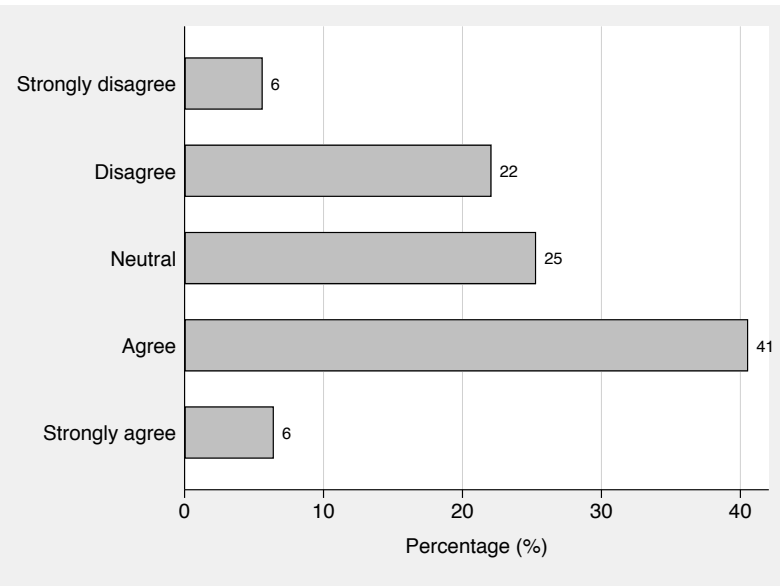

(d) Non-EU

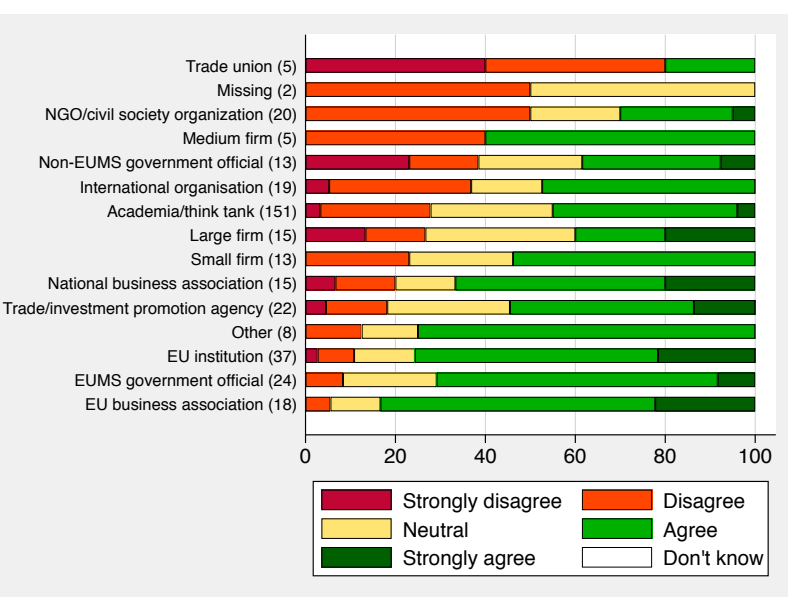

(f) From highest to lowest disagreement 


\section{Question 18}

There is meaningful monitoring of implementation of trade agreements.

Figure 18: Results RESPECT survey, Question 18

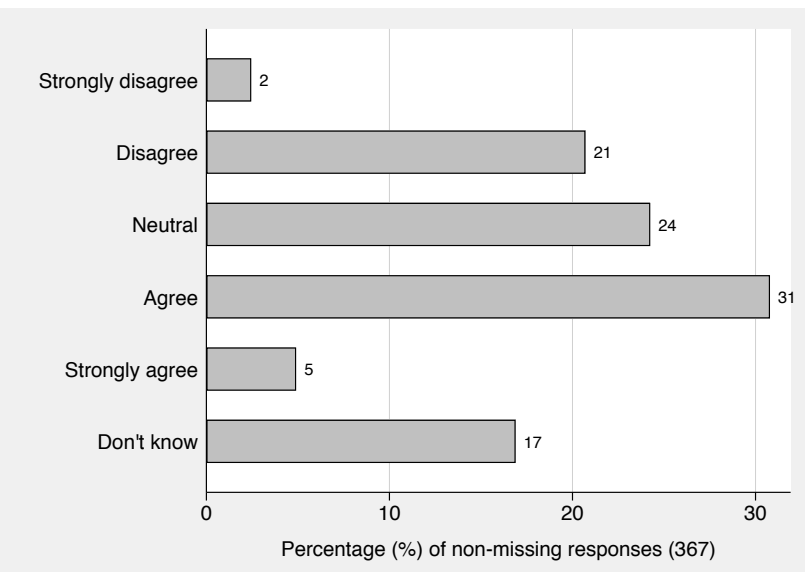

(a) Whole sample

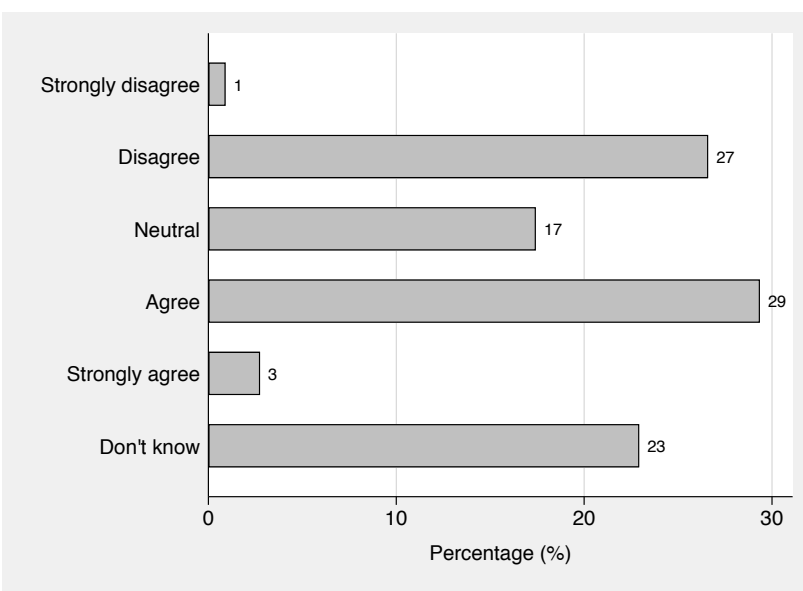

(c) $\mathrm{EU}$

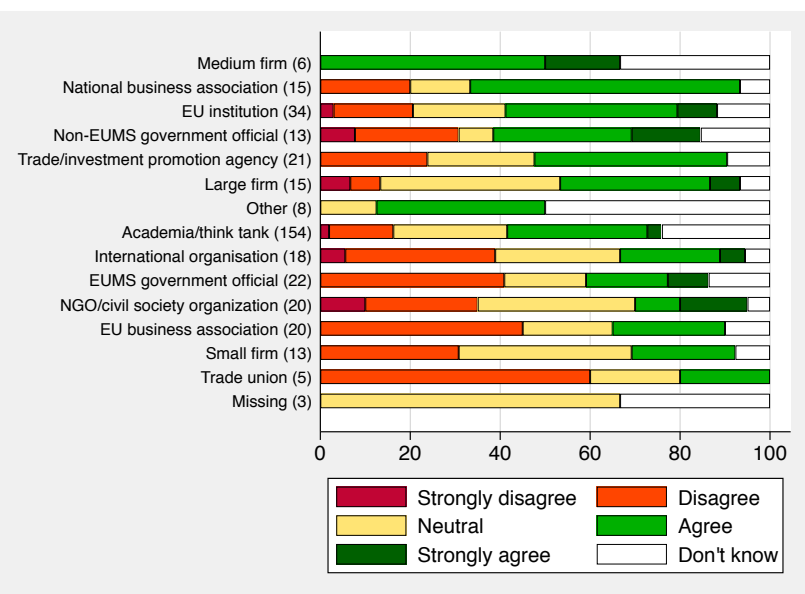

(e) From highest to lowest agreement

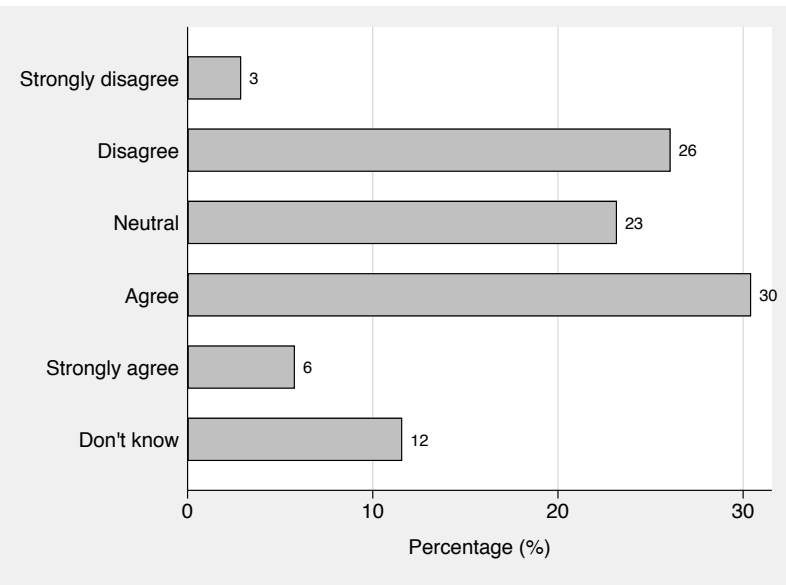

(b) Without academia and think-tanks

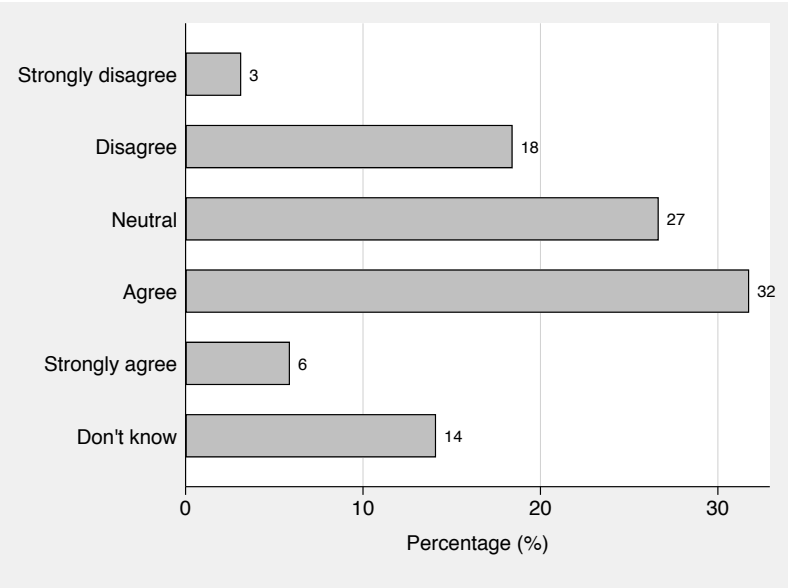

(d) Non-EU

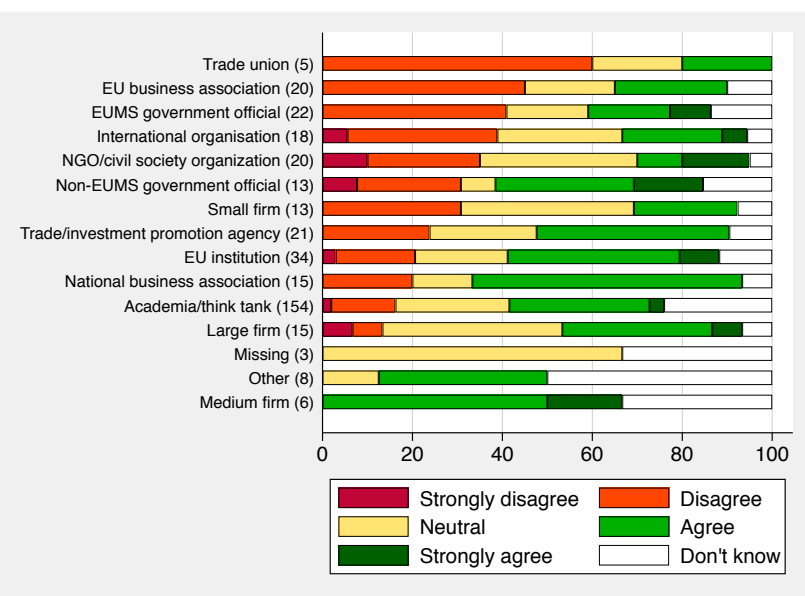

(f) From highest to lowest disagreement 


\section{Question 19}

The EU assesses whether its development assistance is used effectively to support the implementation of trade agreements.

Figure 19: Results RESPECT survey, Question 19

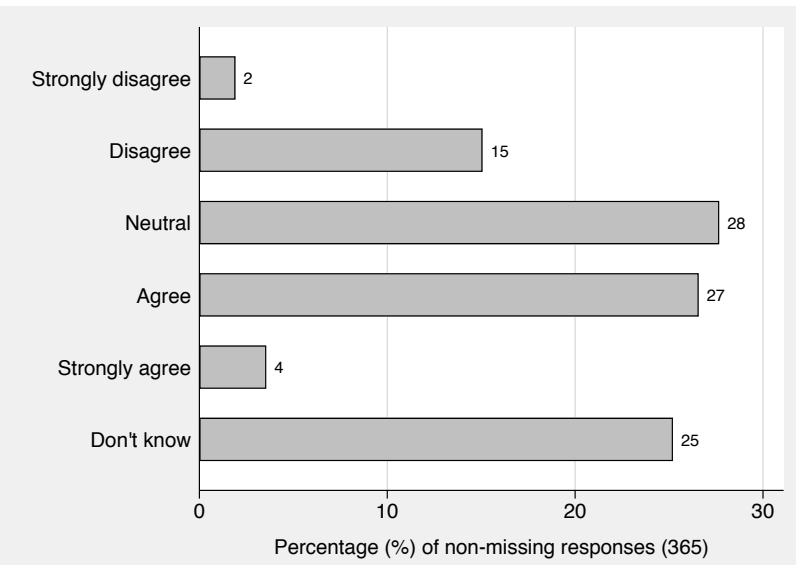

(a) Whole sample

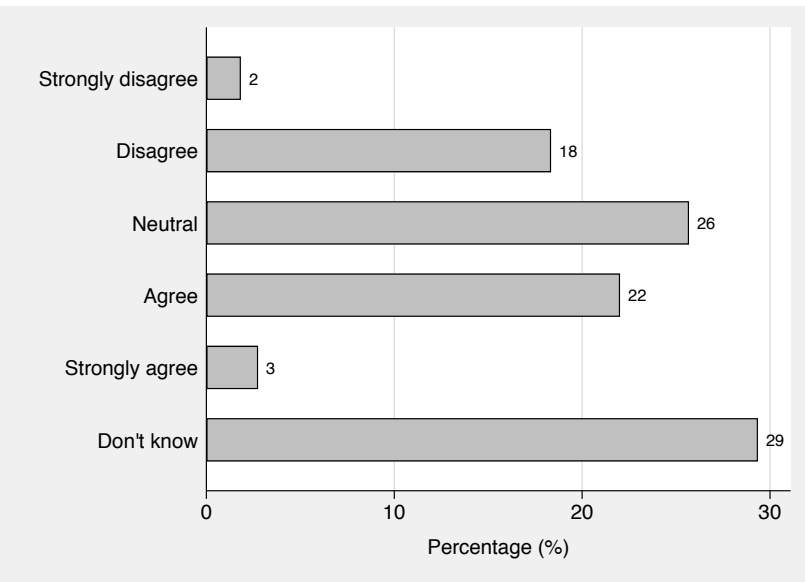

(c) EU

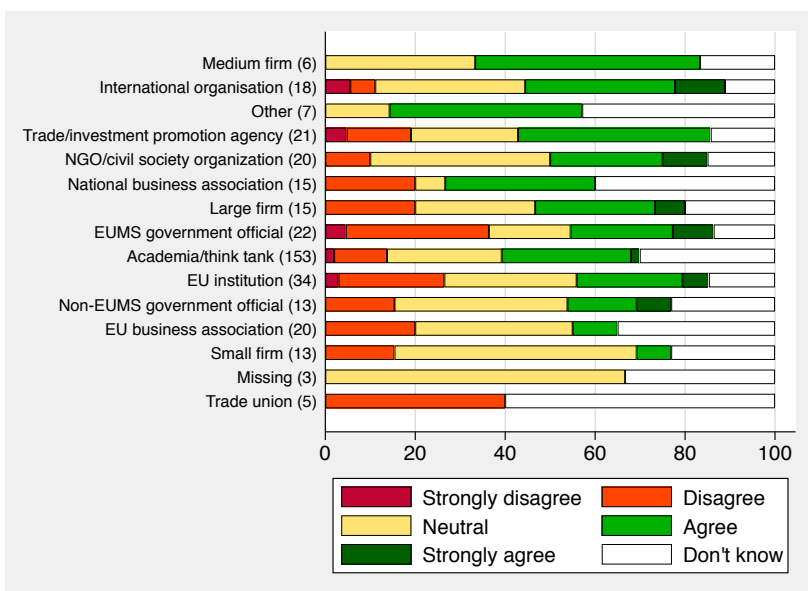

(e) From highest to lowest agreement

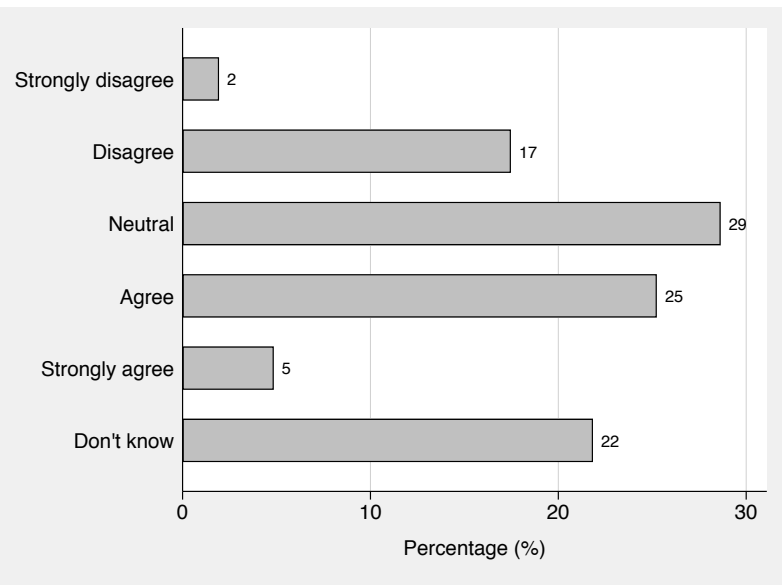

(b) Without academia and think-tanks

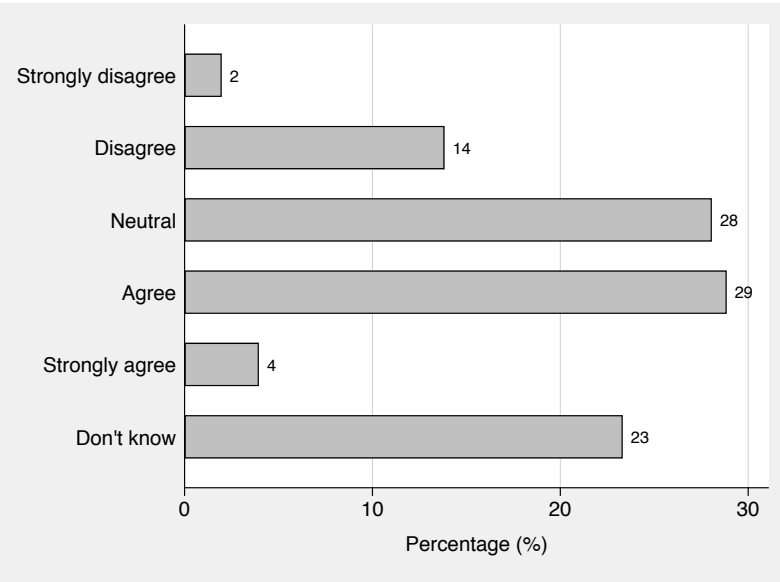

(d) Non-EU

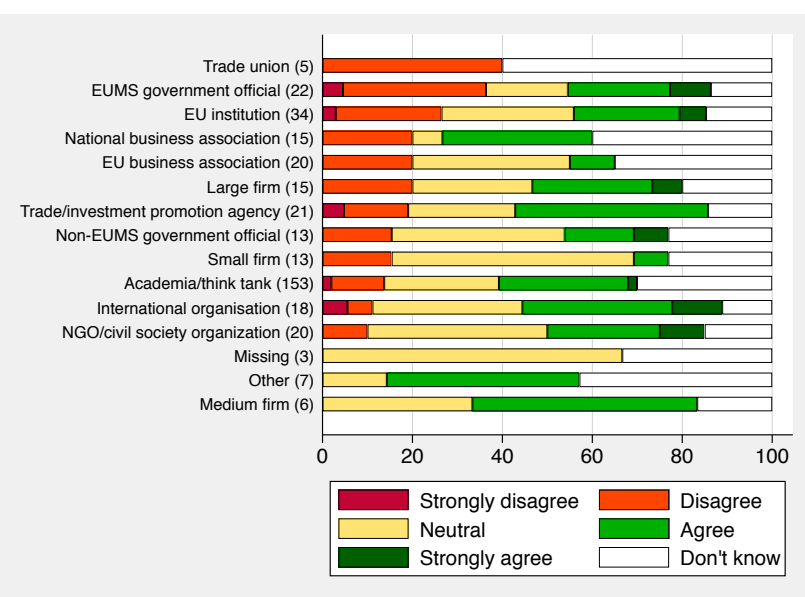

(f) From highest to lowest disagreement 


\section{Question 20}

There is effective monitoring of how the implementation of trade agreements impacts on nontrade outcomes.

Figure 20: Results RESPECT survey, Question 20

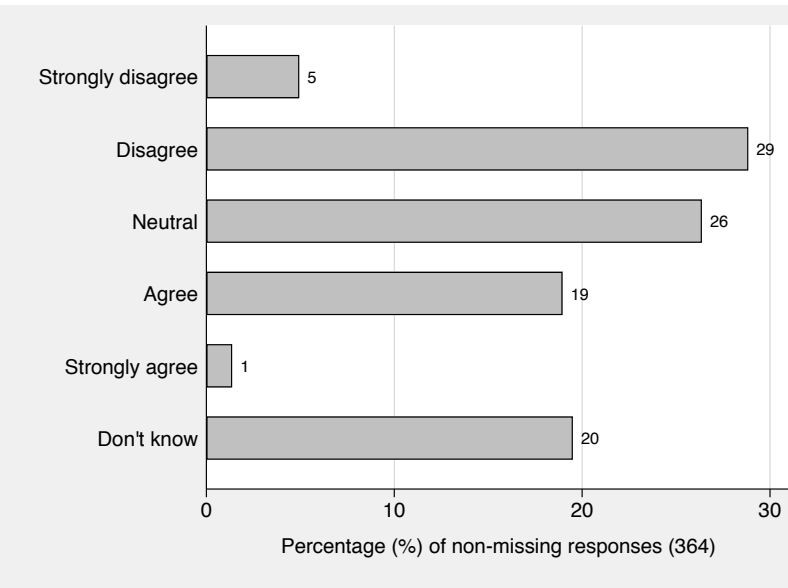

(a) Whole sample

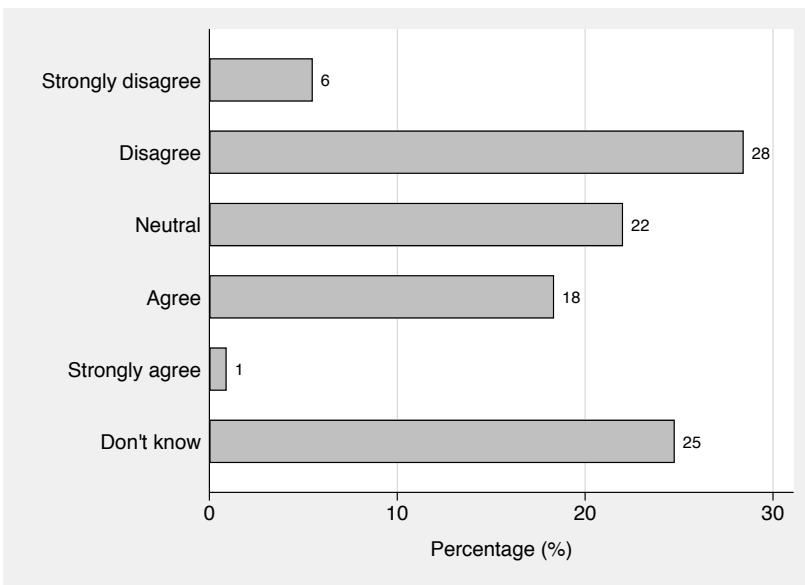

(c) $\mathrm{EU}$

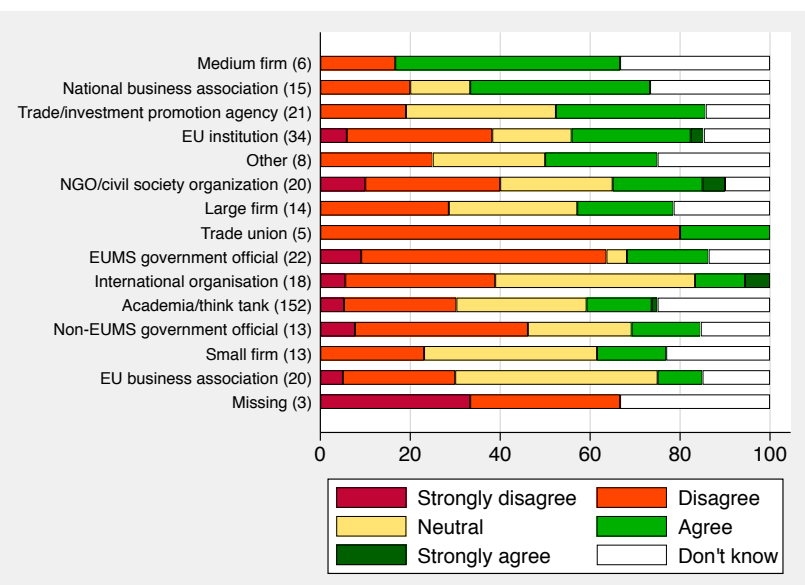

(e) From highest to lowest agreement

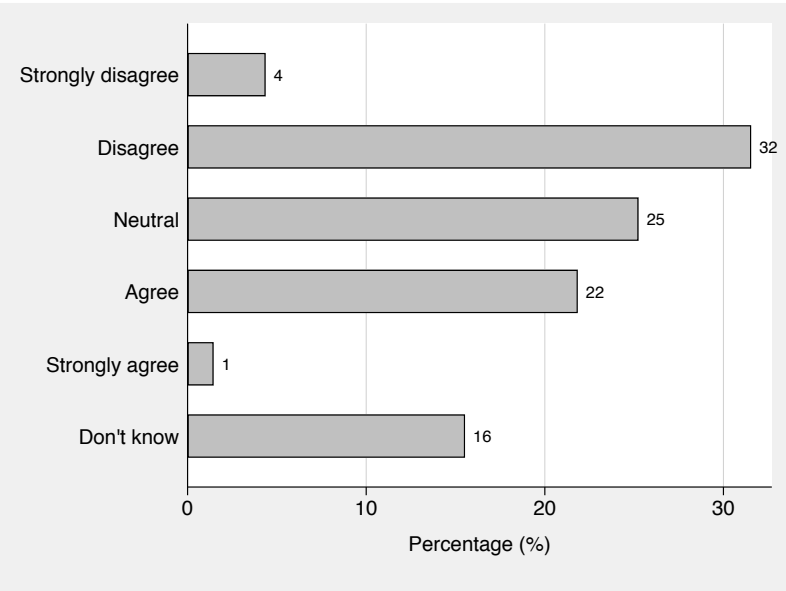

(b) Without academia and think-tanks

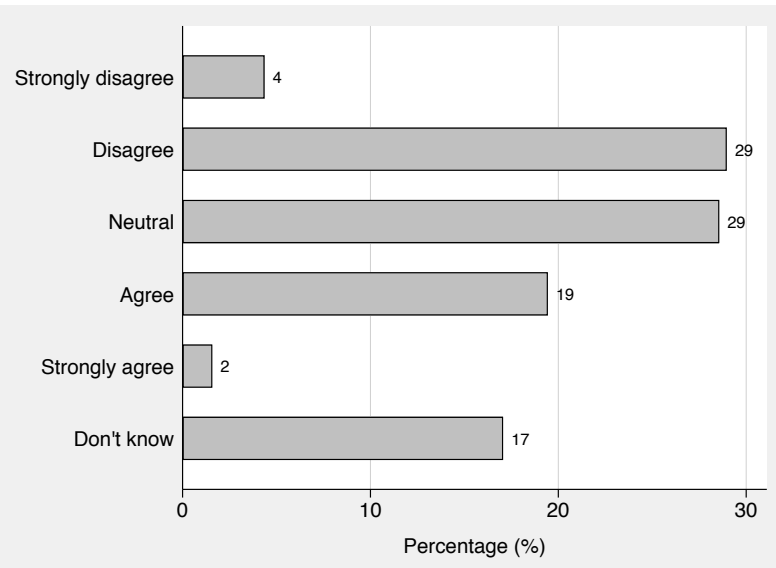

(d) Non-EU

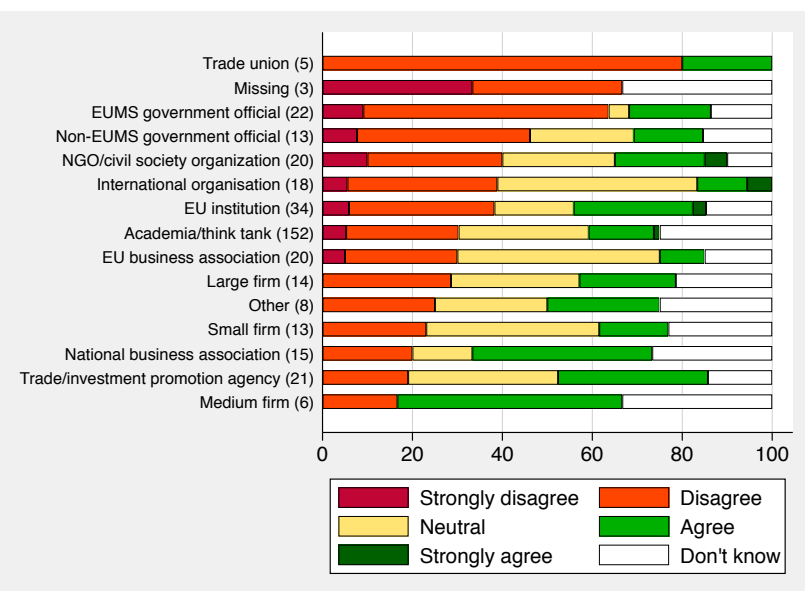

(f) From highest to lowest disagreement 


\section{Question 21}

The EU monitors non-trade outcomes (such as human rights, labor, environmental protection and anti-corruption) in partner countries carefully and consistently.

Figure 21: Results RESPECT survey, Question 21

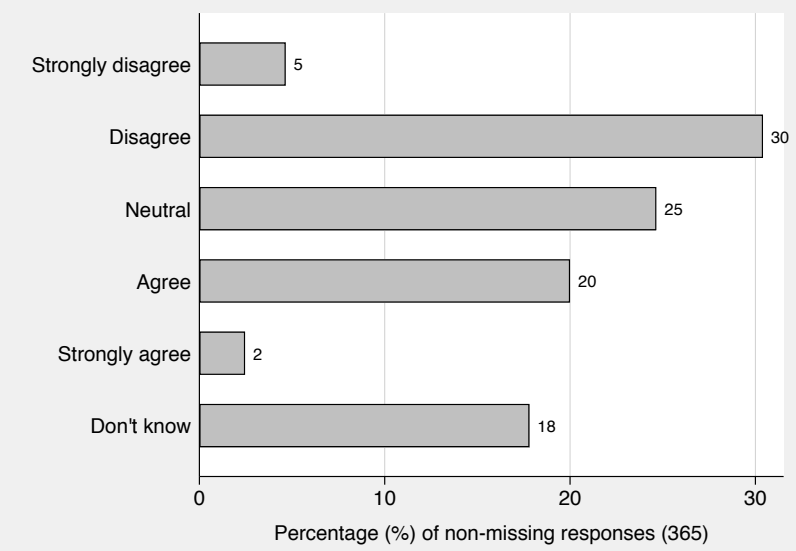

(a) Whole sample

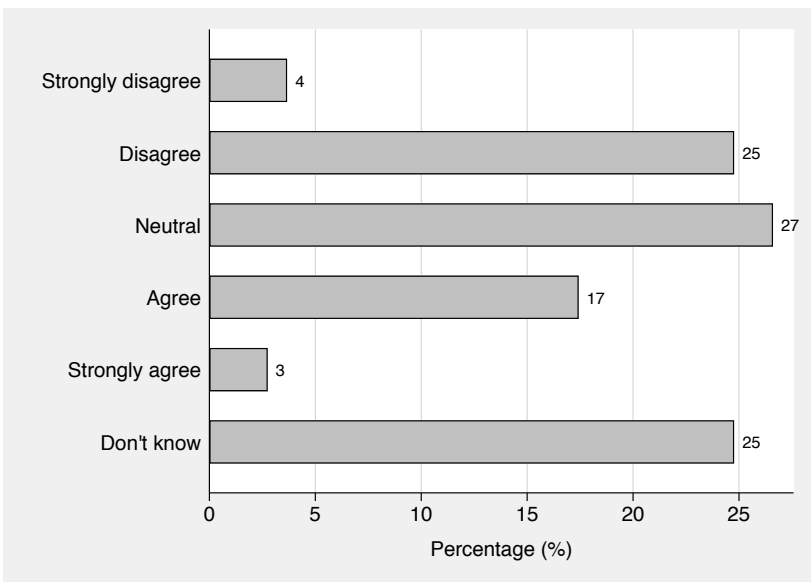

(c) EU

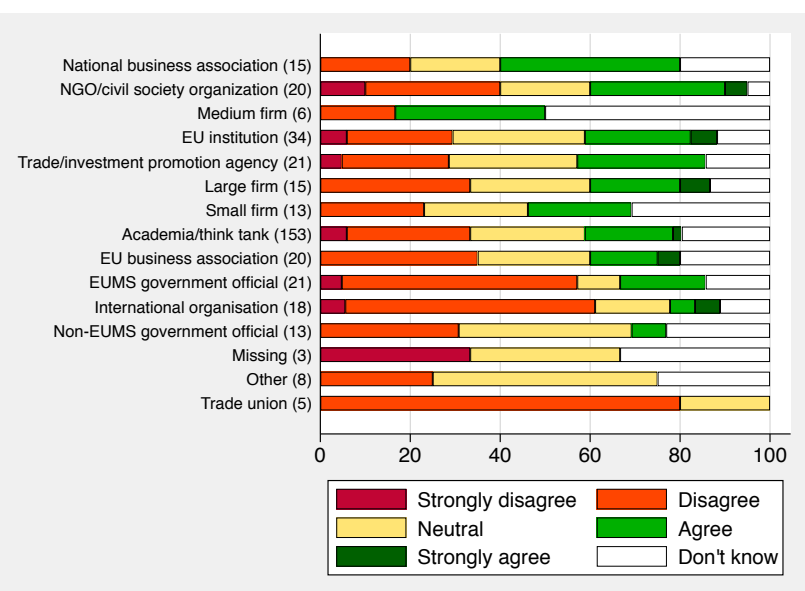

(e) From highest to lowest agreement

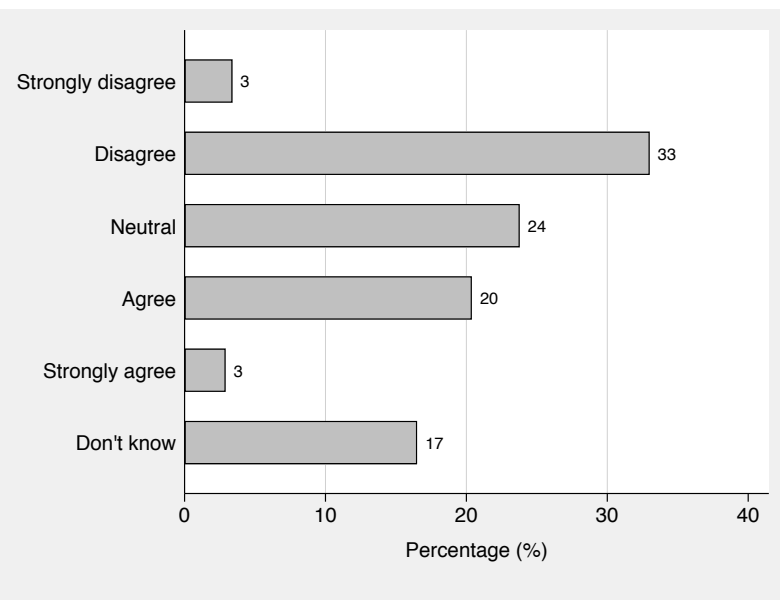

(b) Without academia and think-tanks

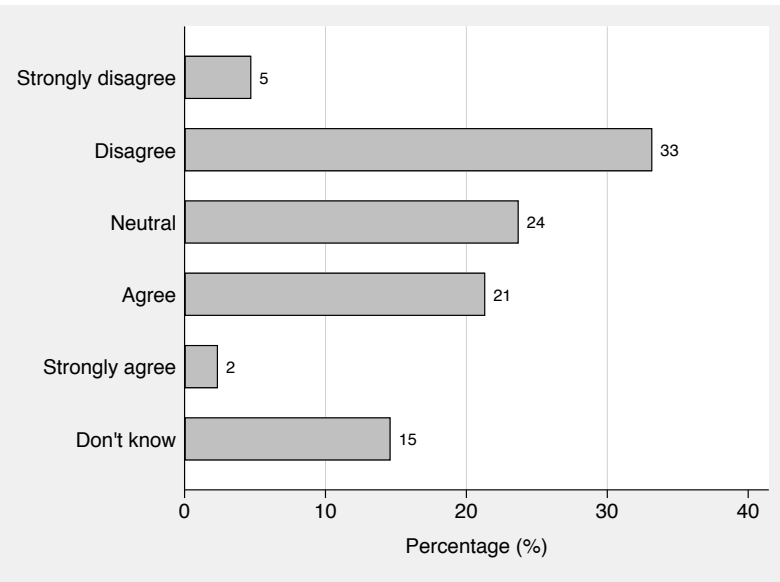

(d) Non-EU

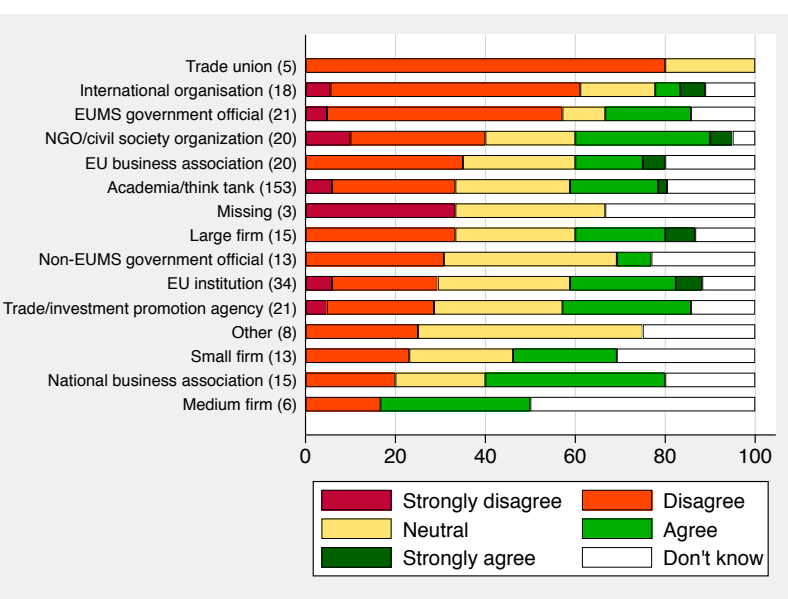

(f) From highest to lowest disagreement 


\section{Question 22}

Evaluation of the impacts of trade agreements informs how the EU pursues trade negotiations.

Figure 22: Results RESPECT survey, Question 22

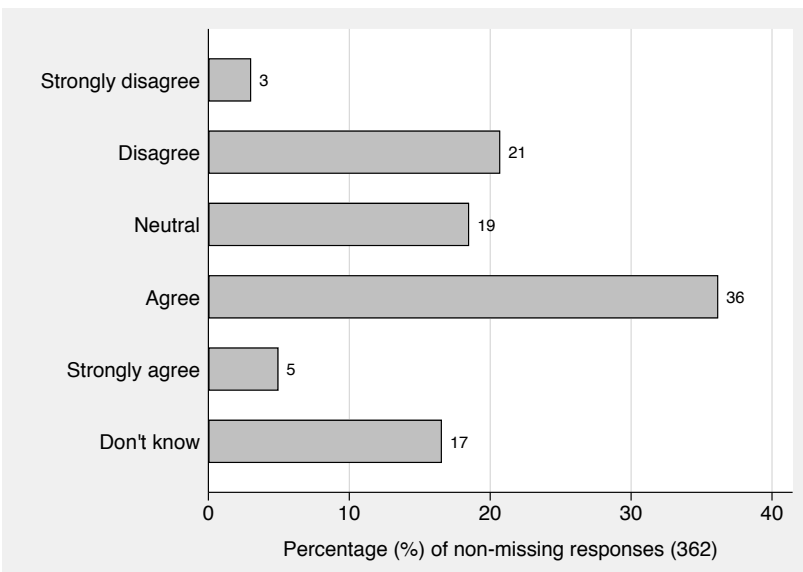

(a) Whole sample

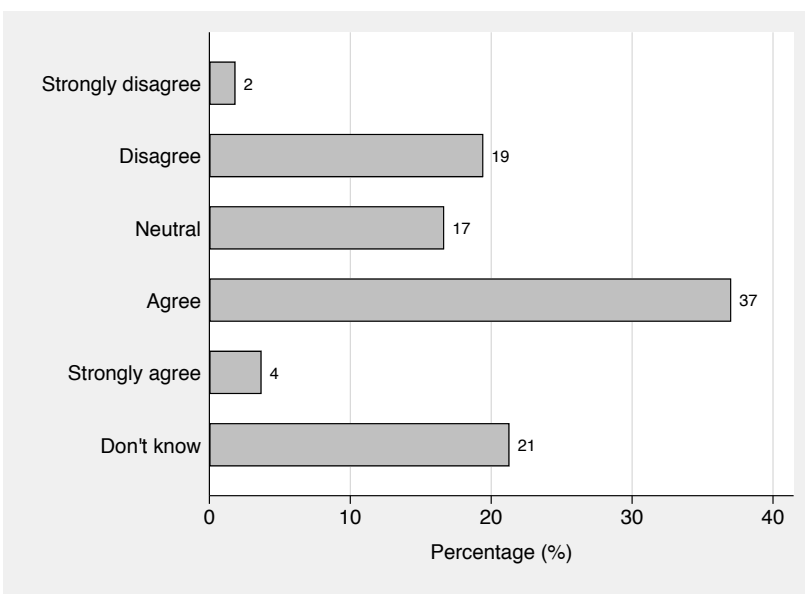

(c) $\mathrm{EU}$

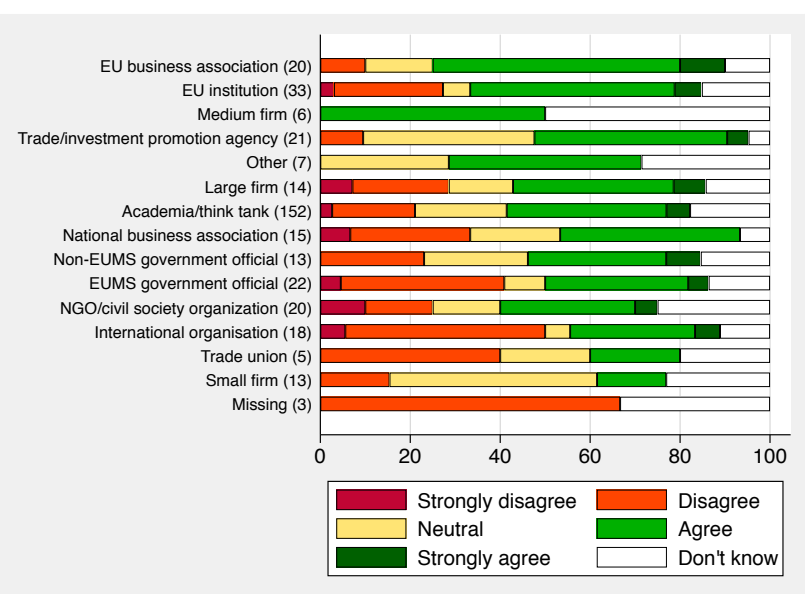

(e) From highest to lowest agreement

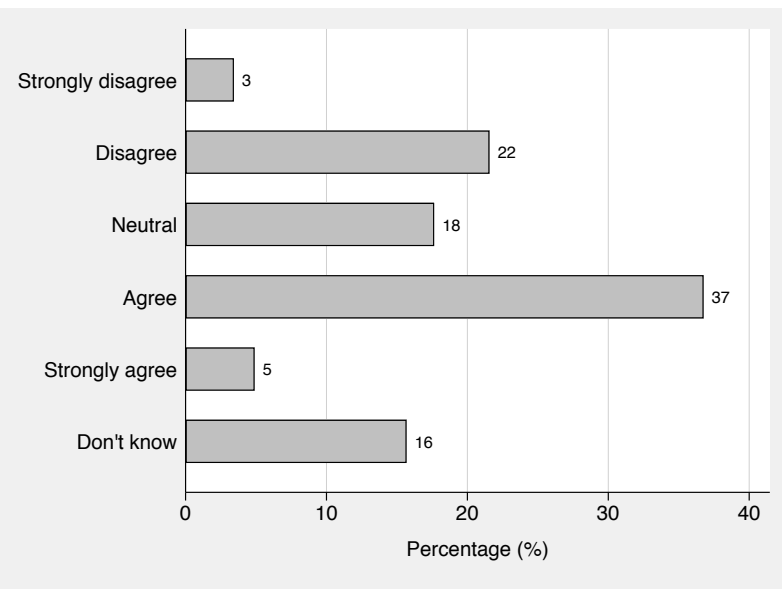

(b) Without academia and think-tanks

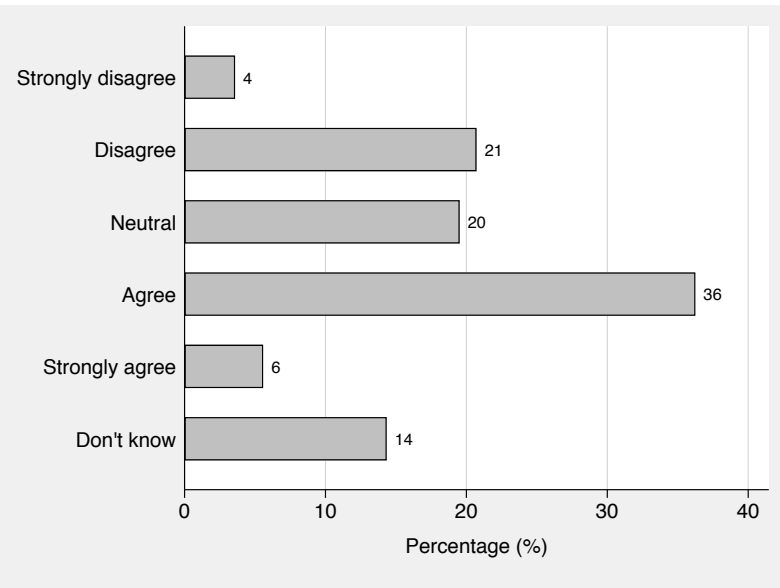

(d) Non-EU

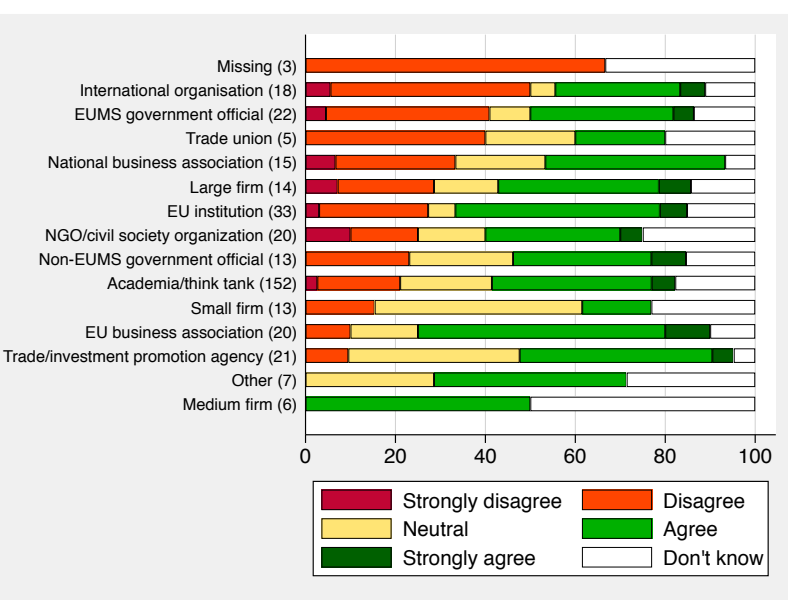

(f) From highest to lowest disagreement 


\section{Question 23}

The EU ignores violations of human / labor rights or environmental regulation if major trade interests are at stake.

Figure 23: Results RESPECT survey, Question 23

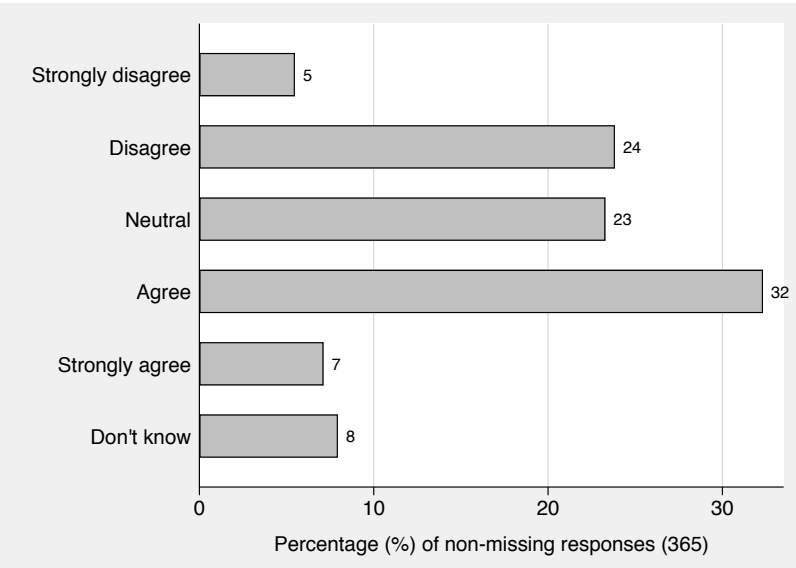

(a) Whole sample

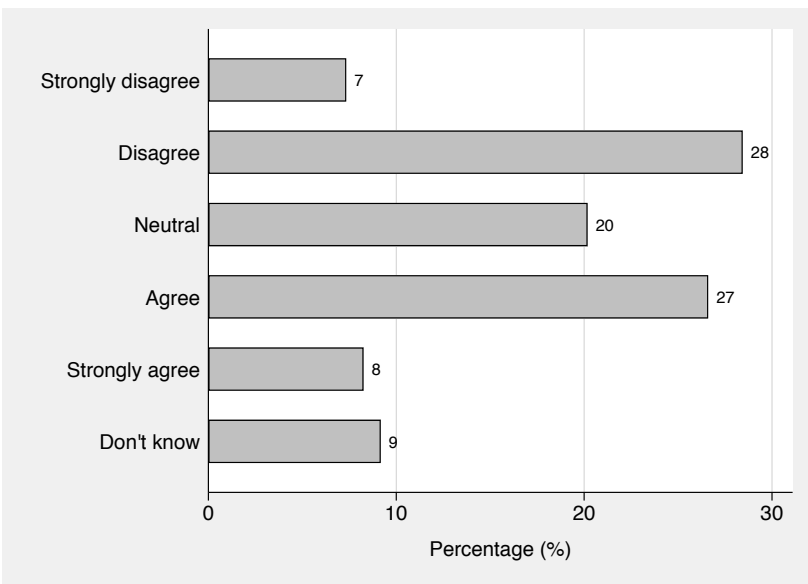

(c) EU

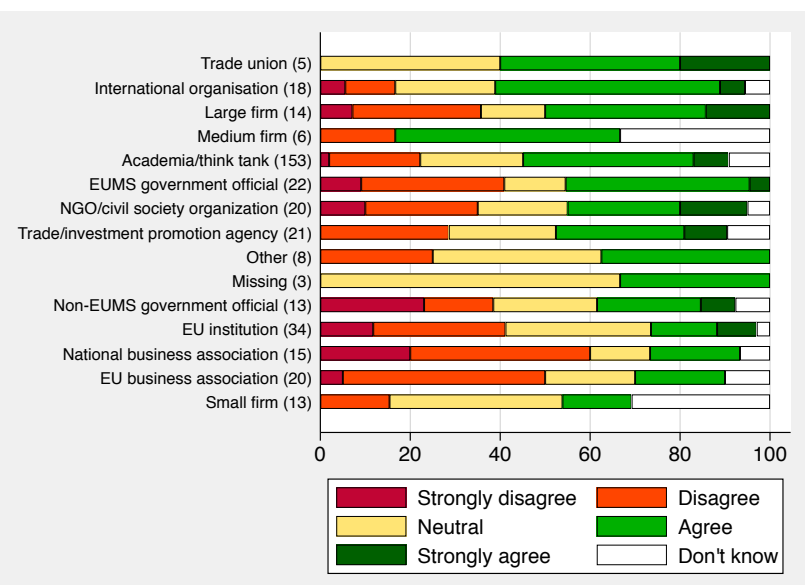

(e) From highest to lowest agreement

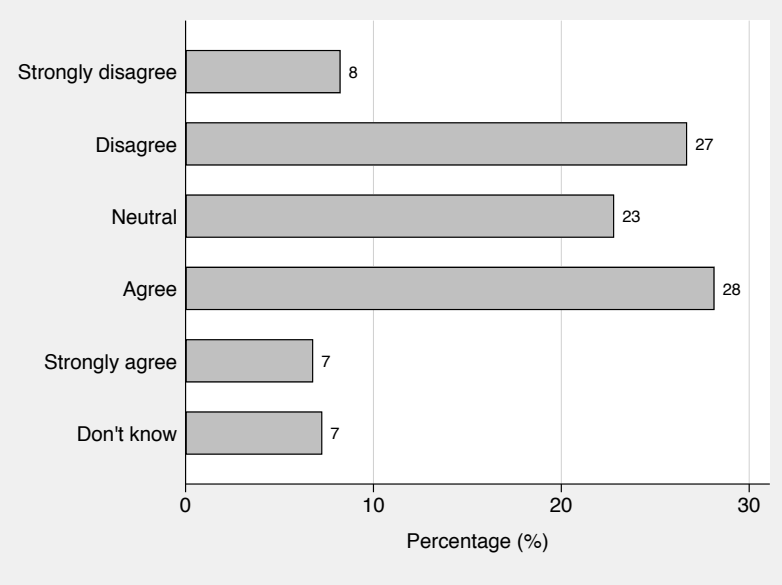

(b) Without academia and think-tanks

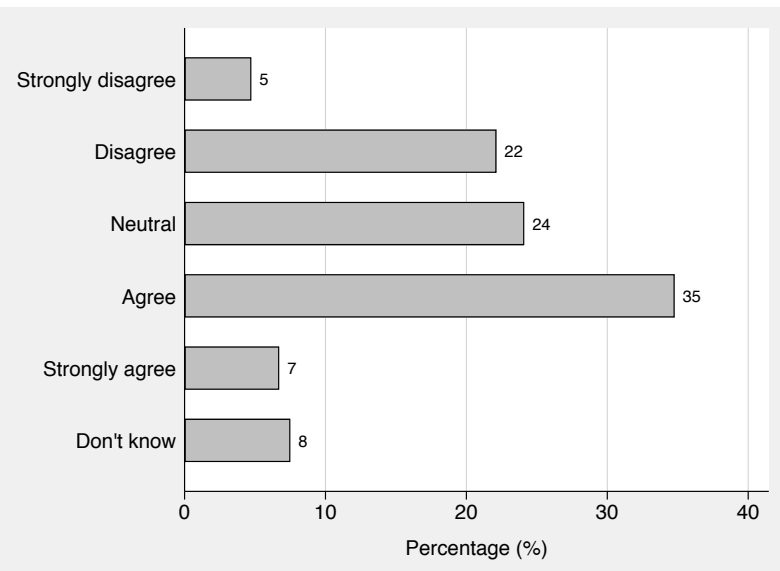

(d) Non-EU

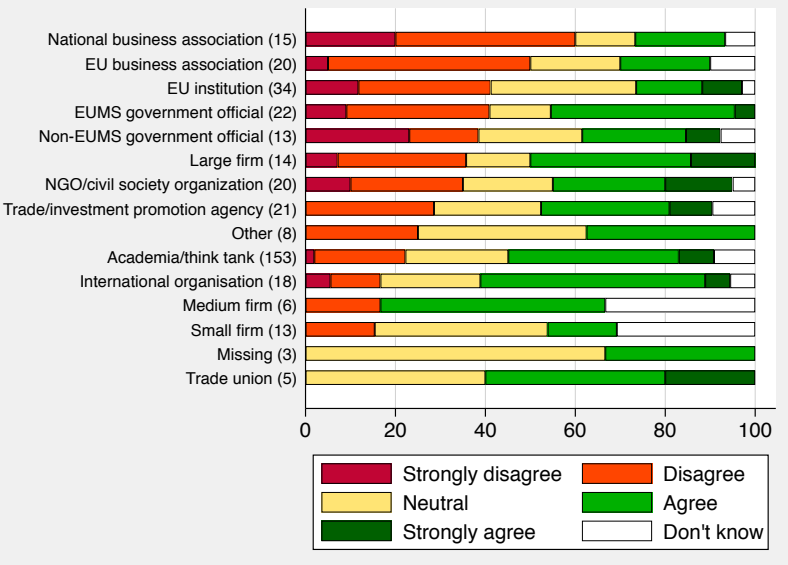

(f) From highest to lowest disagreement 


\section{Question 24}

The EU only takes trade actions against partner countries regarding non-trade issues (such as labor standards) when pushed to do so by NGOs and public opinion.

Figure 24: Results RESPECT survey, Question 24

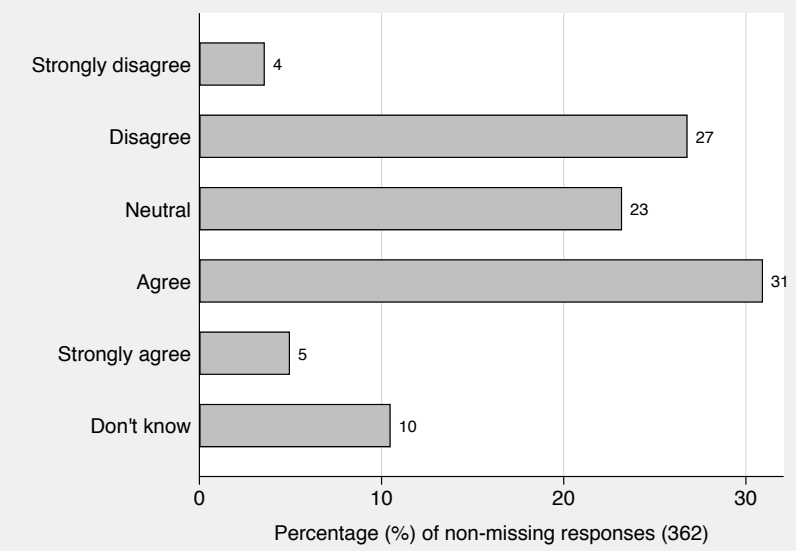

(a) Whole sample

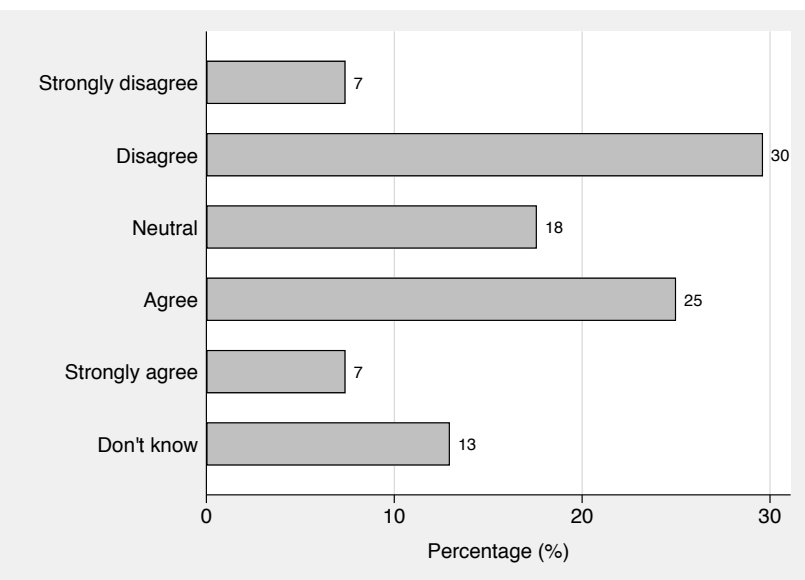

(c) EU

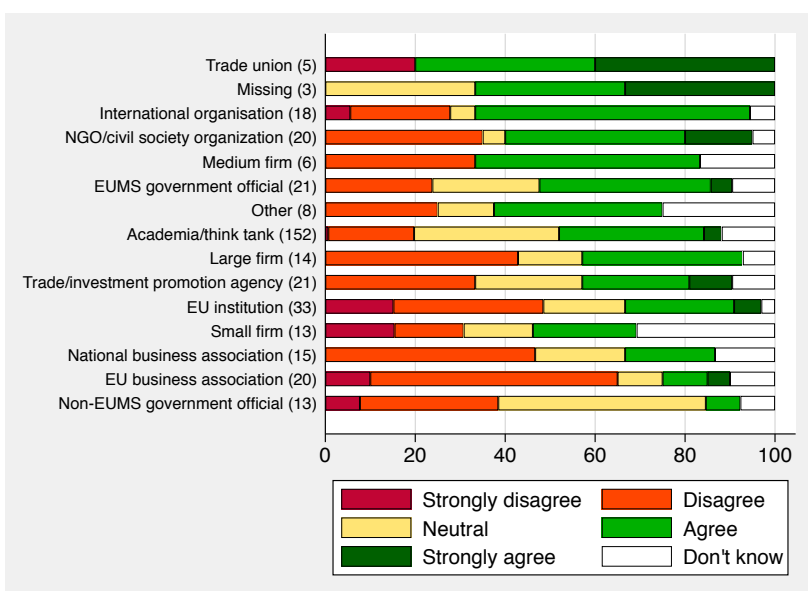

(e) From highest to lowest agreement

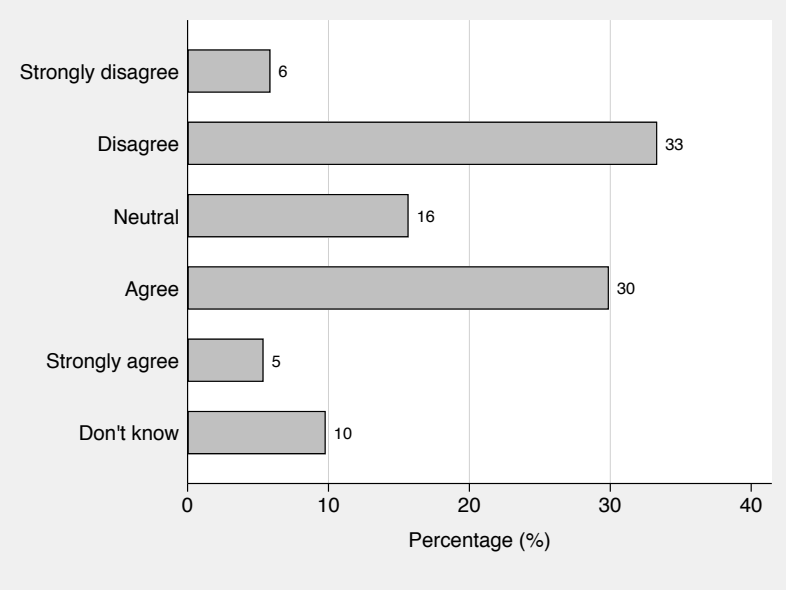

(b) Without academia and think-tanks

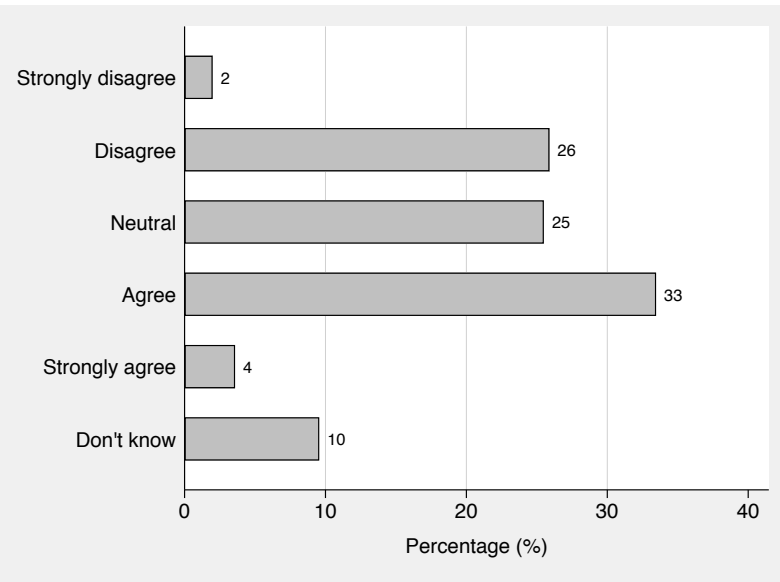

(d) Non-EU

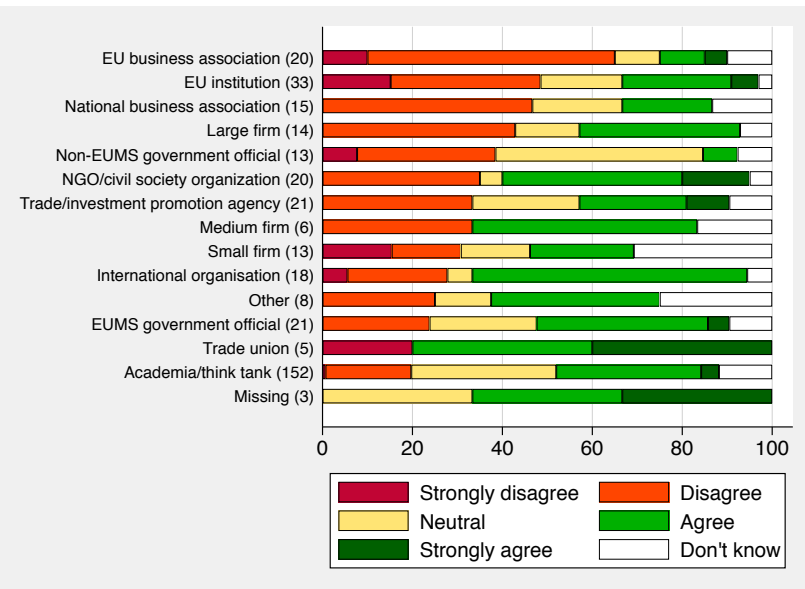

(f) From highest to lowest disagreement 


\section{Question 25}

EU trade agreements have effective mechanisms to resolve trade disputes.

Figure 25: Results RESPECT survey, Question 25

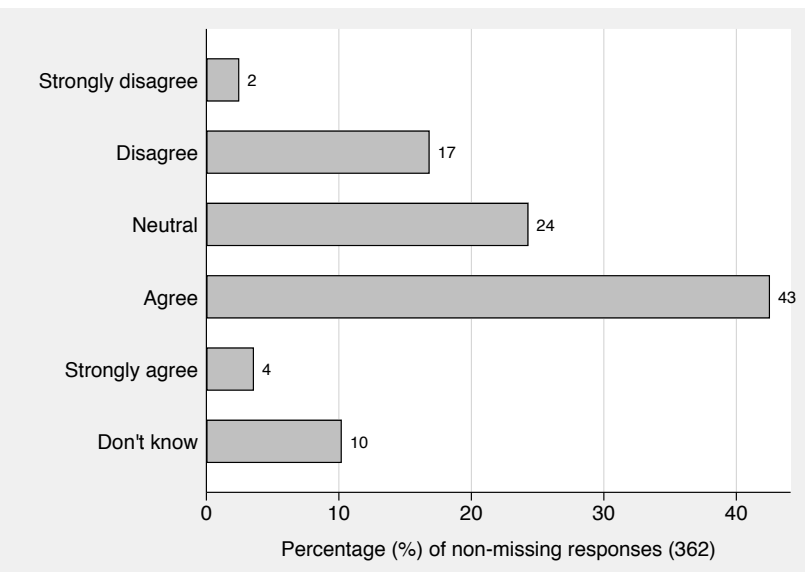

(a) Whole sample

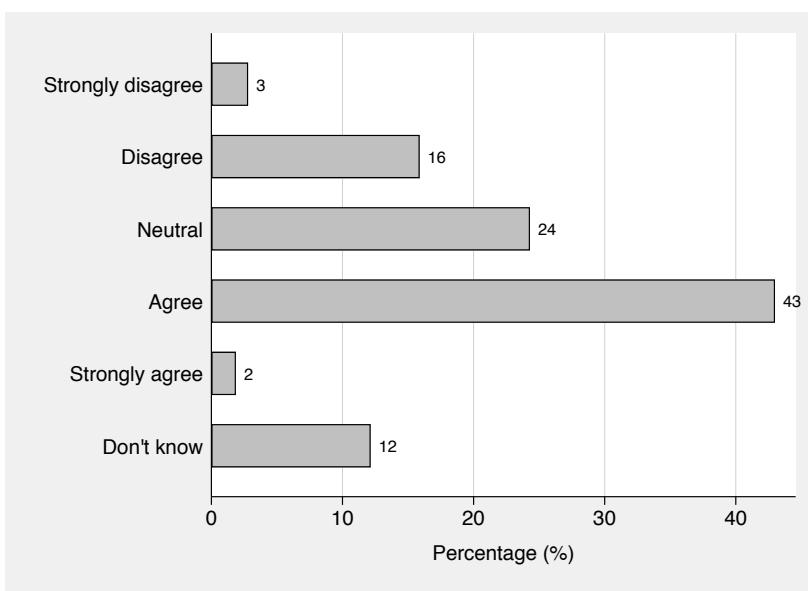

(c) $\mathrm{EU}$

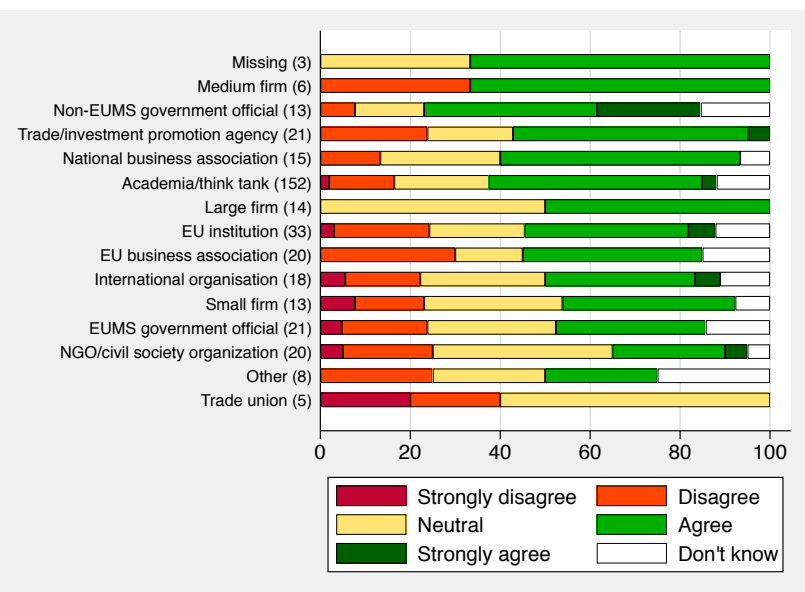

(e) From highest to lowest agreement

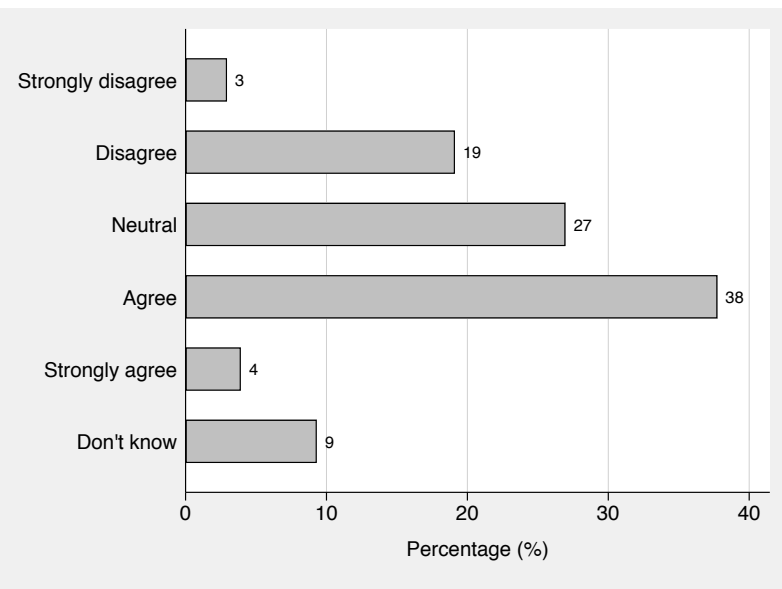

(b) Without academia and think-tanks

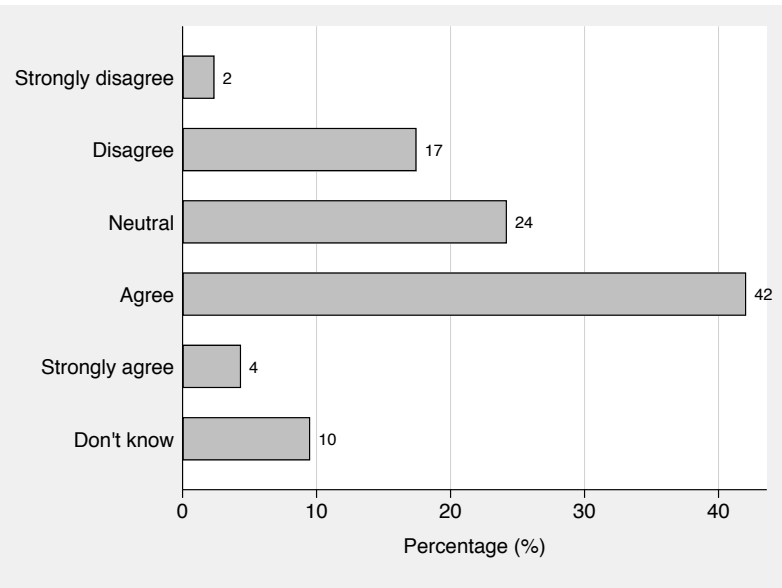

(d) Non-EU

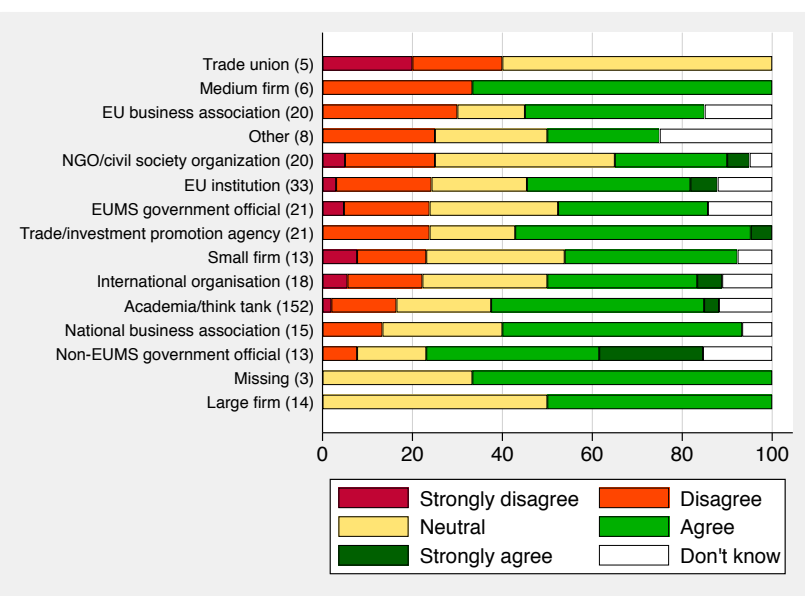

(f) From highest to lowest disagreement 


\section{Question 26}

The EU uses conflict resolution mechanisms of trade agreements to address market access barriers in partner countries.

Figure 26: Results RESPECT survey, Question 26

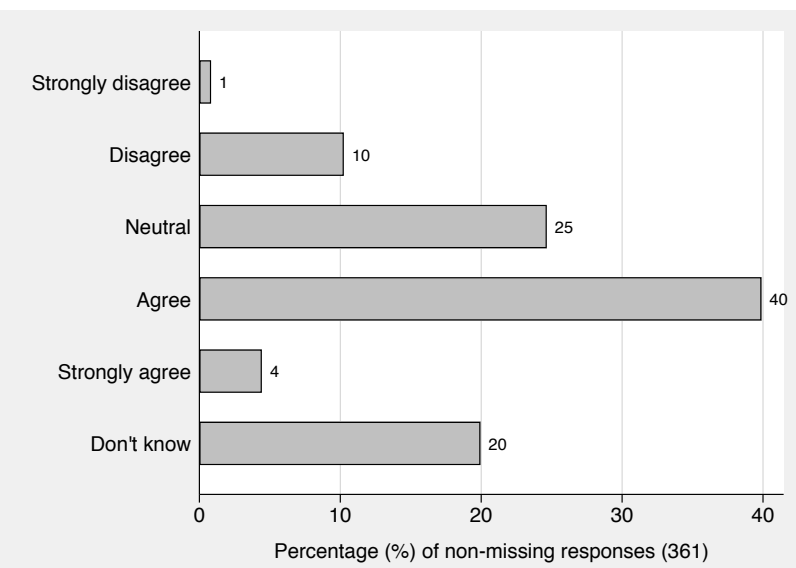

(a) Whole sample

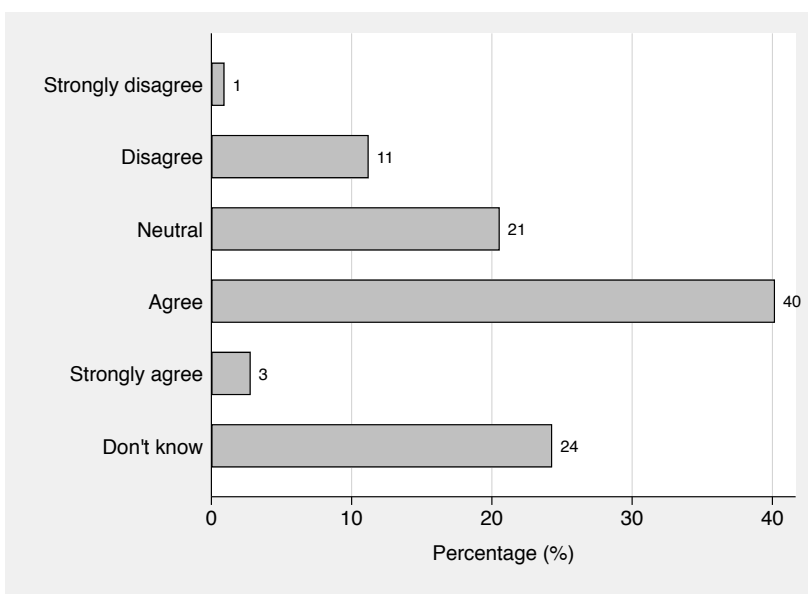

(c) $\mathrm{EU}$

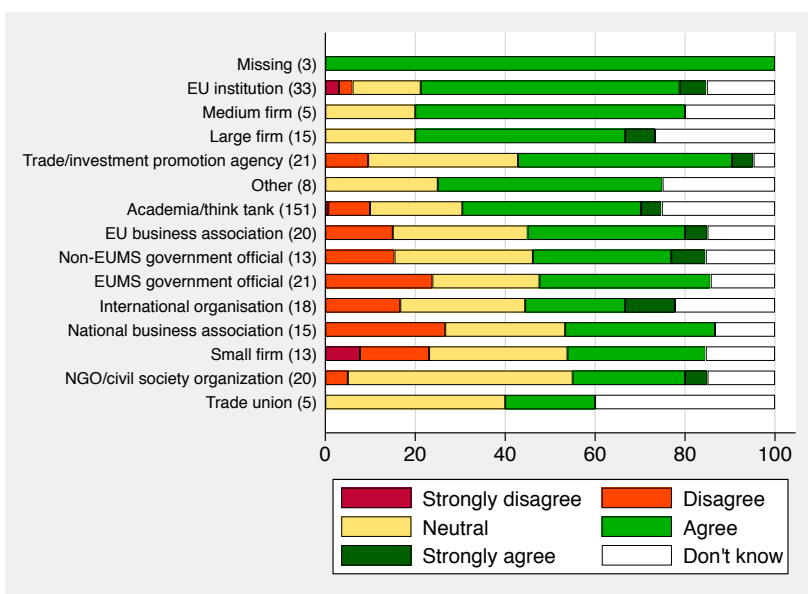

(e) From highest to lowest agreement

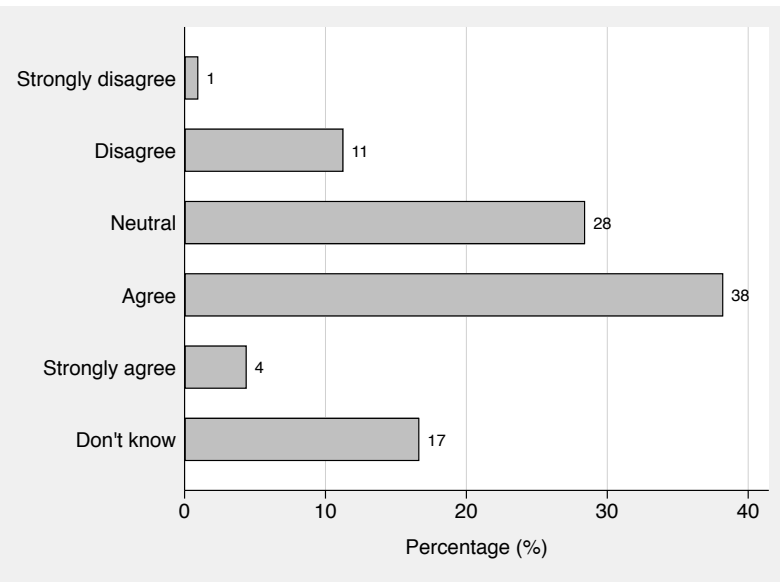

(b) Without academia and think-tanks

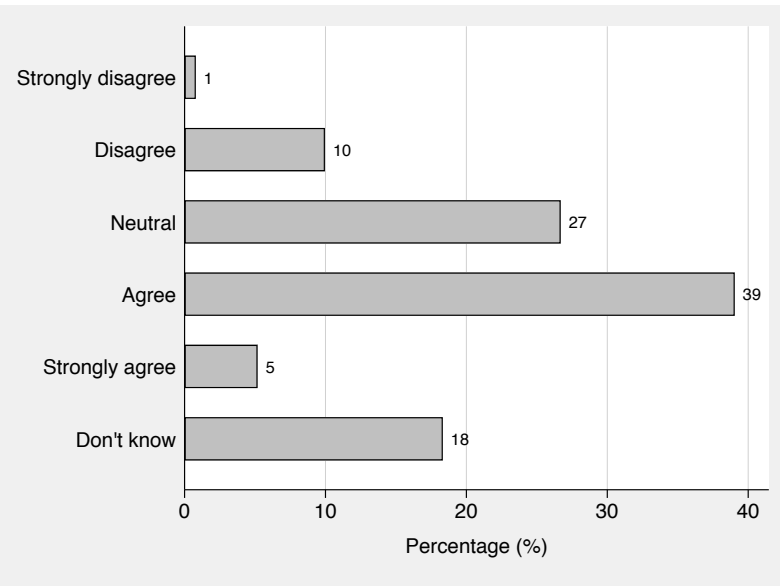

(d) Non-EU

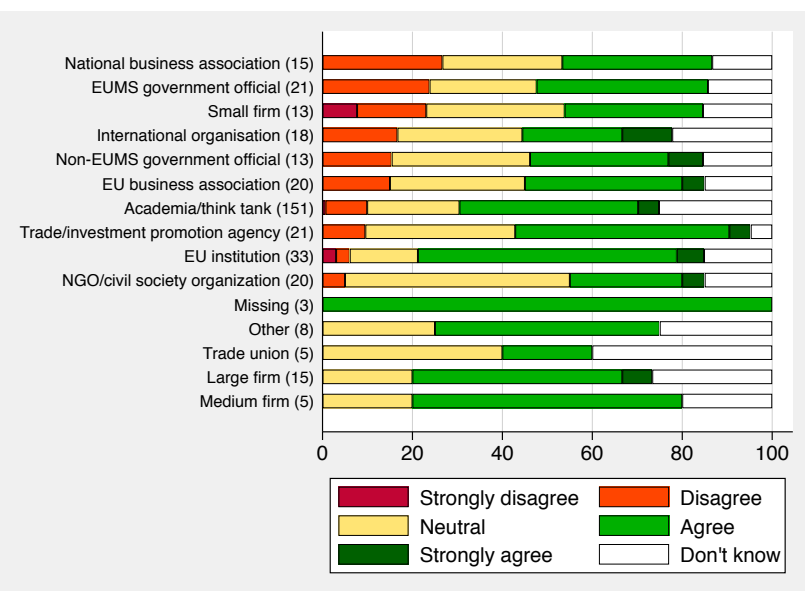

(f) From highest to lowest disagreement 


\section{Concluding remarks}

Respondents tend to agree with the strategy of using trade policy instruments and in particular market access as a tool to to attain NTPOs in third countries. The majority of respondents also express believes that the EU is serious about realising non-trade objectives - such as human rights, labor, environmental protection and anti-corruption - in trade partners as well as about promoting economic development in low income trade partners. However $40 \%$ of the surveyed population of experts and stakeholders believes the EU ignores violations of human/labor rights or environmental regulation when major trade interests are at stake. Similarly, more than one third of respondents agree that the EU only takes trade actions against partner countries regarding non-trade issues (such as labor standards) when pushed to do so by NGOs and public opinion. On the central theme of trade (and trade-related) policy used to attain NTPOs in external relations, responses in the first part of the survey revealed that the population of expert stakeholders and observers tend to believe that the EU should indeed use trade policy to promote NTPOs and that it is theoretically serious about it. Moving from design to implementation, the survey results suggested a number of critical issues. In particular, a non negligible share of respondents hold that the EU ignores violations of human/labor rights or environmental regulation when major trade interests are at stake and that the EU only takes trade actions against partner countries regarding non-trade issues when pushed by NGOs and public opinion. Consistently with these views, respondents consider EU trade policy as particularly influenced by large EUMS and large private companies and identify a number of weaknesses in the relevant EU monitoring processes.

The survey responses suggest that experts and practitioners regard (i) targeted assistance to NGOs and regulatory bodies, and (ii) expert dialogues as most relevant for the realization of NTPOs, while (i) trade agreements, and (ii) technical assistance are identified as the most effective policy instruments to promote trade between the EU and developing countries. Furthermore, the survey results reveal interesting patterns on a number of ancillary topics, including economic diplomacy, where respondents' opinions tend to be rather polarized with respect to the possibility that the activities of national trade promotion agencies of European countries work against each other.

To conclude, interesting descriptive empirical patterns as well as significant polarization is observed across many of the subjects addressed in the survey. These call for a further analysis through targeted interviews to test hypothesis, investigate the robustness of empirical relationships and understand conflicting views. 


\section{References}

Bluth, Christian, "A Safety Net to Foster Support for Trade and Globalisation: International Survey on Attitudes towards Trade and Globalisation 2018," GED Study, Bertlesmann Stiftung 2018.

Eurobarometer, "Les Europeens, la Globalisation et la Liberalisation," Special Eurobarometer Report 152 for DG Trade 2001.

_ , "International Trade," Special Eurobarometer Report 357 for DG Trade 2010.

_ , "Standard Eurobarometer," March 2018.

European Commission, "Trade For All: Towards a More Responsible Trade and Investment Policy," EU, Brussels 2015.

_, "Eurobarometer Timeline," Online at: http://ec.europa.eu/commfrontoffice/ publicopinion/index.cfm/ResultDoc/download/DocumentKy/84606 November 2018.

Pew Research Center, "Americans, Like Many in Other Advanced Economies, Not Convinced of Trade's Benefits," September 2018. 


\section{Author contacts:}

Matteo Fiorini, Bernard Hoekman, Naïs Ralaison, Aydin Yildirim

Global Governance Programme

Robert Schuman Centre for Advanced Studies, European University Institute.

Villa Schifanoia

Via Boccaccio 121

50133 Firenze

Italy

Email: matteo.fiorini@eui.eu; bernard.hoekman@eui.eu; nais.ralaison@eui.eu; aydin.yildirim@eui.eu 